JOINT TRANSPORTATION RESEARCH PROGRAM

FHWA/IN/JTRP-2009/26

Final Report

IMPLEMENTATION OF EROSION CONTROL WARRANTY SPECIFICATION

Bob G. McCullouch

Kok Kuan Ng

December 2009 


\section{TECHNICAL Summary}

INDOT Research

Technology Transfer and Project Implementation Information

TRB Subject Code: 33-1 Construction Control

Publication No.: FHWA/IN/JTRP-2009/26, SPR-2378

August 2009

Draft Final Report

\section{Implementation of Erosion Control Warranty Specification}

\section{Introduction}

Currently, INDOT uses subjective means to determine if vegetation cover (grass) is adequate to satisfy contract provisions. Additionally, INDOT specifies the methods and materials that should be used. Over the last ten years there have been hundreds of products introduced to the market to stabilize soils and prevent erosion. Selecting what products and approving them for use has proved problematic. In order to improve upon the current process of using a method specification INDOT is examining the use of an erosion control warranty specification/ provision. To date this process has been applied to three projects. The process allows the contractor to select from the market place various combinations of erosion control measures. The adequacy of these measures is secured by using warranty over a stated time period. The performance warranty is a written

specification/ provision that in most cases will enable the contractor and INDOT to arrive at an equitable objective decision regarding the adequacy of the treatment the contractor selected. Should the erosion control measures fall short of the expected performance the contractor must take remedial action.

To achieve a higher level of objectivity regarding the warranty, this research effort examined using photographic techniques to resolve possible disputes. Specifically the research attempted to digitize photographic images and examine them for the percentage of "grass" cover. This approach was tested and applied to one contract.

\section{Findings}

INDOT selected three projects for the erosion control warranty special provision. Due to the timing of the contracts, the digital analysis process developed by this research could only be applied to the SR 69 project as an objective means to resolve disputes between INDOT and the contractor. Due to the contract characteristics, multiple sections starting at different times, the digital photographic procedures developed could be used but were not used. The contract turned out to be very problematic for erosion control. The recommendations are based on the findings of the technical research accomplished by this project and an overview of current vegetation management practices of INDOT.

\section{Implementation}

Concerning Implementation the SAC recommended that the final report be disseminated to the Erosion Control Committee for review and determination of any future action. 


\section{Contacts}

For more information:

Dr. Bob McCullouch

Principal Investigator

School of Civil Engineering

Purdue University

West Lafayette IN 47907

Phone: (765) 494-0643

E-mail: bgm@purdue.edu

Indiana Department of Transportation

Office of Research and Development

1205 Montgomery Street

P.O. Box 2279

West Lafayette, IN 47906

Phone: (765) 463-1521

Fax: (765) 497-1665

Purdue University

Joint Transportation Research Program

School of Civil Engineering

West Lafayette, IN 47907-1284

Phone: (765) 494-9310

Fax: (765) 496-7996

E:mail: jtrp@ecn.purdue.edu 
Final Report

FHWA/IN/JTRP-2009/26

\title{
IMPLEMENTATION OF EROSION CONTROL WARRANTY SPECIFICATION
}

\author{
By \\ Bob G. McCullouch \\ Research Scientist \\ Kok Kuan Ng \\ Research Assistant \\ School of Civil Engineering \\ Purdue University
Joint Transportation Research Program
Project Number: C-36-61II
File Number: 6-14-35
SPR- 2378

\begin{abstract}
Conducted in Cooperation with the
Indiana Department of Transportation

and the U.S. Department of Transportation

Federal Highway Administration
\end{abstract}

The contents of this report reflect the views of the authors, who are responsible for the facts and the accuracy of the data presented herein. The contents do not necessarily reflect the official views or policies of the Indiana Department of Transportation or the Federal Highway Administration at the time of publication. The report does not constitute a standard, specification, or regulation.

Purdue University

West Lafayette, Indiana 47907

December 2009 
TECHNICAL REPORT STANDARD TITLE PAGE

\begin{tabular}{|c|c|c|}
\hline $\begin{array}{l}\text { 1. } \text { Report No. } \\
\text { FHWA/IN/JTRP-2009/26 }\end{array}$ & 2. Government Accession No. & 3. Recipient's Catalog No. \\
\hline \multirow{2}{*}{\multicolumn{2}{|c|}{$\begin{array}{l}\text { 4. Title and Subtitle } \\
\text { IMPLEMENTATION OF EROSION CONTROL WARRANTY } \\
\text { SPECIFICATION }\end{array}$}} & $\begin{array}{l}\text { 5. Report Date } \\
\text { December } 2009\end{array}$ \\
\hline & & 6. Performing Organization Code \\
\hline \multicolumn{2}{|l|}{$\begin{array}{l}\text { 7. Author(s) } \\
\text { Bob McCullouch, Kok Kuan Ng }\end{array}$} & $\begin{array}{l}\text { 8. Performing Organization Report No. } \\
\text { FHWA/IN/JTRP-2009/26 }\end{array}$ \\
\hline \multirow{2}{*}{\multicolumn{2}{|c|}{$\begin{array}{l}\text { 9. Performing Organization Name and Address } \\
\text { Joint Transportation Research Program } \\
1284 \text { Civil Engineering Building } \\
\text { Purdue University } \\
\text { West Lafayette, IN 47907-1284 }\end{array}$}} & 10. Work Unit No. \\
\hline & & $\begin{array}{l}\text { 11. Contract or Grant No. } \\
\text { SPR-2378 }\end{array}$ \\
\hline \multirow{2}{*}{\multicolumn{2}{|c|}{$\begin{array}{l}\text { 12. Sponsoring Agency Name and Address } \\
\text { Indiana Department of Transportation } \\
\text { State Office Building } \\
100 \text { North Senate Avenue } \\
\text { Indianapolis, IN } 46204\end{array}$}} & $\begin{array}{l}\text { 13. Type of Report and Period Covered } \\
\text { Final Report }\end{array}$ \\
\hline & & 14. Sponsoring Agency Code \\
\hline
\end{tabular}

\section{Supplementary Notes}

Prepared in cooperation with the Indiana Department of Transportation and Federal Highway Administration.

\section{Abstract}

One of the main issues in a warranty specification for erosion control items is how to evaluate performance objectively. This project developed a methodology that uses digital images to measure compliance with defined vegetation cover requirements. It is designed essentially for areas where vegetation (grass) is selected as the erosion control measure. The research was a technical approach to examine the feasibility of using digital photographic analysis. It does not address all issues related to field conditions and as such would require review by interested parties to be complete. For example, how often should sample pictures to taken. Should a random selection process be developed similar to ones currently used to sample asphalt materials? What criteria should be used to elect when the technical process becomes binding to both parties etc. and what wording in the warranty provision should be used? Additional items include who makes the inspection and how do they become trained in the process and become equipped with the necessary camera and light meter.

This project provides some technical answers with using this approach. Due to some of the uncertainties discovered with using warranty erosion control on three INDOT projects it was decided to take a cautious approach to implementing this provision. Therefore the findings are being disseminated to the Erosion Control Committee for further consideration and action.

17. Key Words
Erosion control, vegetation management, warranty contracts,
digital images,
digital images,

\section{Distribution Statement}

No restrictions. This document is available to the public through the National Technical Information Service, Springfield, VA 22161
19. Security Classif. (of this report)

Unclassified

20. Security Classif. (of this page)

Unclassified

21. No. of Pages
75

75 


\section{TABLE OF CONTENTS}

PAGE

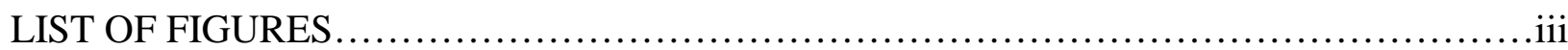

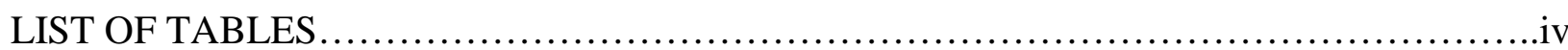

\section{CHAPTER 1 INTRODUCTION}

CHAPTER 2 COLOR ANALYSIS

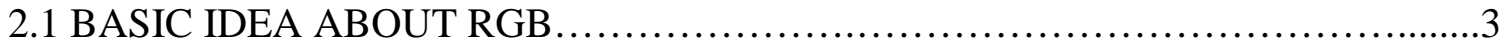

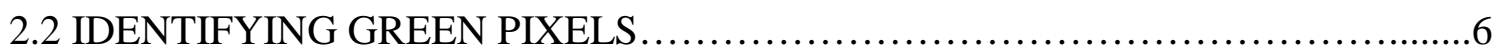

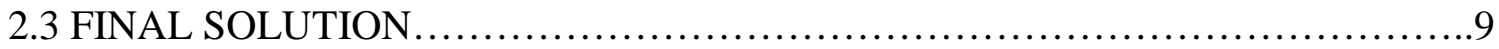

CHAPTER 3 IMAGE TAKING TECHNIQUES

3.1 VERTICAL SHOTS.............................................................

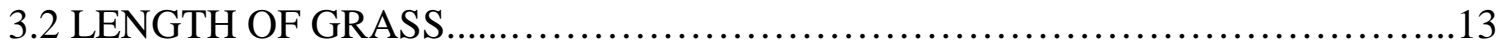

3.3 RANDOM SAMPLES....................................................14

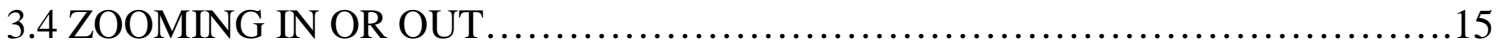

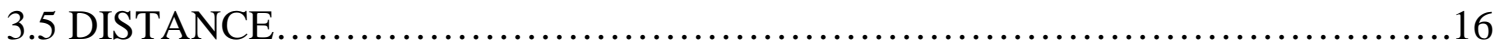

3.6 LIGHT INTENSITY ..................................................18

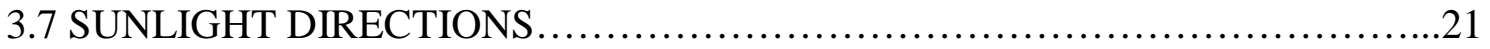

\section{CHAPTER 4 DIGITAL CAMERAS}

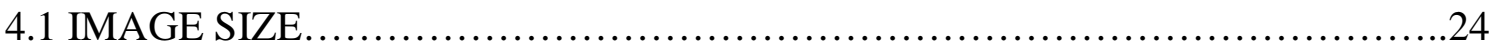

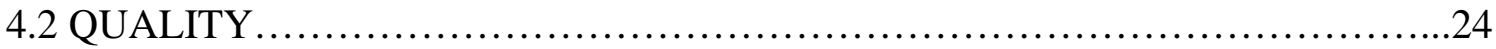

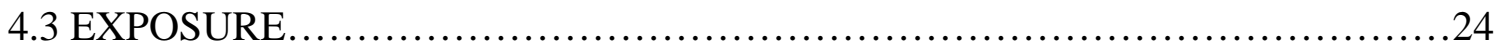

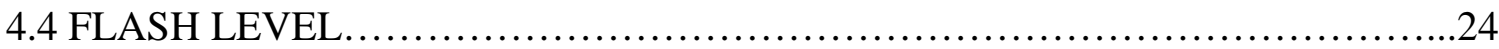

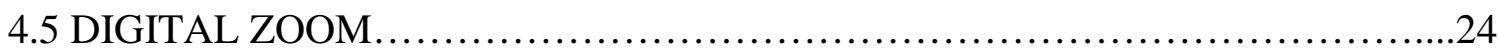

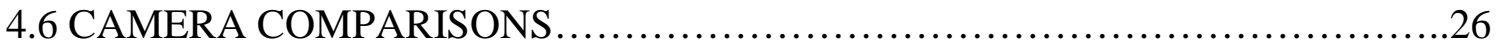

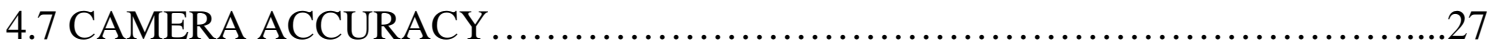

\section{CHAPTER 5 FIELD ANALYSIS PROCEDURES}

5.1 TAKING PICTURES AND IMPORTING IMAGES ............................29

5.2 MAKING CHANGES TO IMPORTED IMAGES ................................30

5.3 VEGETATION ANALYSIS PROCEDURE....................................36

CHAPTER 6 SAMPLE PICTURES AND ANALYSIS $\ldots \ldots \ldots \ldots \ldots \ldots \ldots \ldots \ldots \ldots \ldots \ldots$ CHAPTER 7 INSPECTION PROCEDURES

7.1 PRE-FIELD ........................................................... 51

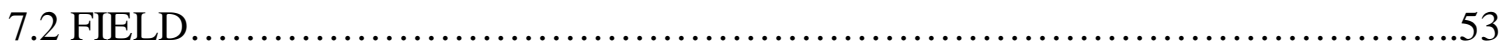

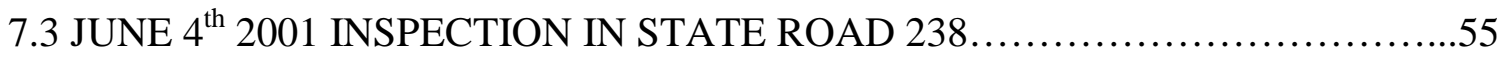

7.4 EFFECTS OF HERBICIDES...............................................56 
7.5 INSPECTION PROGRAM ON RANDOM LOCATIONS - FOR SLOPES

\section{CHAPTER 8 CONCLUSIONS}

8.1 DISTANCE .......................................................... 59

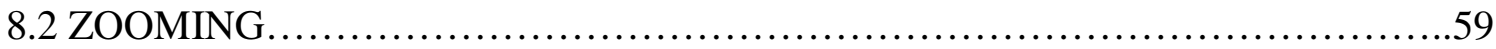

8.3 ANGLE OF IMAGE TAKEN.............................................59

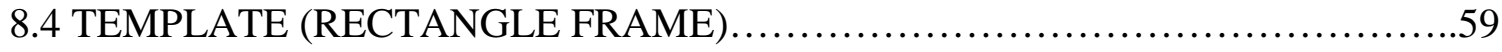

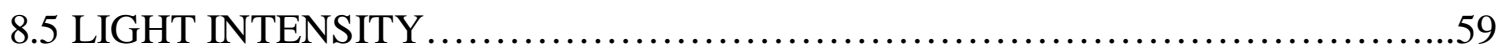

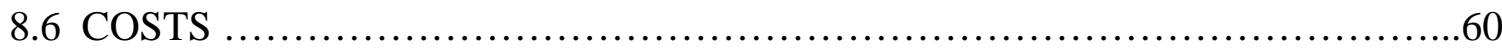

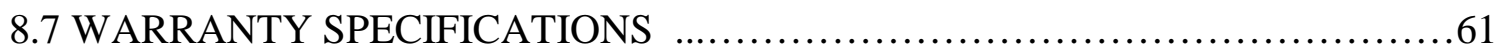

8.8 PROJECT HISTORY .................................................61

8.9 RECCOMENDATIONS ..................................................64

APPENDIX - WARRANTED PERMANENT EROSION CONTROL SPEC ................66 


\section{CHAPTER 2 COLOR ANALYSIS}

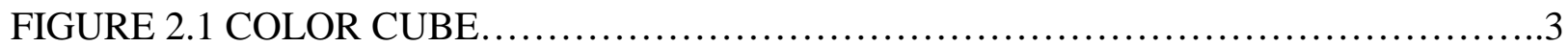

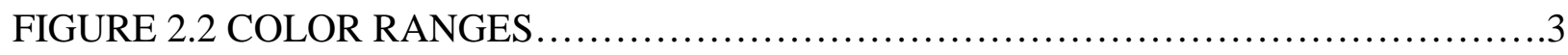

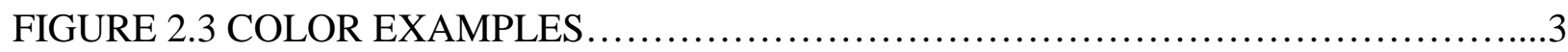

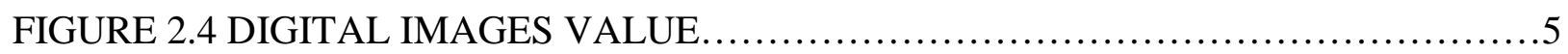

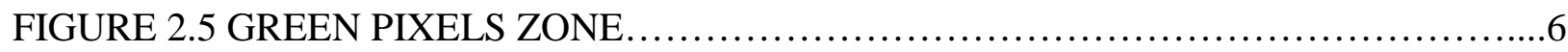

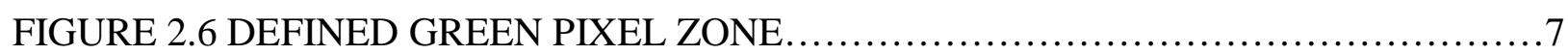

FIGURE 2.7 FIELD IMAGE................................................................

\section{CHAPTER 3 IMAGE TAKING TECHNIQUES}

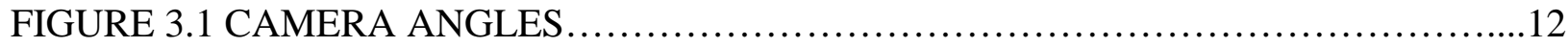

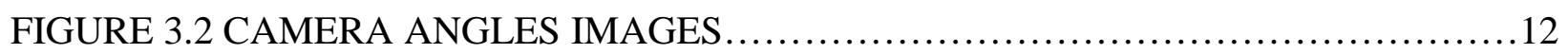

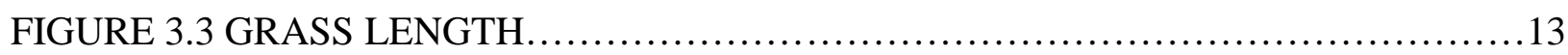

FIGURE 3.4 GRASS LENGTH IMAGE...................................................

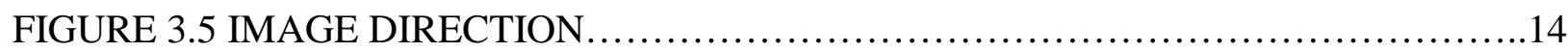

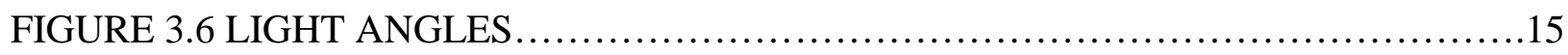

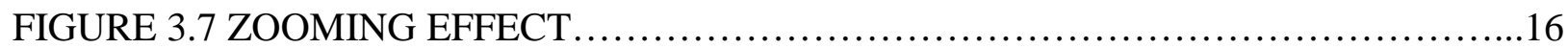

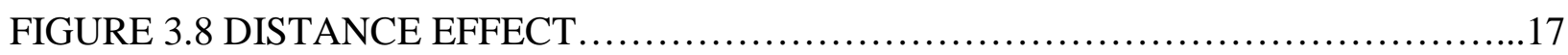

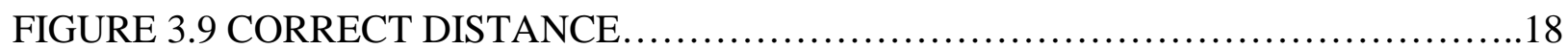

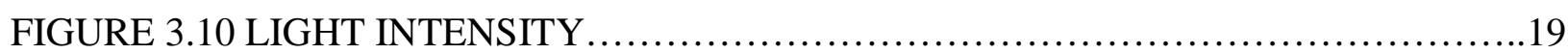

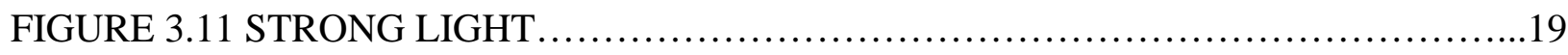

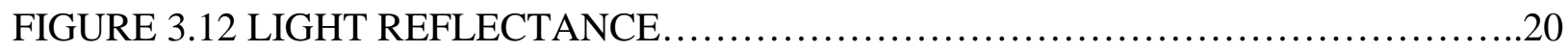

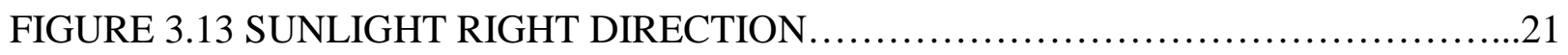

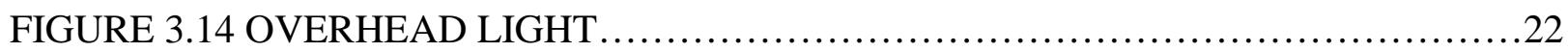

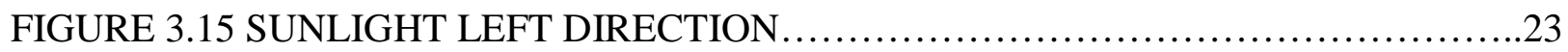

\section{CHAPTER 4 DIGITAL CAMERAS}

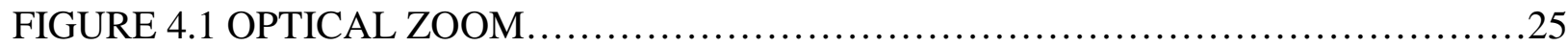

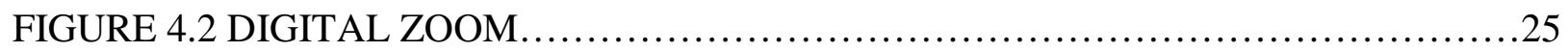

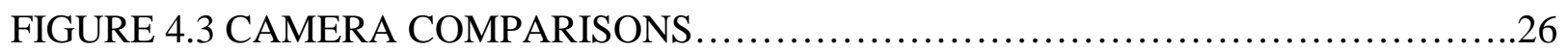

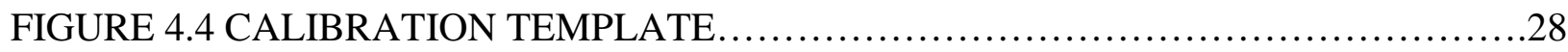

\section{CHAPTER 5 FIELD ANALYSIS PROCEDURES}

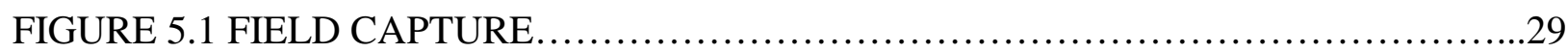

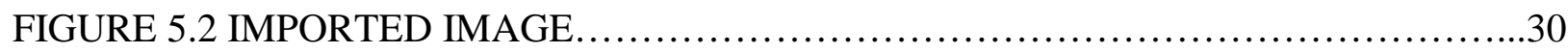

FIGURE 5.3 IMPORTED INTO ADOBE PHOTOSHOP ......................................

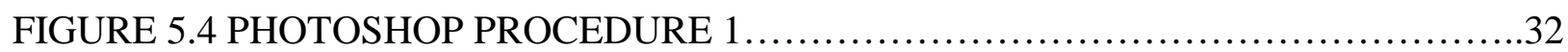


FIGURE 5.5 PHOTOSHOP FEATURE ...........................................33

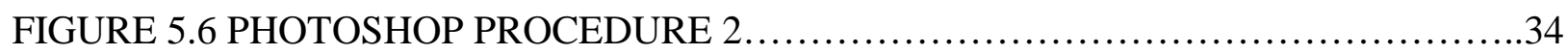

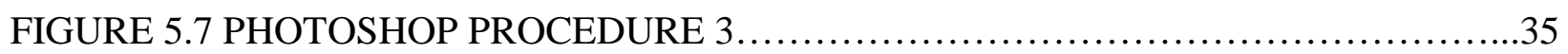

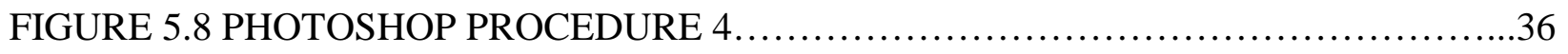

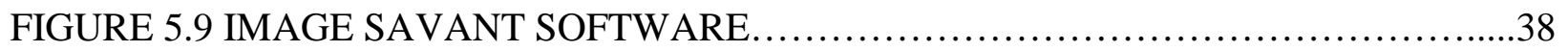

CHAPTER 7 INSPECTION PROCEDURES

FIGURE 7.1 CALIBRATION CHART ................................................ 52

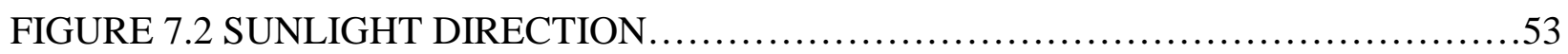

FIGURE 7.3 IMAGE AREAS ........................................................ 54

FIGURE 7.4 INSPECTION RESULTS ............................................. 56

FIGURE 7.5 RANDOM LOCATION ................................................57

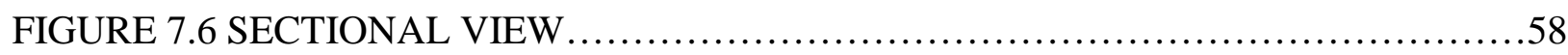

\section{LIST OF TABLES}

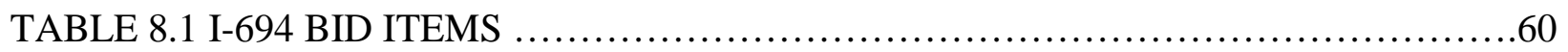




\section{Chapter 1 - Introduction}

Currently, INDOT uses subjective means to determine if vegetation cover (grass) is adequate to satisfy contract provisions. Additionally, INDOT specifies the methods and materials that should be used. Over the last ten years there have been hundreds of products introduced to the market to stabilize soils and prevent erosion. Selecting what products and approving them for use has proved problematic. In order to improve upon the current process of using a method specification INDOT is examining the use of an erosion control warranty specification/ provision. To date this process has been applied to three projects. The process allows the contractor to select from the market place various combinations of erosion control measures. The adequacy of these measures is secured by using warranty over a stated time period. The performance warranty is a written specification/ provision that in most cases will enable the contractor and INDOT to arrive at an equitable objective decision regarding the adequacy of the treatment the contractor selected. Should the erosion control measures fall short of the expected performance the contractor must take remedial action.

To achieve a higher level of objectivity regarding the warranty, this research effort examined using photographic techniques to resolve possible disputes. Specifically the research attempted to digitize photographic images and examine them for the percentage of "grass" cover. The implications of the results are discussed in the Recommendations Section of the report.

By using a digital vegetation cover analyzer it is possible to obtain a more objective measure of "grass" coverage from photographs of contested areas. This quantification lends decisive support to the warranty process.

In essence photographs are analyzed and a vegetation coverage percentage is presented via a software program. The software also presents the dark shade coverage percentage (disputed area) where vegetation may or may not be present.

However, the accuracy of the digital analysis relies heavily upon the quality of the digital photographs. The quality of the images in turn relies heavily upon the type of

digital camera used. Therefore, the accuracies of the analysis will vary from $85 \%$ to $95 \%$. The digital analyzer tool is to be used as a tool to determine vegetation coverage if the visual inspection program fails.

The equipments used are Sony DSC-F505 Digital Camera, Gossen Mavolux 5032C Digital Light Meter. The software used are Adobe Photoshop, IO industries Image Savant and Digital Vegetation Analyzer.

This report starts by introducing the basic concept about the color analysis. It briefs readers about the basic idea of RGB. It also, informs the readers about the process of developing required equations to calculate green pixels. Second, some recommendations about the camera setting are discussed. Third, techniques needed to take quality vegetation images are shown. The techniques include a set of 
recommendations of what to do and what not to do, from the position of taking the images to the light intensity of the images taken. Fourth, the entire procedure from modifying the images to exporting results in a text file is presented. Finally, conclusions and recommendations are drawn to finalize this report. 


\section{Chapter 2 - Color Analysis}

\subsection{Basic Idea about RGB}

A color image is a combination of 3 basic colors named Red, Green and Blue (RGB). These three colors form a three dimensional color cube that gives a combination of millions of colors.

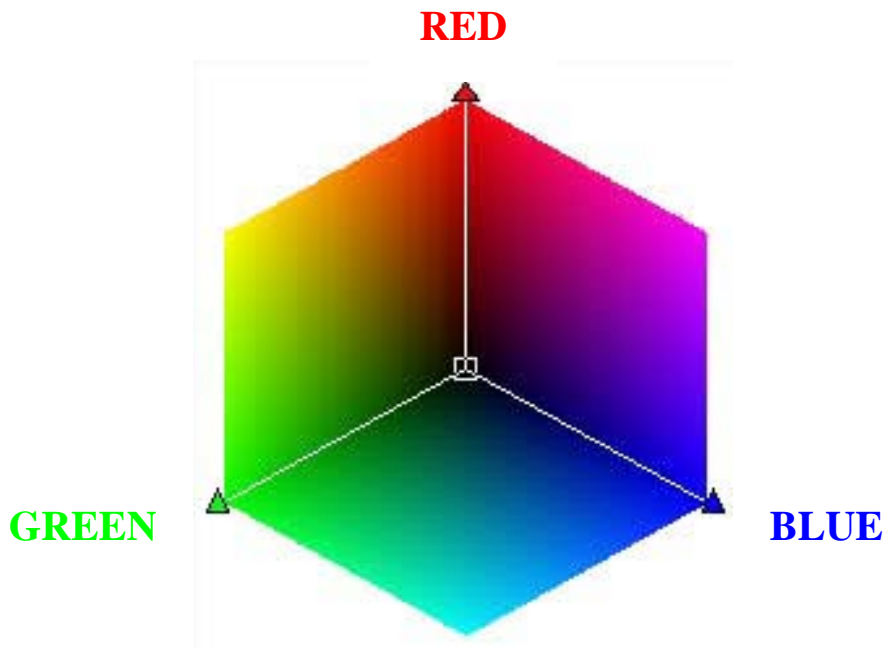

Figure 2.1 - Color Cube

There are different shade levels for each color. Each color can be ranged from shade level 0 to shade level 255 as shown.

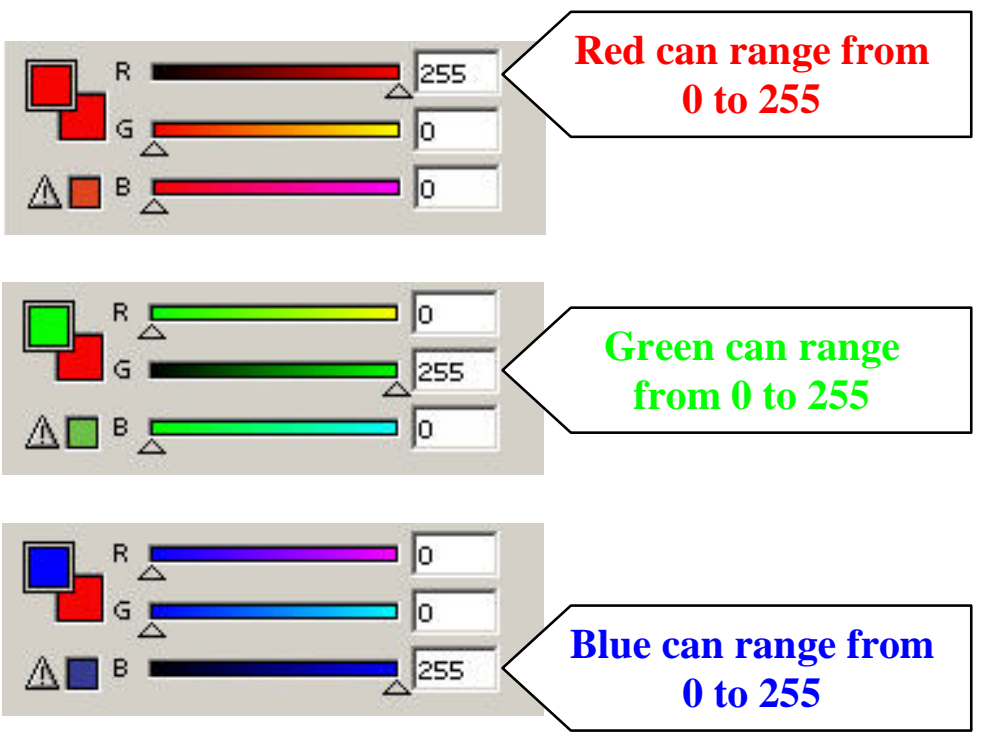

Figure 2.2 - Color Ranges 
Therefore, there are $256 \times 256 \times 256=16,777,216$ colors .

Below are some examples where colors are represented by their respective Red, Green and Blue (RGB) values.

\section{Colors}
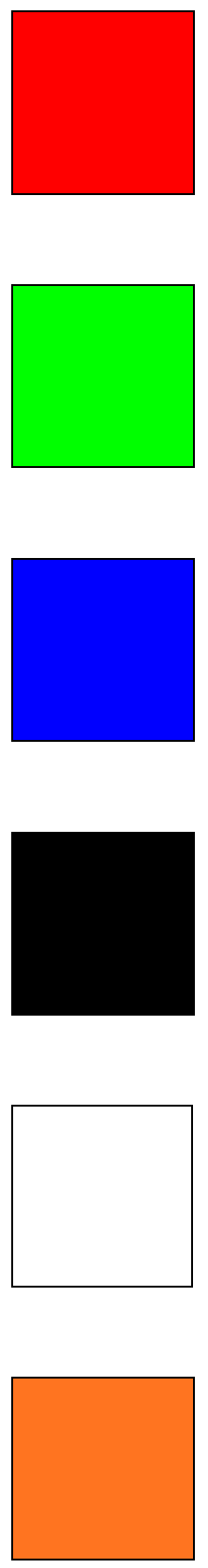

\section{$\underline{\text { RGB Values }}$}

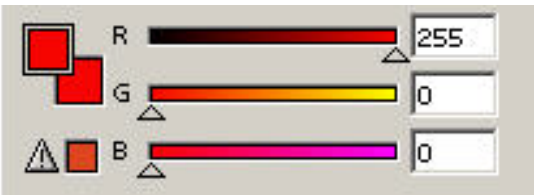

$$
\begin{gathered}
255,0,0 \\
\text { OR } \\
255 / 0 / 0
\end{gathered}
$$

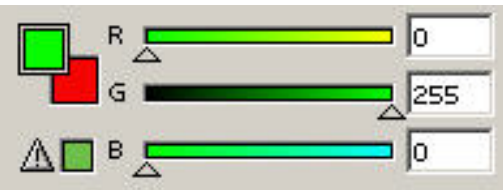

$$
\begin{gathered}
\text { 0,255,0 } \\
\text { OR } \\
\text { 0/255/0 }
\end{gathered}
$$

$$
\begin{gathered}
\text { 0,0,255 } \\
\text { OR } \\
\text { 0/0/255 }
\end{gathered}
$$

$0,0,0$

OR

$0 / 0 / 0$

$255,255,255$

OR

$255 / 255 / 255$

255,116,32

OR

255/116/32

Figure 2.3 - Color Examples 
Therefore, a graphical image like this

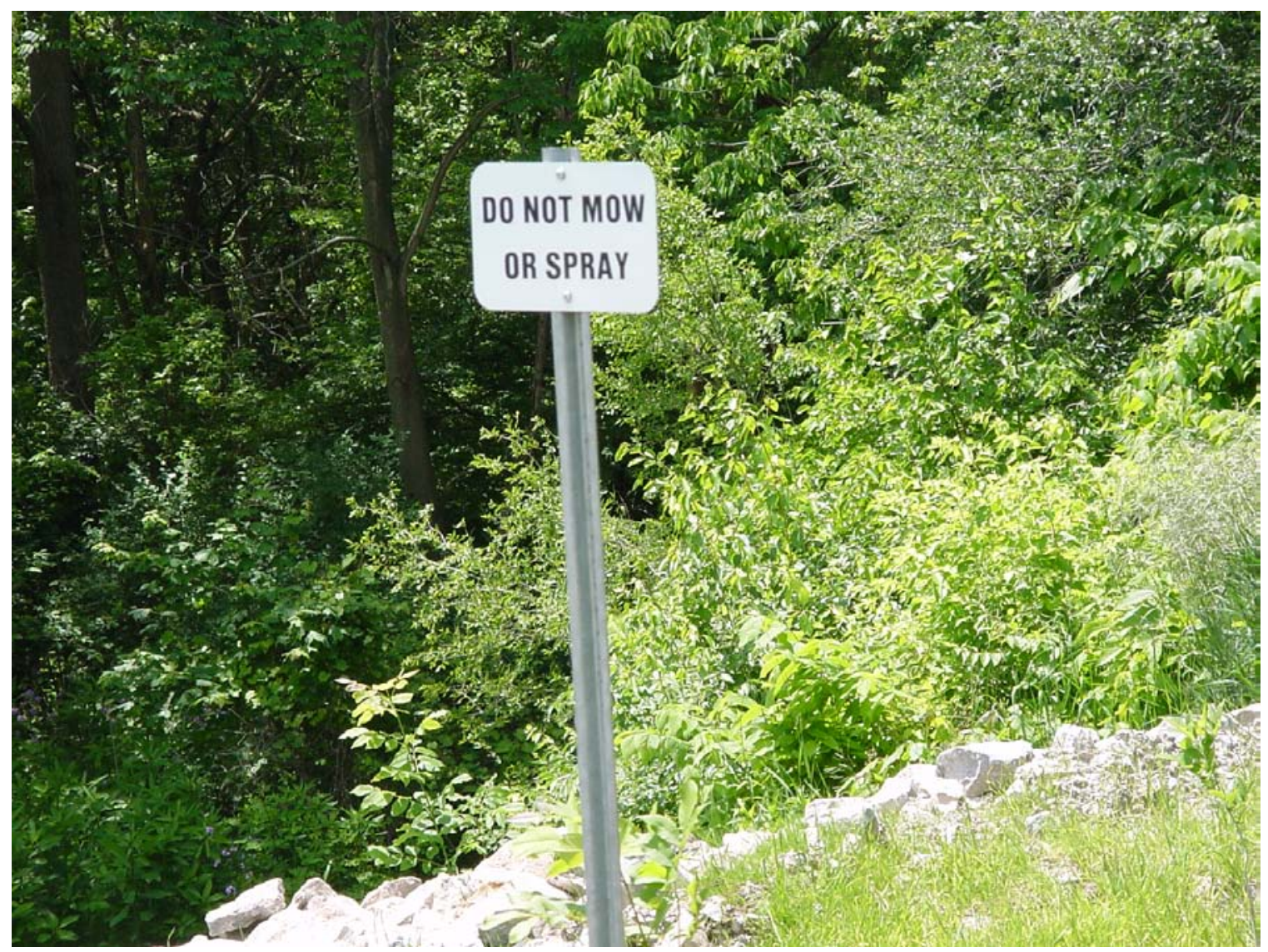

Figure 2.4 - Digital Image Values

can be represented by the following in RGB text format:

108/126/100 90/110/75 68/92/40 62/89/22 91/120/40 91/120/36 71/100/16 45/73/0 44/74/2 41/70/4 48/76/17 34/61/8 24/50/3 8/33/0 16/39/10 45/65/38 66/81/50 72/83/51 44/55/23 37/44/13 37/43/15 37/41/16 35/37/15 33/34/16 28/30/17 29/30/22 31/32/26 29/30/25 26/25/21 29/25/22 29/26/21 24/21/16 21/22/17 25/27/22 25/30/23 23/28/21 29/35/25 30/36/26 22/30/17 27/35/22 29/37/24 23/31/18 36/42/28 32/38/24 28/34/20 38/44/30 22/25/14 29/32/23 22/25/16 27/30/23 28/36/23 26/34/19 34/47/29 37/50/30 25/39/14 37/51/26 36/49/23 31/44/18 24/36/12 20/32/10 21/35/12 25/38/20 24/41/22 26/40/23 33/44/27 27/36/17 22/31/10 24/34/10 25/40/11 27/43/14 25/45/10 23/47/11 20/47/12 17/47/13 11/42/10 21/51/23 21/49/26 23/48/29 12/37/18 15/40/19 44/74/46 98/133/93 107/146/91 115/156/88 119/162/83 98/141/59 99/141/59 101/139/66 64/96/33 93/120/67 148/167/122 218/233/190 244/253/206 184/191/139 81/87/25 45/51/0 38/48/0 
whereas 108/126/100 represents a pixel $(\mathbf{1 0 8 , 1 2 6 , 1 0 0 )}$ in $(\mathbf{R}, \mathrm{G}, \mathbf{B})$ and so on.

\subsection{Identifying Green Pixels}

A program will only be able to determine the percentage of green by analyzing the image's RGB text file. However, it is difficult to tell which ones are green by just looking at those numbers alone. As a result, references such as a color cube model should be utilized to specify green regions and select green pixels.

At first, efforts were made to include the "green" region in the cube. It had been determined that the green regions were within the curve bounded by the red lines forming the curve (figure 3).

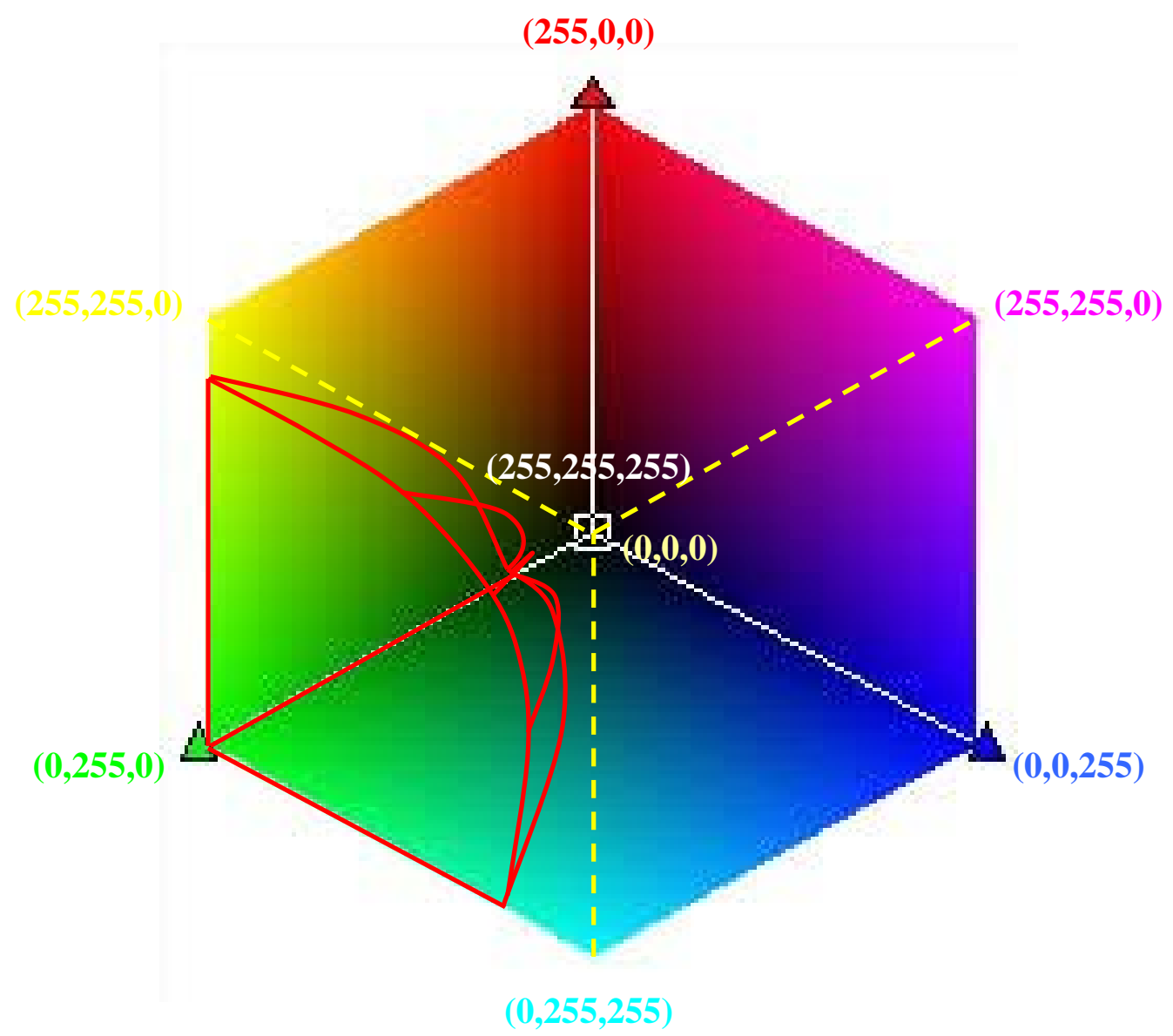

Figure 2.5 - Green Pixels Zone 
However, this curve is somewhat arbitrary. The actual shape and points of the curves are difficult to establish. Additionally, it would be very difficult to define a mathematical equation to represent the boundaries of the "green area".

Also, there is no clear boundary between the green, bluish green, yellowish green. Therefore, there are, in fact, no clear distinct points to establish a curve.

Since it is very difficult to establish a clear curve, a modification is made. It is assumed to be straight lines instead of the red curves in figure 3 . Therefore, the curve surface is now a flat plane as shown in figure 4.

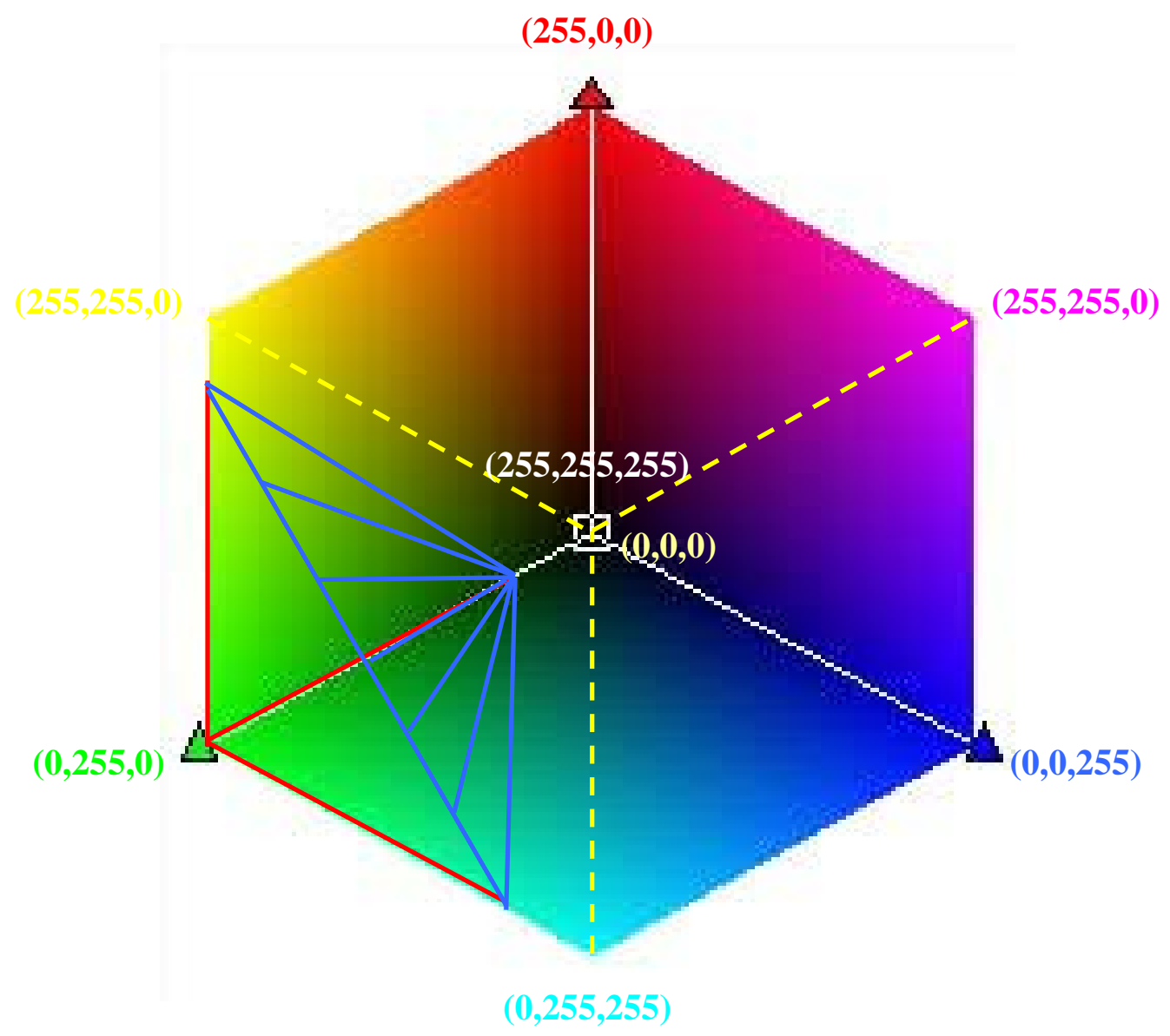

Figure 2.6 - Defined green pixel zone

Since the curve is now a flat plane, an equation of the plane can be found and points within the enclosed region can be specified and selected. Using this assumption will cause some possible colors to be eliminated and not counted. Since these are fringe colors, they most likely will not have a significant impact on the analysis. Next, a 
program is needed to read the RGB text file and compare the pixels inside the files to the pre-selected pixels and determine how many pixels match the pre-selected pixels.

Initially, IO Industries Inc, manufacturer of Image Savant software provided a pixel count program. However, to use it would require entering all acceptable green pixel combinations into a file as shown below.

$(0,50,0),(1,50,0) \ldots(50,50,0)$

$(1,50,1),(1,50,2) \ldots(1,50,50)$

-

$(0,51,0),(1,51,0) \ldots(51,51,0)$

$(1,51,1),(1,51,2) \ldots(1,51,51)$

-

$(0,52,0),(1,52,0) \ldots(52,52,0)$

$(1,52,1),(1,52,2) \ldots(1,52,52)$

$$
\cdot
$$

.

$(0,255,0),(1,255,0) \ldots(200,255,0)$

$(0,255,1),(1,255,1) \ldots(200,255,1)$

$(0,255,150),(1,255,150) \ldots(200,255,150)$

As shown, there are millions of these selected pixels to key in, at least $1 / 5$ or $1 / 6$ of $16,777,216$. As a result, the program file with its setting file becomes very huge in size. Also, when running the program there would be many pre-selected pixels to be compared with the pixels in the file. So, the whole process would be very time consuming. It would take couple of hours to run just a single RBG text file. Consequently, the method is not workable.

Later, efforts were made to obtain equations of the flat plane. With these equations, a program can be written using the equations as the algorithm. The image text file is then compared with the equations and matched pixels are counted. However, this method presented significant problems since the flat plane is too idealized to be true because it eliminates lots of green pixels. 


\subsection{Final Solution}

From the results of the investigation, it was realized that a more general and workable solution should be sought. An approach was made to relate the relationship between shade levels of red, green and blue. There are three sliders, namely red, green and blue in any color combinations.

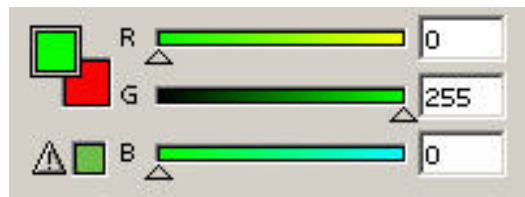

The three sliders make 3 unknowns since if one slider is fixed the other two are still movable. By pinning BLUE to 0 and moving both GREEN and RED, it was found that the RED and GREEN will gave a combination of red, brown, yellow and green. By pinning RED and moving BLUE and GREEN, it was found that the BLUE and GREEN would give a combination of just BLUE and GREEN. For a typical vegetation image, there is no need to worry about the blue since there should not be any blue within the images. Therefore, the main focus is on red and green combinations. This produces just two unknowns. This makes it easier to establish a relationship.

A processed image may look like one below and the main objective is to determine the percentages of green within the "desired" area. However, there is also a red area and some dark spots as mentioned. These dark spot areas are those contradictory areas since there may be grasses beneath or dead spots. The result may have to be judged by the one who performs the analysis or the one who takes the picture. 


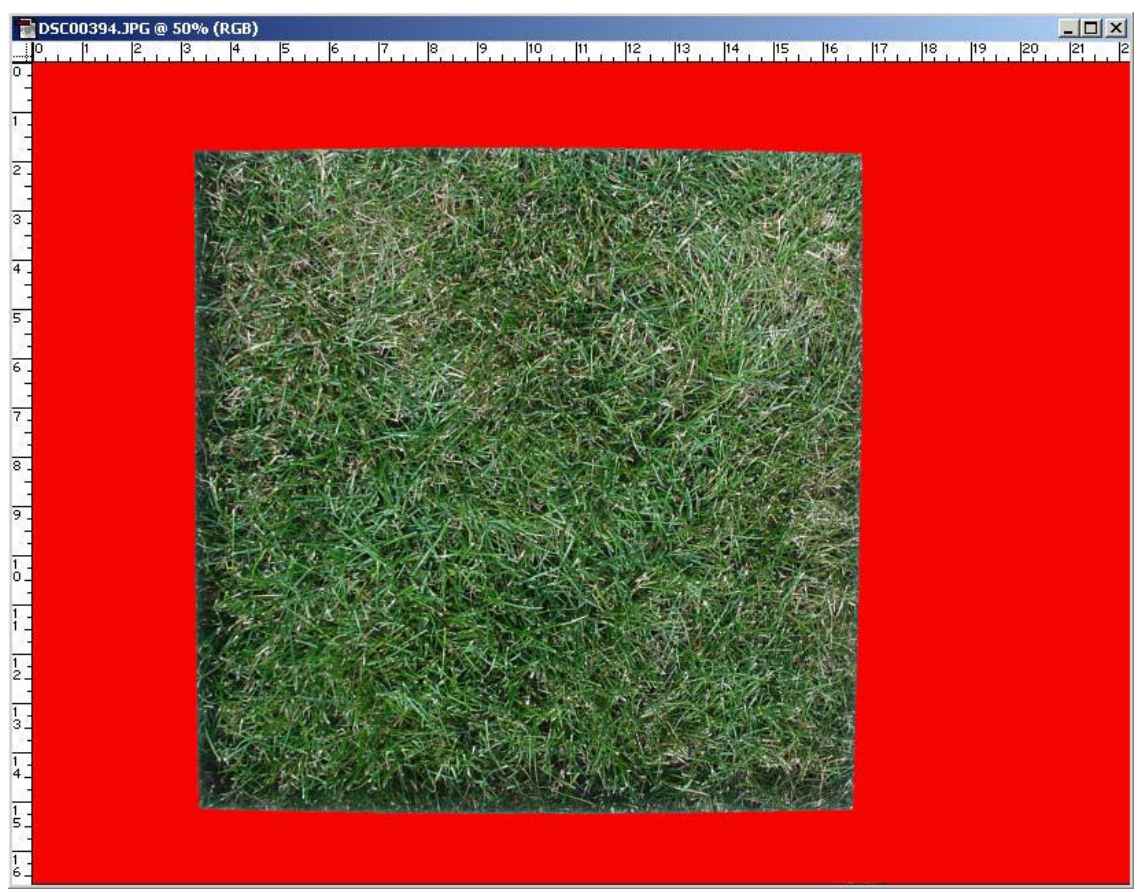

Figure 2.7 - Field image

In order to determine the percentage of green within the desired area, the percentage of red should be determined first. To determine the number of red pixels, the following algorithms were established:

$$
\begin{aligned}
& \text { RED } \geq 240 ; \\
& \text { GREEN } \leq 50 ; \\
& \text { BLUE } \leq 50
\end{aligned}
$$

Next, the number of green pixels is determined using the following algorithms.

$$
\begin{aligned}
& \text { GREEN } \geq \text { RED } \\
& 50 \leq \text { GREEN } \leq 255
\end{aligned}
$$

The percentage of green pixels within the desired area is determined using the following equation. This is the actual final percentage of green.

$$
\text { Percentage }=\frac{\text { Number of GREEN Pixels }}{(\text { Total Number of Pixels in the Image }- \text { Number of Red Pixels })} \times 100 \%
$$
algorithms.

Also, the number of dark spot pixels is determined using the following 


$$
\begin{aligned}
& \text { GREEN < 50; } \\
& \text { RED < } 240
\end{aligned}
$$

Finally, the percentage of dark spot pixels within the desired area is determined using the following equation. This is the actual final percentage of dark spots.

Percentage $=\frac{\text { Number of Dark Spot Pixels }}{(\text { Total Number of Pixels in the Image }- \text { Number of Red Pixels })} \times 100 \%$ 


\section{Chapter 3 - Image Taking Techniques}

\subsection{Vertical Shots}

The camera lens should be faced vertical (in straight line) to the desired area of vegetation shot as shown below:

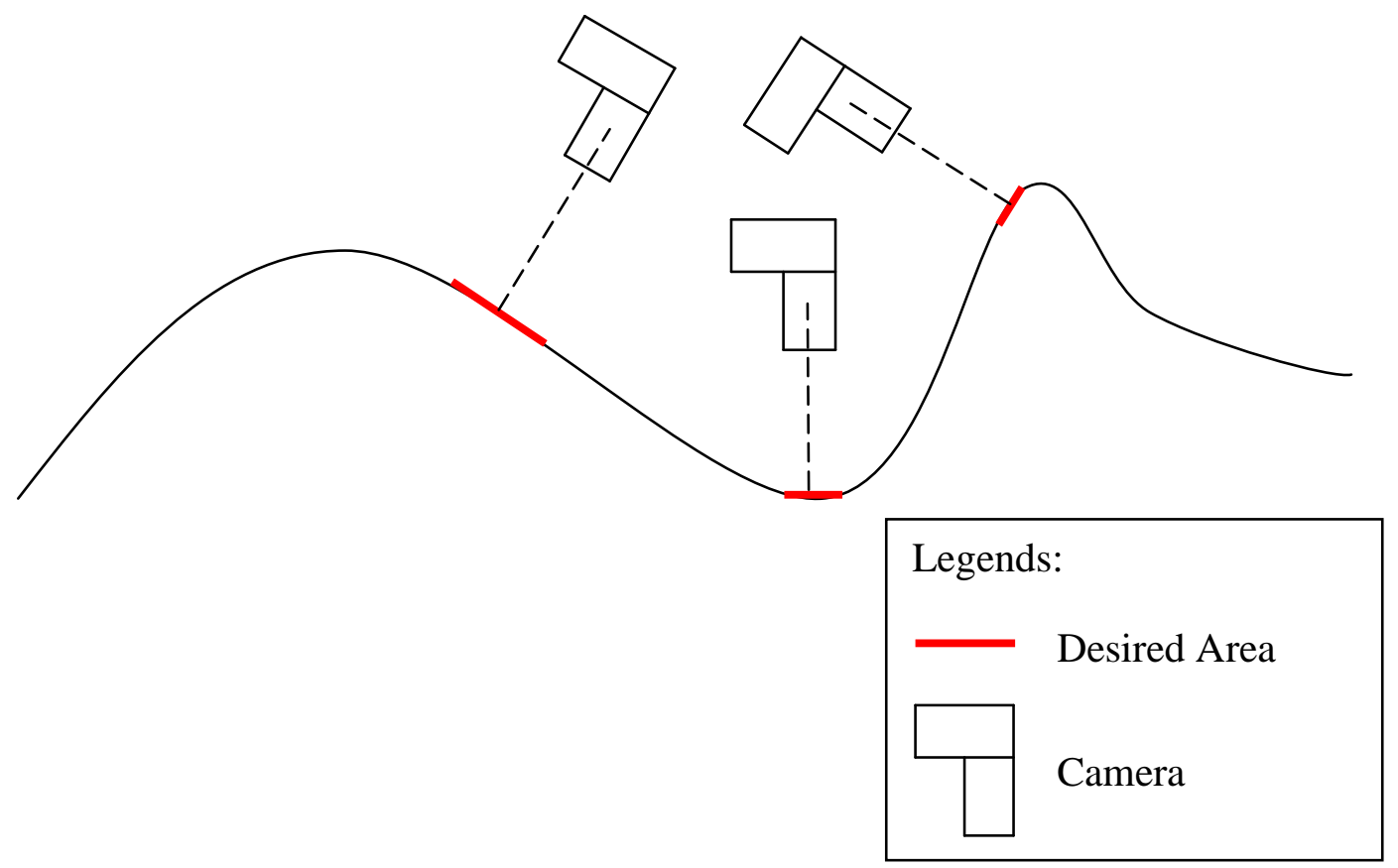

Figure 3.1 - Camera angles

There is a reason for shooting vertically and it will be best explained with the following example below:

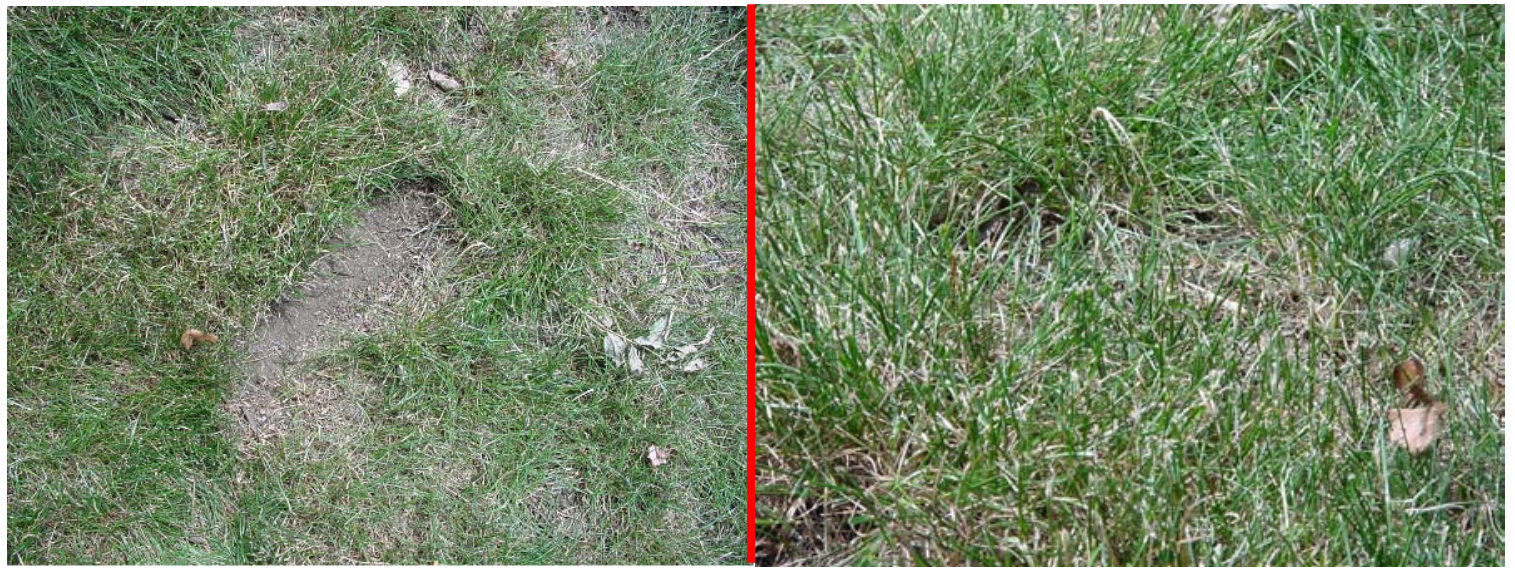

An image taken vertically to the lens

Same image taken at an angle to the lens

Figure 3.2 - Camera angle Images 
There are some gray spots (spots where no vegetation is present) visible when the image is shot vertically. At an angle, some of the grasses may block the gray spots. From the image on the right, you can notice that most of the gray spots have been blocked. Therefore, for accuracy purposes, vertical shots should be made.

It may be impossible to have a $90^{\circ}$ shot in the field most of the time. However, the photographer should set the camera as vertical as possible.

\subsection{Length of Grass}

There are problems caused by long grasses. They seem to bend a lot as shown in figure 10 . When they bend, they will cover some "gray spots". This can be deceptive since the covered areas may be wrongly interpreted as areas with grasses.

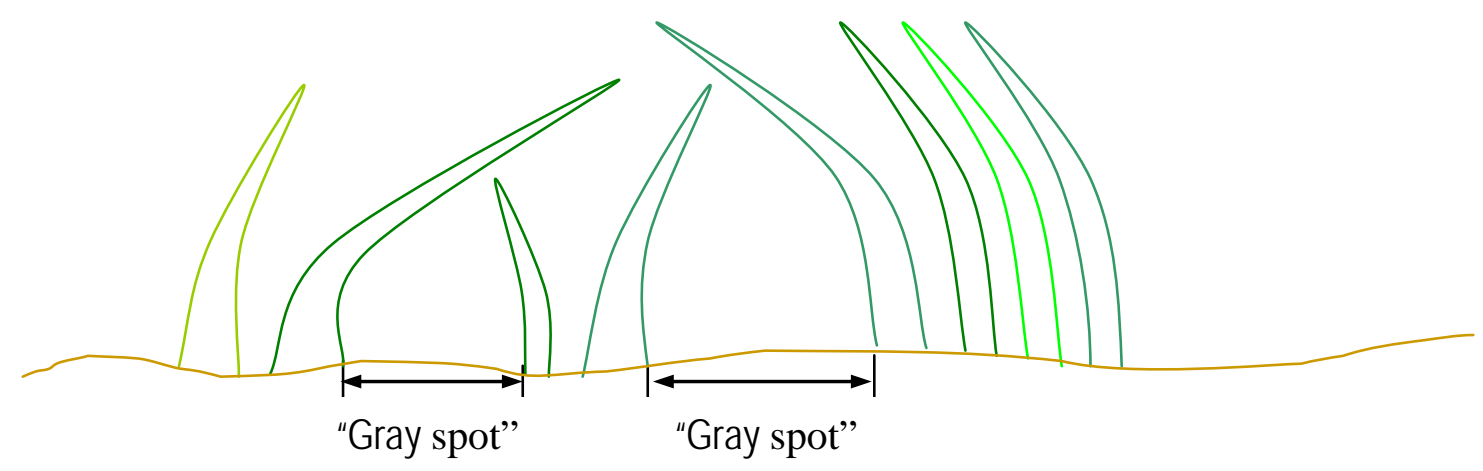

Figure 3.3 - Grass length

When grasses bend over, they create dark spots. It can be seen in the image below. Therefore, grass length should be so they are not long enough to bend over (although it may be nearly impossible to have no dark spots in between grasses.). 


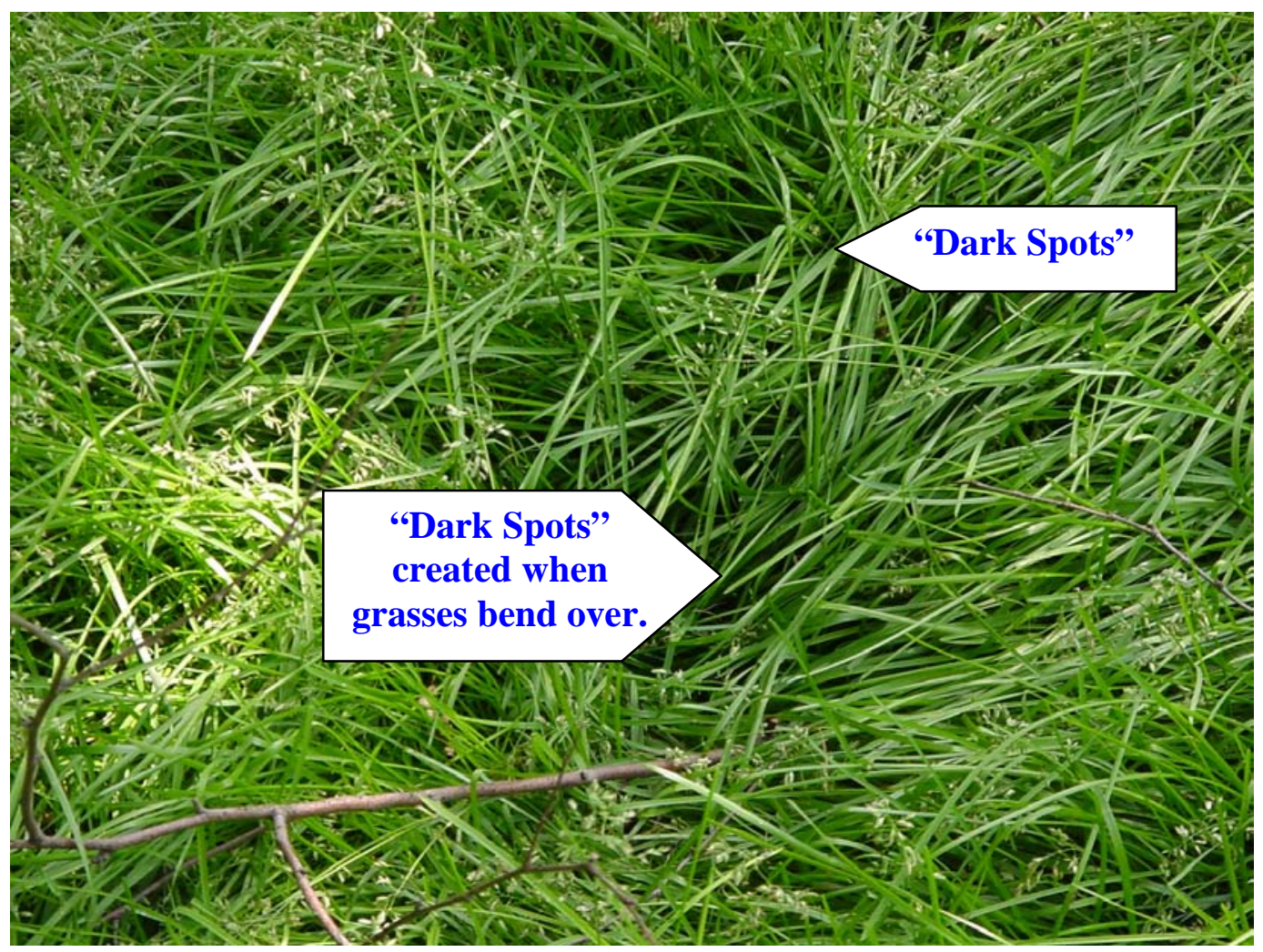

Figure 3.4 - Grass length image

\subsection{Random Samples}

Taking pictures at different directions may have slight differences in the percentages of green pixels due to the fact that it would be very difficult to take an image exactly 180 degree. There are cases where desired areas taken are not flat and even.

Let's consider an example by referring to the image below. The red curve is the desired area of the shooting.

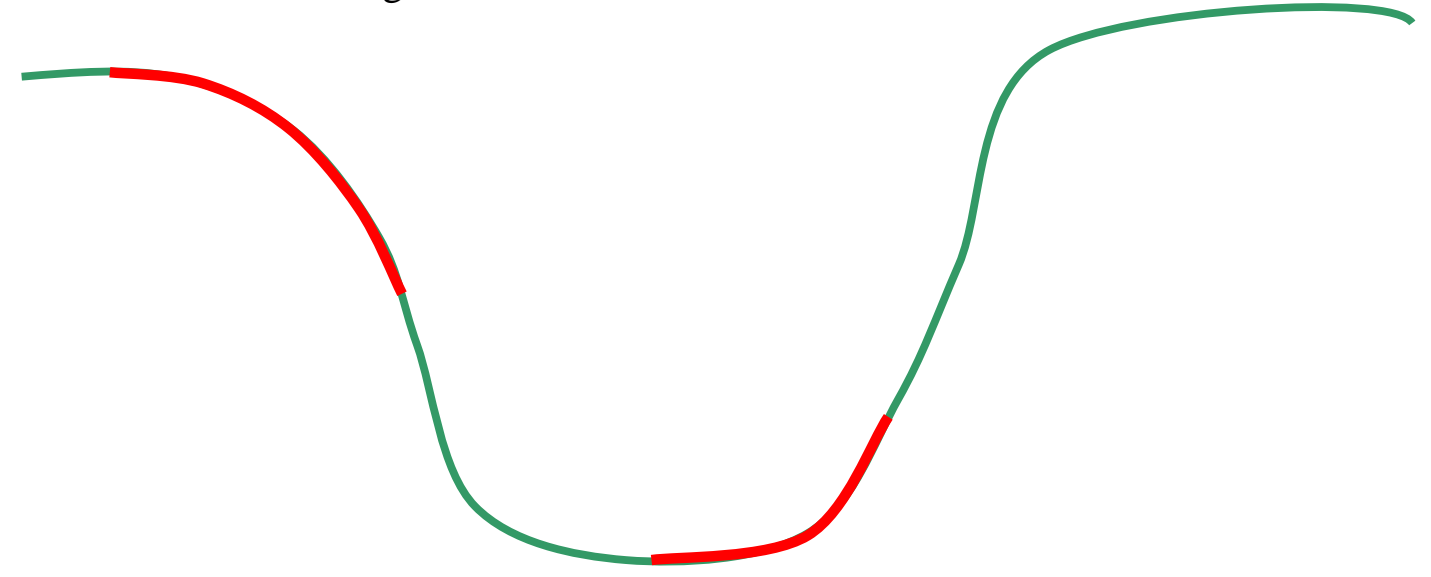

Figure 3.5 - Image direction 
There are a few tangencies (blue dotted lines) to one area. So, images from different directions may have different ranges of green due to different incident and reflected angle of sunlight.

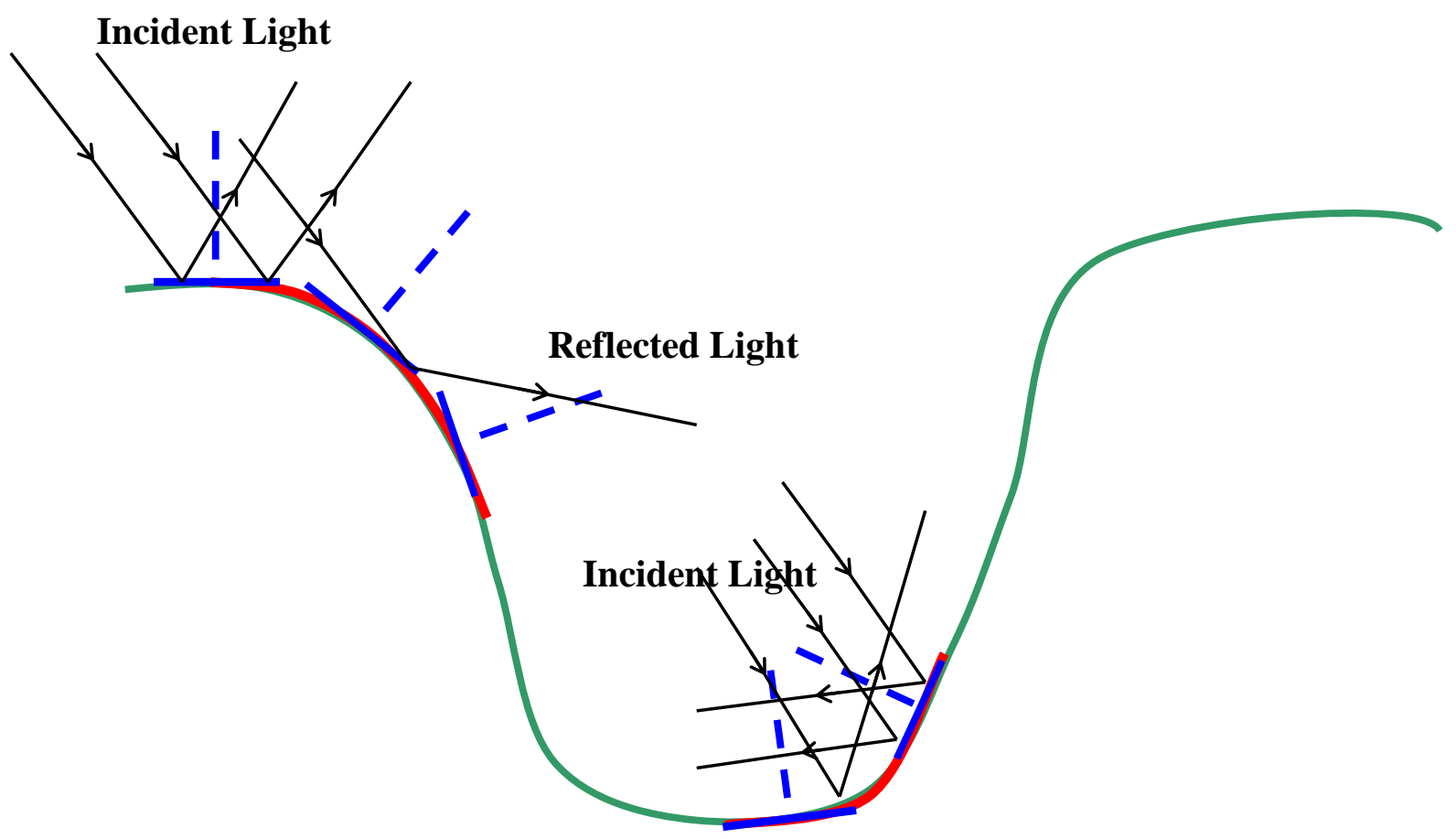

\subsection{Zooming In or Out}

Figure 3.6 - Light Angles

Zooming in or zooming out does not appear to affect the percentage of green pixels, theoretically since:

1. It is still taken at the same spot at the same direction and orientation.

2. It only enlarges the desired area by lens zoom.

However, it is found that the same picture taken with different zooms possesses different brightness probably due to the "Auto Focus" feature most cameras have.

Consider the two images taken below. 


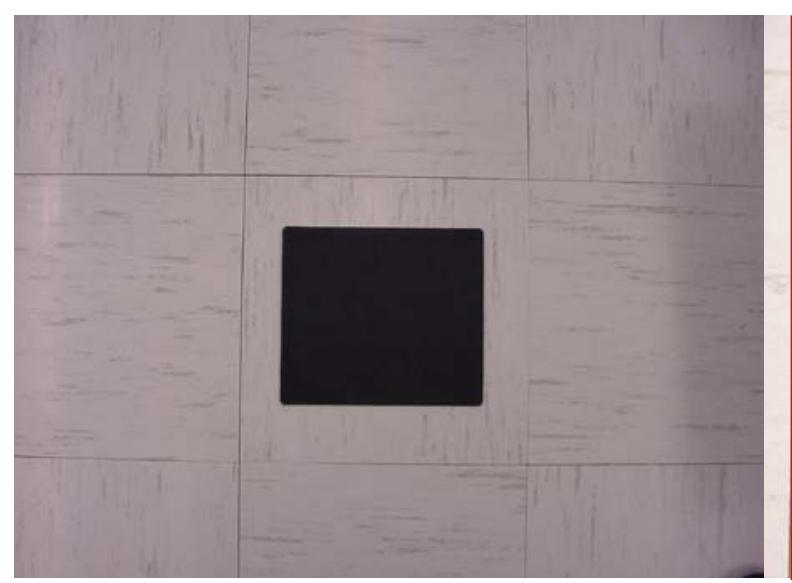

An image taken without zooming in

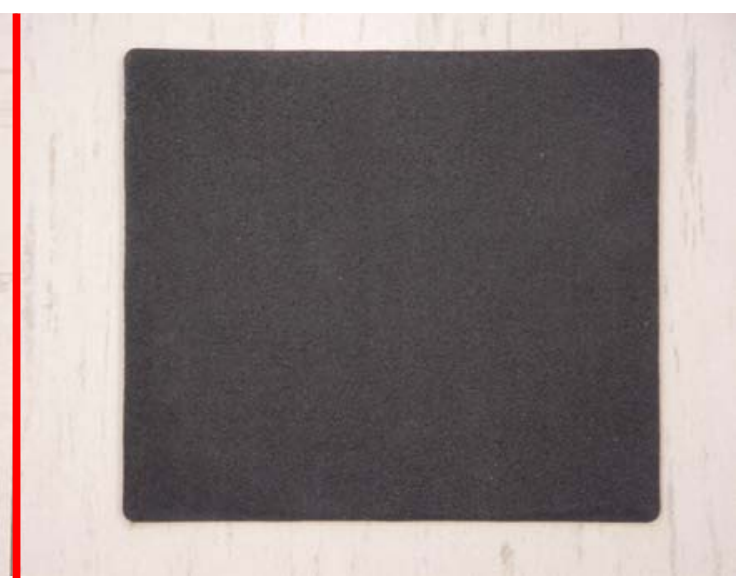

Same image taken with zooming in

Figure 3.7 - Zooming effect

The image is a black rectangle. The picture taken without zooming (on left) is still a black rectangle. However, when the rectangle is zoomed in, it becomes gray. This may be due to the "Auto Focus" feature of the camera. Therefore, to avoid any lightening of color, zooming in should not be done. Objects photographed (grass areas) should be left as they are though they are not fully utilizing the whole image size.

\subsection{Distance}

The distance between the object photographed and the camera lens should not be too far so that details and features are shown. Yet, the distance should not be too near either. Below is a rectangle taken at a very close distance (1 feet) from the camera lens. 


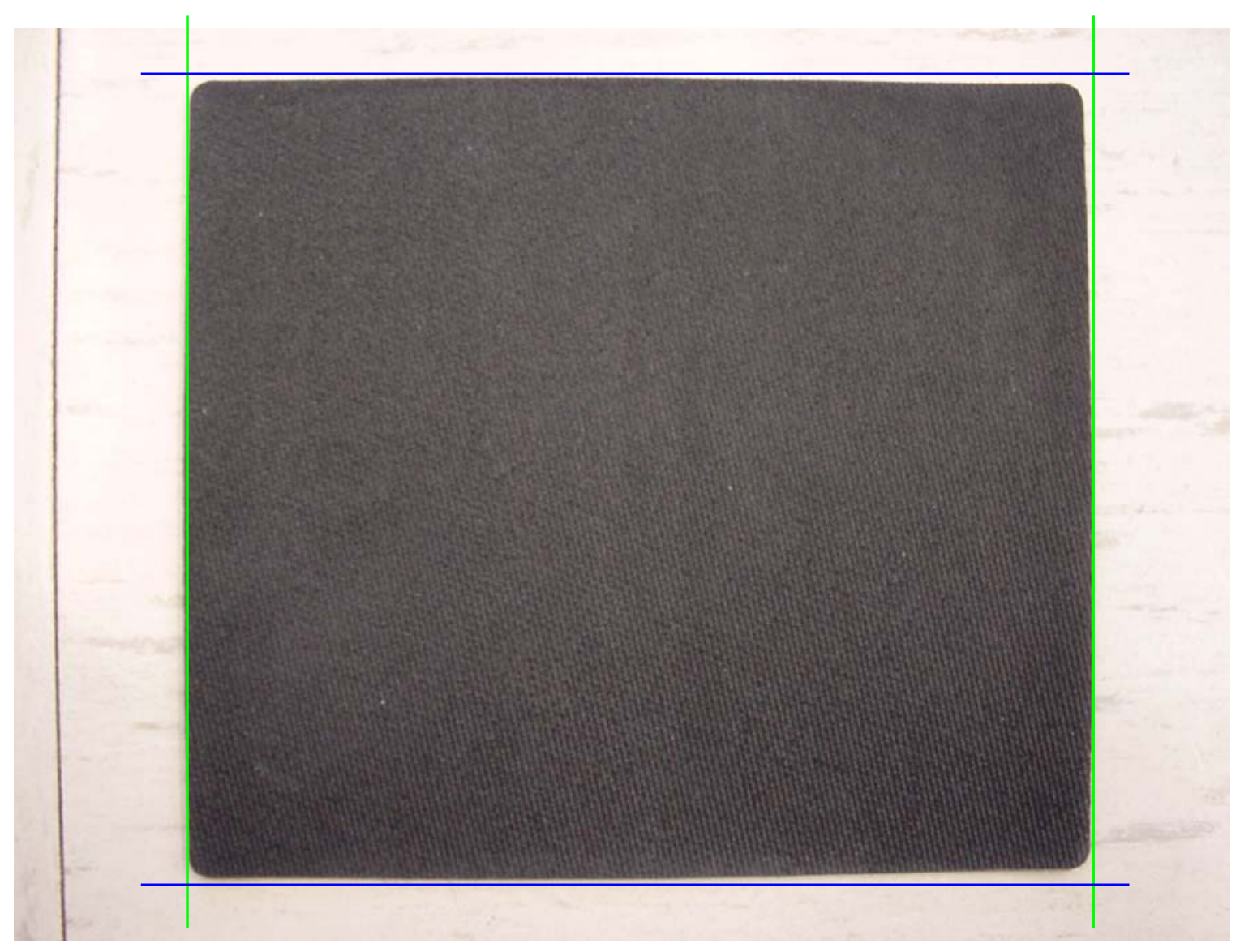

Figure 3.8 - Distance effect

The blue and green lines served as base lines for comparison purposes. Notice that the edges of the rectangle are curvy and are no longer straight. In general, these lines curve outwards due to the fact that the lens of the camera is round and spherical. The object is distorted, with the edges following the shape of the lens, spherical.

Image taken at 3 feet away from the object, the edges are showing no significant curving out effect. 


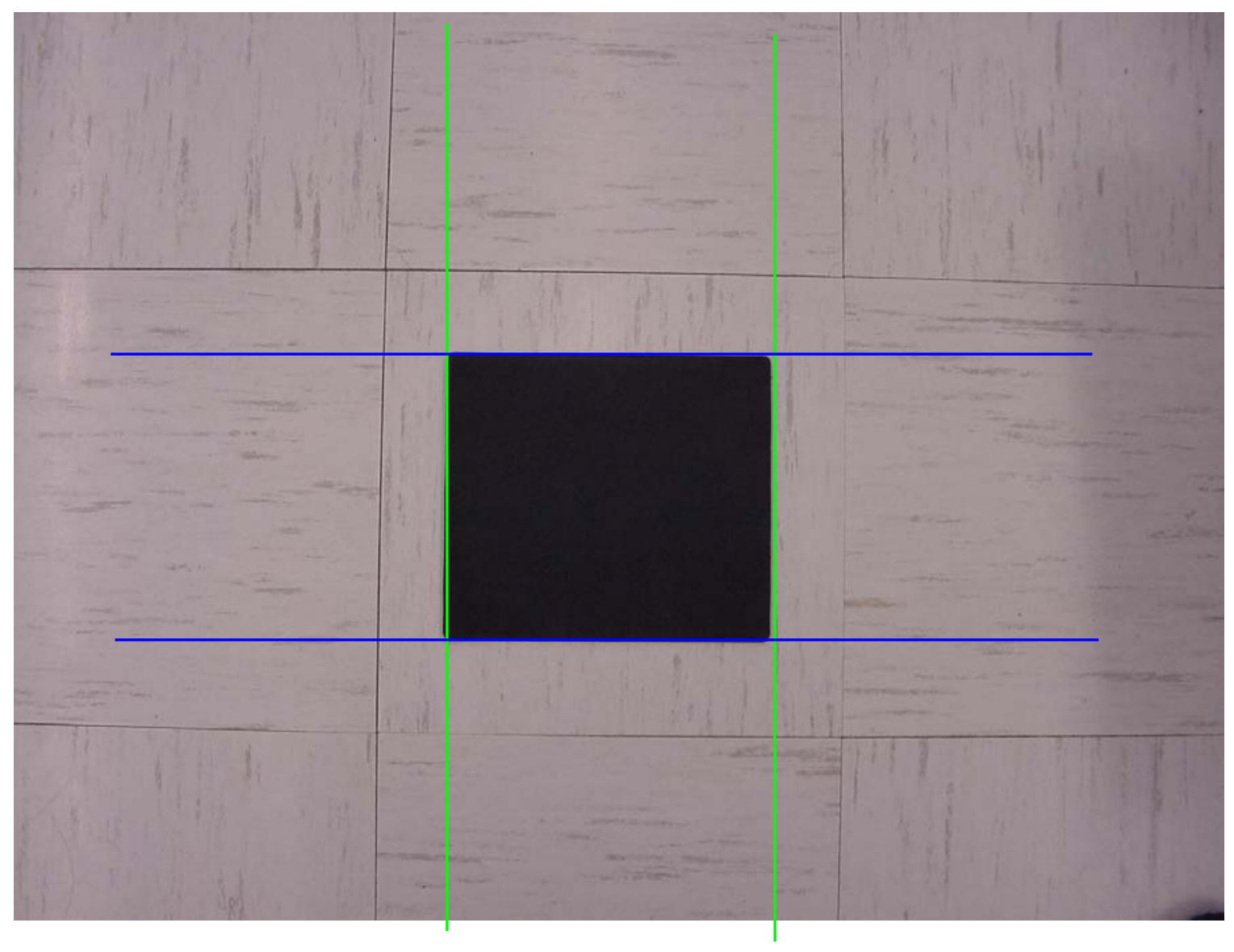

Figure 3.9 - Correct distance

Therefore, in order to minimize curving out and include enough of detail for analyzing, the camera lens should be 3 to 7 feet away from the object photographed.

\subsection{Light Intensity}

Light intensity affects the quality (shade levels, brightness and contrast) of the green pixels within digital images. However, there is no consistent change of pattern to the quality of the digital images. In general, there is only one thing to note. The light intensity should be bright enough for the camera to capture all the needed green pixels. If green pixels are too dark in the shade, they may be analyzed as non-green by the digital vegetation analyzer program. Also, the light should not be too dark to create too many dark spots. This can be illustrated by the following pictures. 


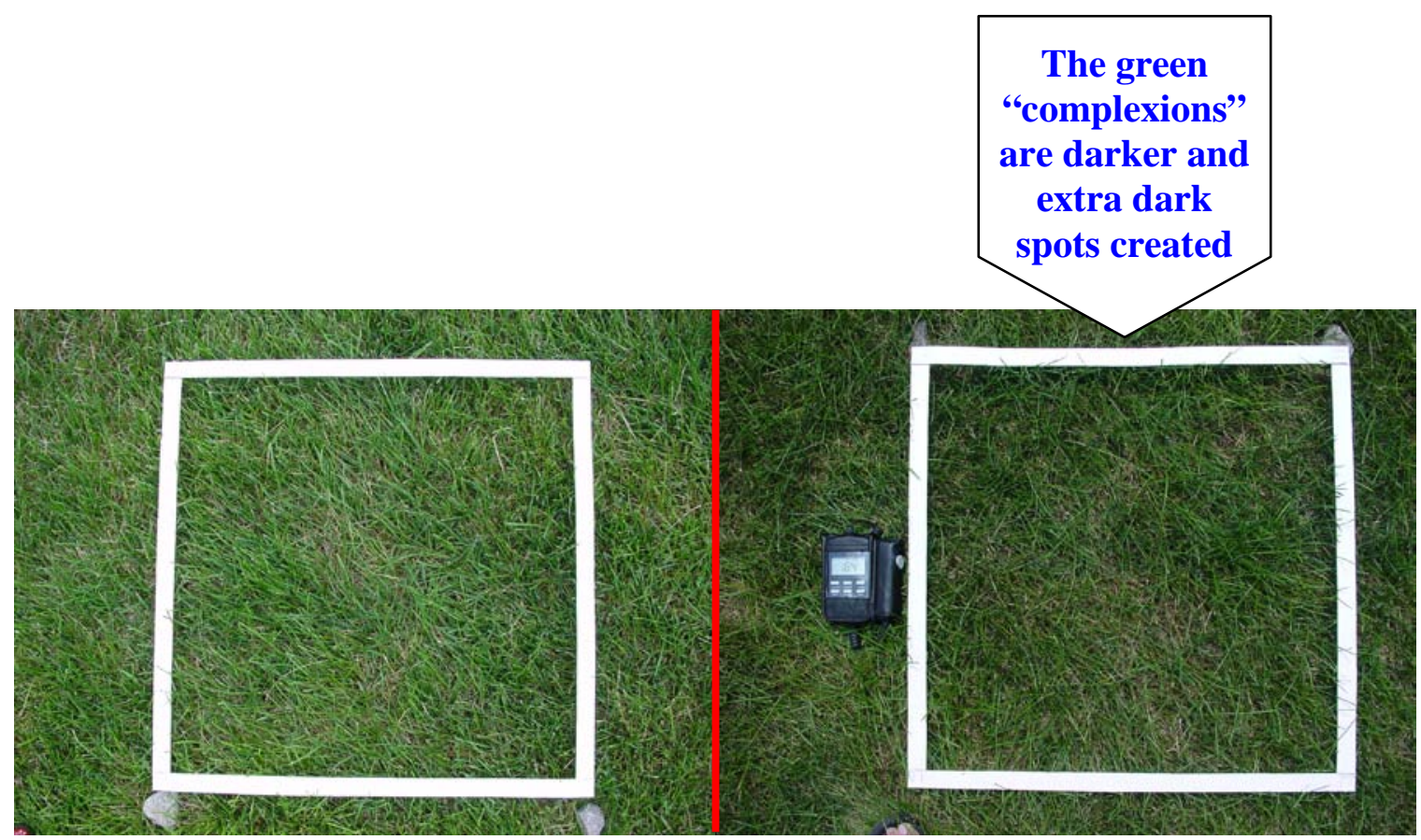

Figure 3.10 - Light Intensity

An image at normal brightness

(\% Of Green is $82.67 \%$ )

(\% Of Dark Spots/Shades is $9.92 \%$ )
Same image on a cloudy day

(\% Of Green is $74.47 \%$ )

(\% Of Dark Spots/Shades is 22.28\%)

Note the differences in the quality of the images. One is expected to get a significant difference in the percentage of green pixels within the desired area.

Strong light is not good either. A high intensity light source can lighten the green pixels until the pixels turn almost white. It can also create some unwanted and unnecessary dark shades. This can best be illustrated by two images below.

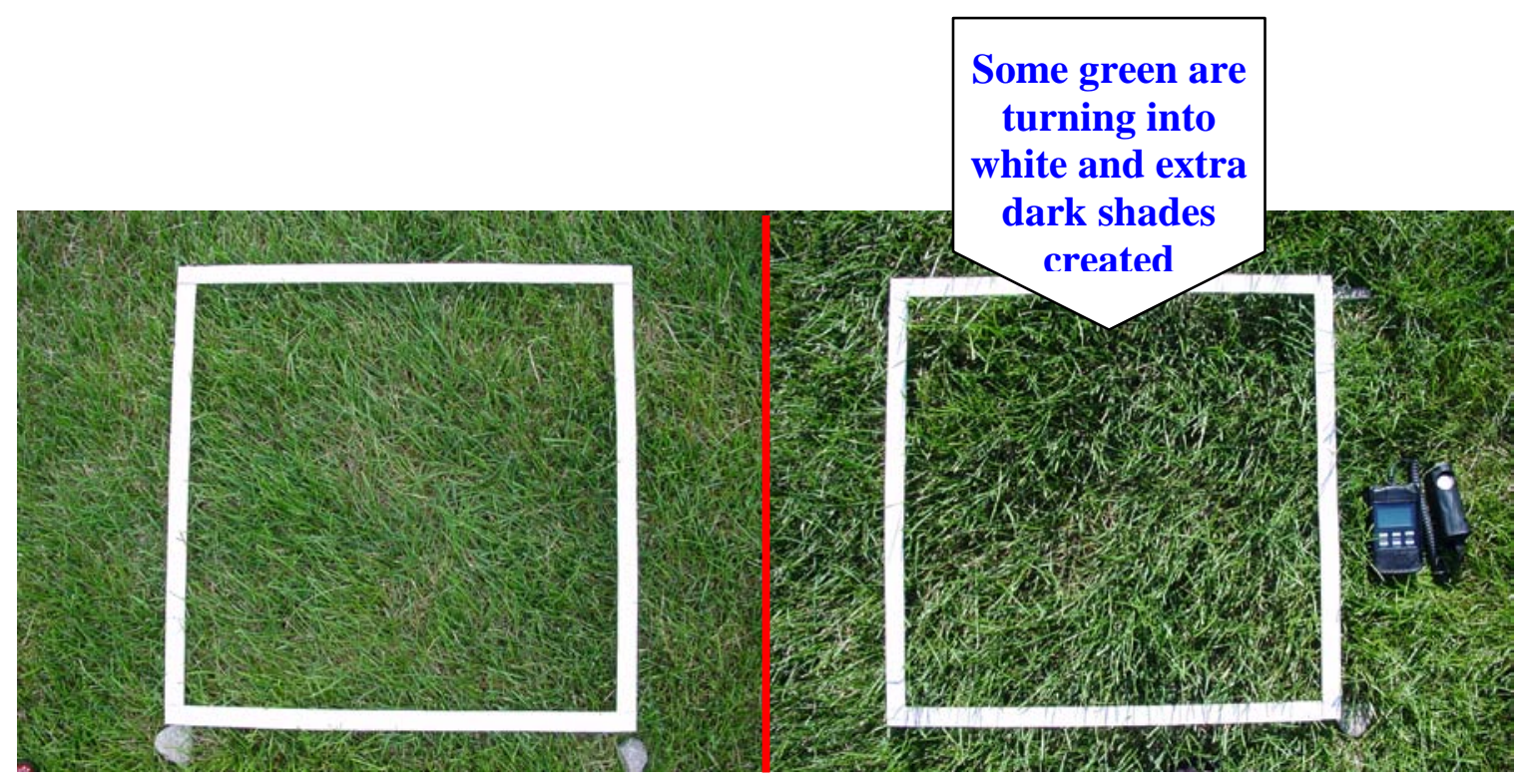

Figure 3.11 - Strong Light

An image at normal brightness

(\% Of Green is $82.67 \%$ )

(\% Of Dark Spots/Shades is 9.92\%)
Same image on a sunny day

(\% Of Green is 61.85\%)

(\% Of Dark Spots/Shades is 33.41\%) 
By trial and error, the optimum light intensity suited for pictures to be taken falls between 500 foot-candle and 3,000 foot-candle, which is about the light intensity for a cloudy day. Since most of the sunny days have light intensity about 7,000 foot-candle to 10,000 foot-candle, a shield should be used. The shield should be placed above the object to block excessive sunlight. It can be anything from a cloth to an umbrella as long as it can effectively lower the light intensity to between 500 and 3,000 foot-candle. For example an umbrella used on a sunny day lowered the light intensity from 7,000 footcandle to 1,200 foot-candle. The research did not experiment with different types and colors for the shield. The main emphasis here was determining light intensity influence on image accuracy. A shield that does not add a tint to the image is necessary, so a neutral colored shield needed. If another research phase is performed this aspect should be investigated further.

The optimum light intensity (500 foot-candle and 3,000 foot-candle) is preferred for typical type of grass alone. It may be different for different vegetation. This is because different vegetation have different light reflectance and light transmittance (translucency).

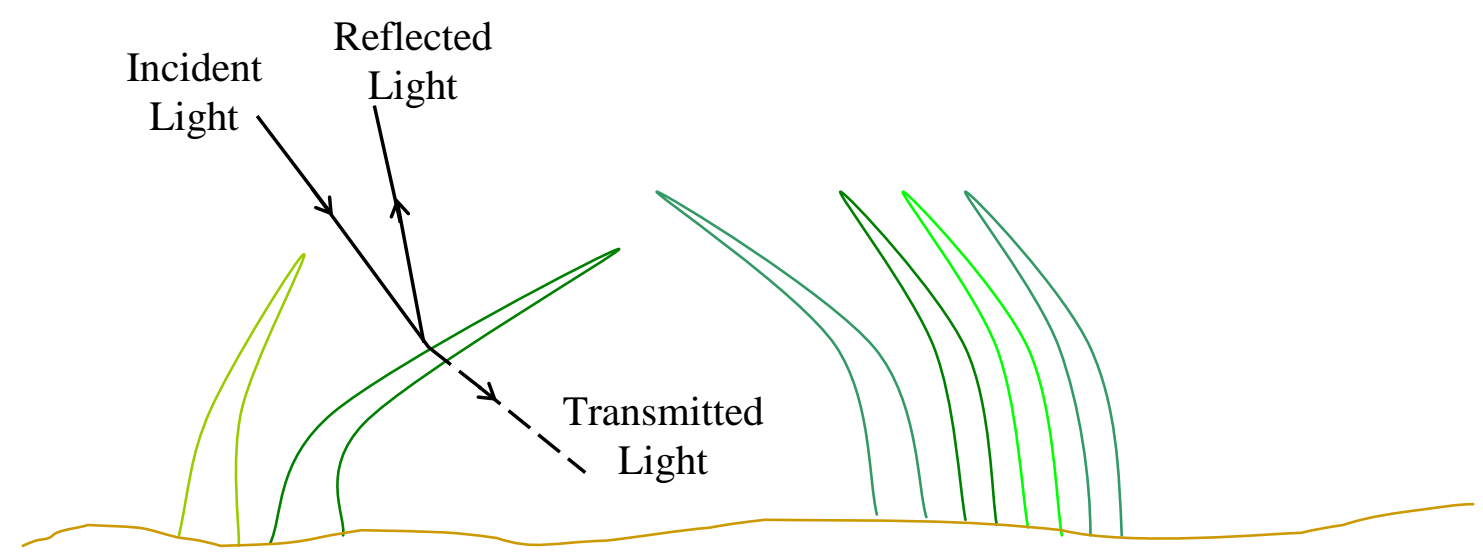

Figure 3.12 - Light Reflectance

Some grasses appear to be almost white under sunlight because they have high reflectance and they reflect a lot of ambient light. Other may become dark green if they have low reflectance that they absorb most of the lights.

Some grasses can appear to be very light if they are transmitting most of the light through them. Some grasses can appear to be darker if they have poor light transmittance.

Different kinds of vegetations have different characteristics in terms of their reflectance and transmittance. Field test results reveal small differences which are within acceptable tolerances and will not significantly affect the final determination. 


\subsection{Sunlight Directions}

The directions of sunlight have a major impact on the percentage of dark spots and dark shades. Consider the following illustrations.

\section{$\underline{\text { Case } 1}$}

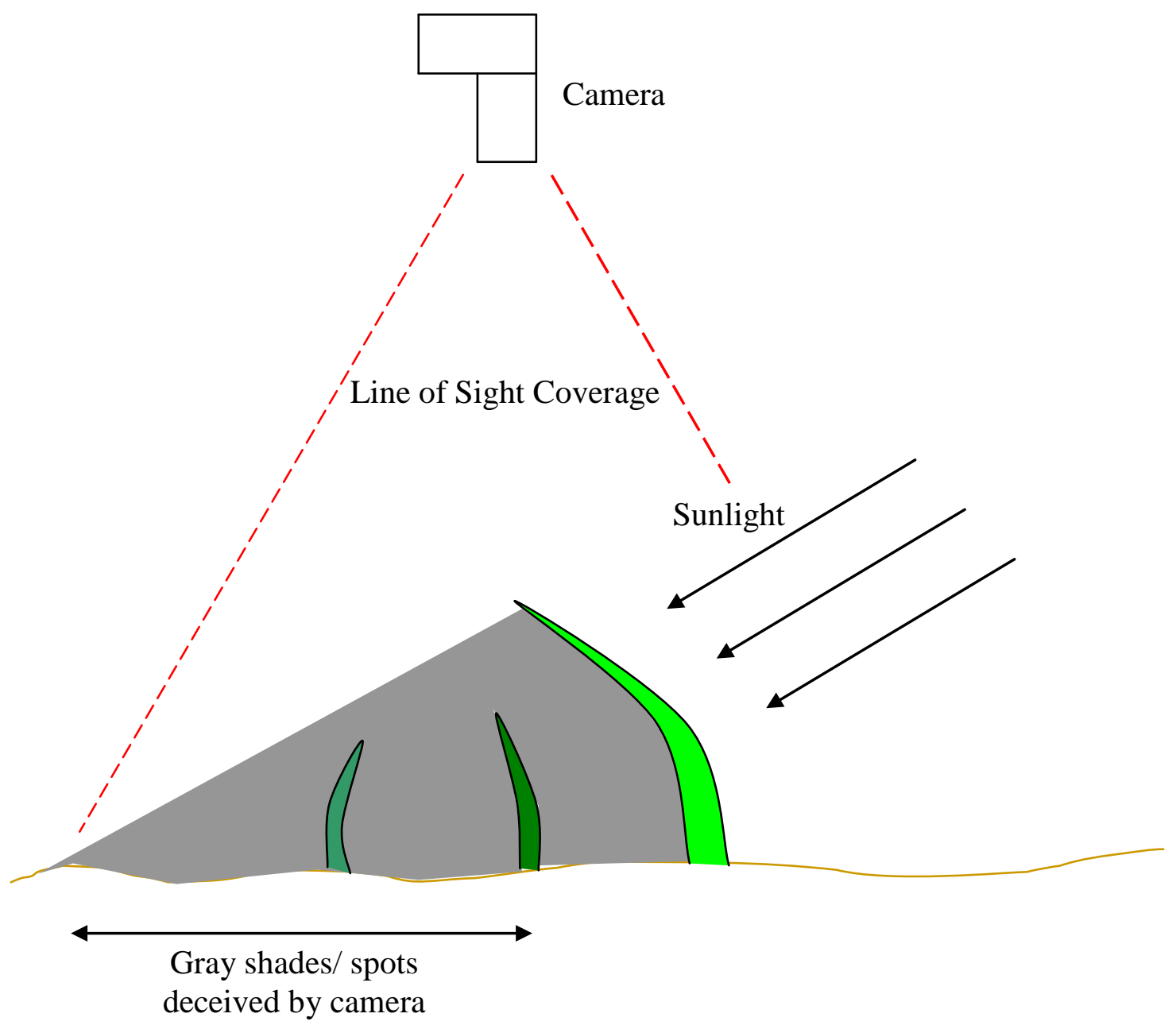

Figure 3.13 - Sunlight right direction

Sunlight from the right side of the picture creates gray shades on the left. Vegetations on the left are totally blocked. They are perceived as gray shades and spots by cameras. 


\section{$\underline{\text { Case } 2}$}

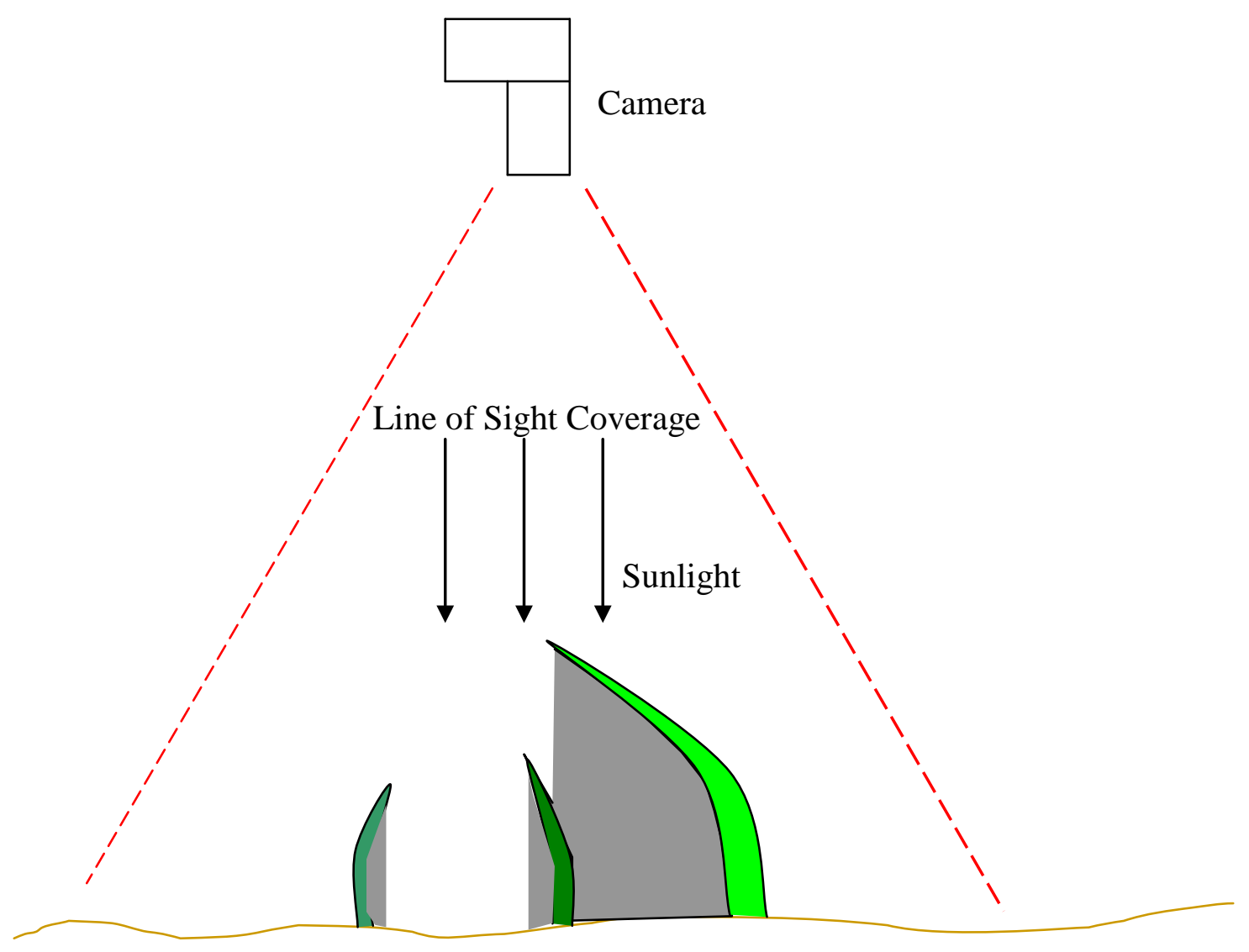

Figure 3.14 - Overhead light

Theoretically, there are gray shades and spots. However, these areas are not seen by cameras. This is the best time to take an image. 


\section{$\underline{\text { Case } 3}$}

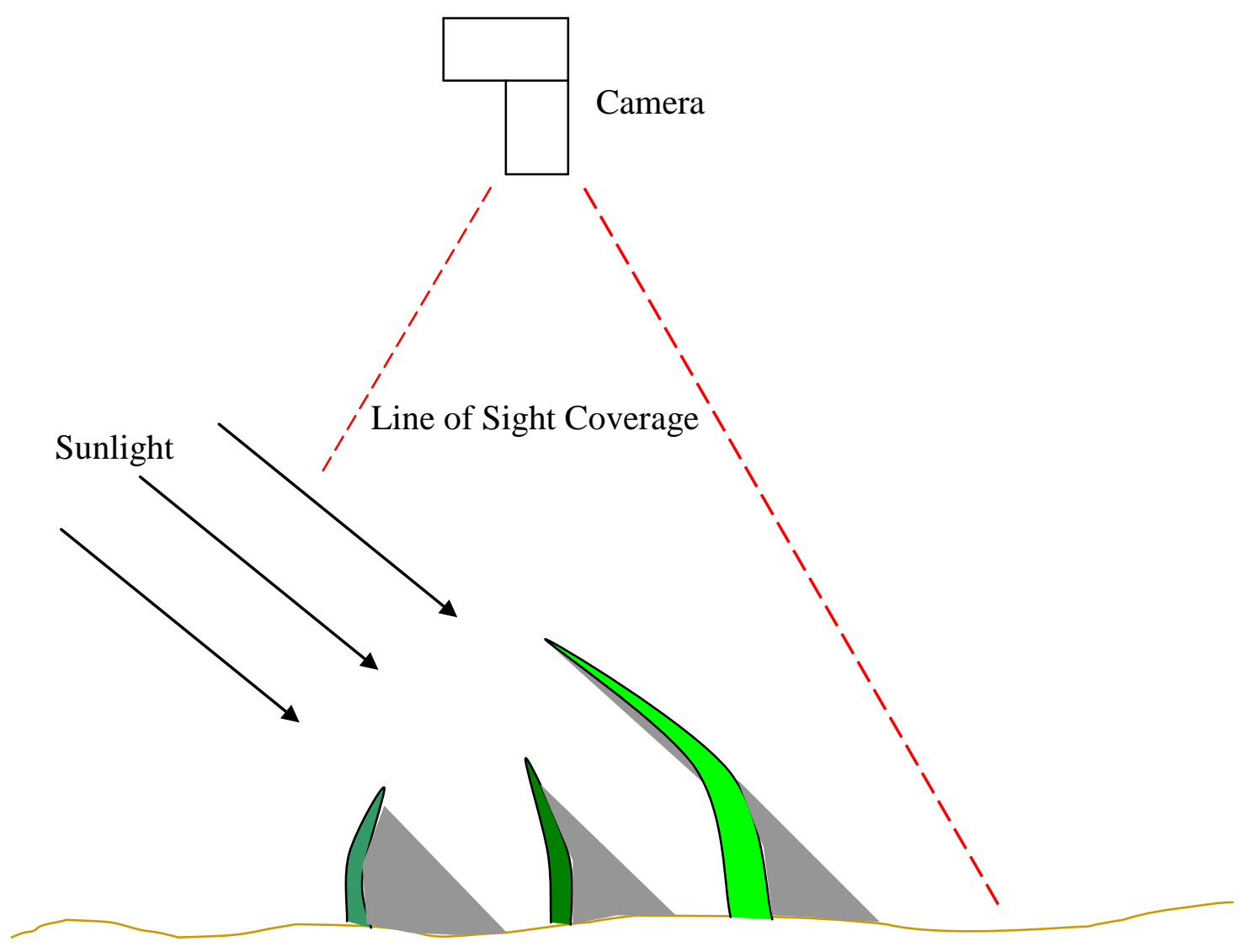

Figure 3.15 - Sunlight left direction

Sunlight from the left side of the picture creates gray shades on the right. Vegetation on the right are not blocked in this case. It might be a good time to take a picture as well. 


\section{Chapter 4 - Digital Cameras}

\subsection{Image Size}

Image Sizes available for the Sony Digital Camera DSC-F505 (one of the cameras used in the analysis) are $1600 \times 1200,1024 \times 768$, and $640 \times 480$. The total number of pixels and the approximate dimension of each settings are as shown:

\begin{tabular}{|c|l|c|}
\hline Image Sizes & \multicolumn{1}{|c|}{ Total Number of Pixels } & Dimension in inches \\
\hline $1600 \times 1200$ & $=1600 \times 1200=1920000$ & $22.222 \times 16.667$ \\
\hline $1024 \times 768$ & $=1024 \times 768=786432$ & $14.222 \times 10.667$ \\
\hline $640 \times 480$ & $=640 \times 480=307200$ & $8.889 \times 6.667$ \\
\hline
\end{tabular}

The larger the image size, the bigger number of pixels is in an image that makes the image a better quality picture to analyze. However, the bigger the image size, more time is needed to spend in analyzing the result.

Typically, for better accuracy, it is advisable to choose the largest size available; that is, $1600 \times 1200$. A $1600 \times 1200$ image usually takes about 10 to 15 minutes to be analyzed. The percentage of green pixels is more accurately reported.

\subsection{Quality}

There are 2 qualities available: Fine and Standard. For better accuracy, Fine quality is preferred.

\subsection{Exposure}

The exposure levels range from $-1.5 \mathrm{EV}$ to $+1.5 \mathrm{EV}$. Low exposure darkens the background of the image and high exposure adds additional lightings to the background. For neutral and accurate analysis, it is preferably not to add or take out any lighting from the background. Therefore, the exposure level should always be set to $0 \mathrm{EV}$.

\subsection{Flash Level}

Flash level should be left alone as default (normal flash level) since flash will not be used. Flash should never be turned on because it whitens the image. A whiten image may cause some green pixels to be white. Analysis would then be inaccurate.

\subsection{Digital Zoom}

The digital zoom should be turned off. The camera zoom lens can zoom in and out optically by using the optical formula built into the lens. On the other hand, digital zoom can do the same by magnifying the existing image. Consider the two pictures taken on the next page with different ways of zooming: optical zoom and digital zoom. 


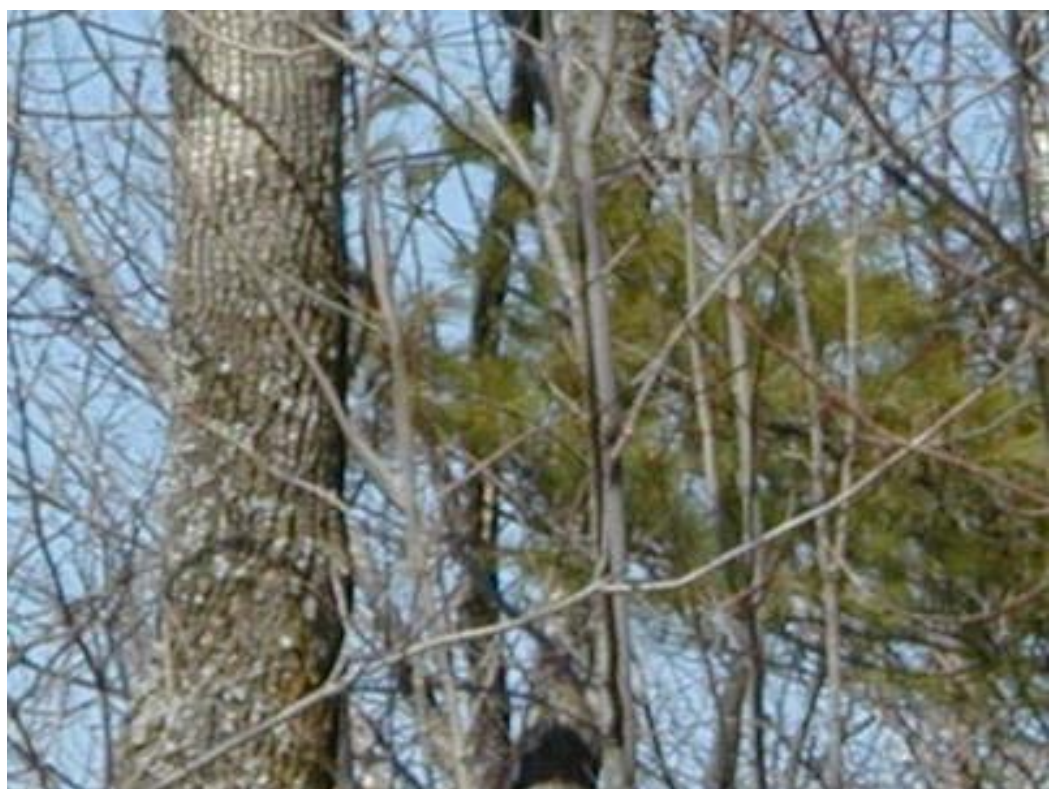

Figure 4.1- Optical Zoom

(http://www.cs.mtu.edu/ shene/DigiCam/User-Guide/990/ON-CAMERA-LENS/digital-zoom.html)

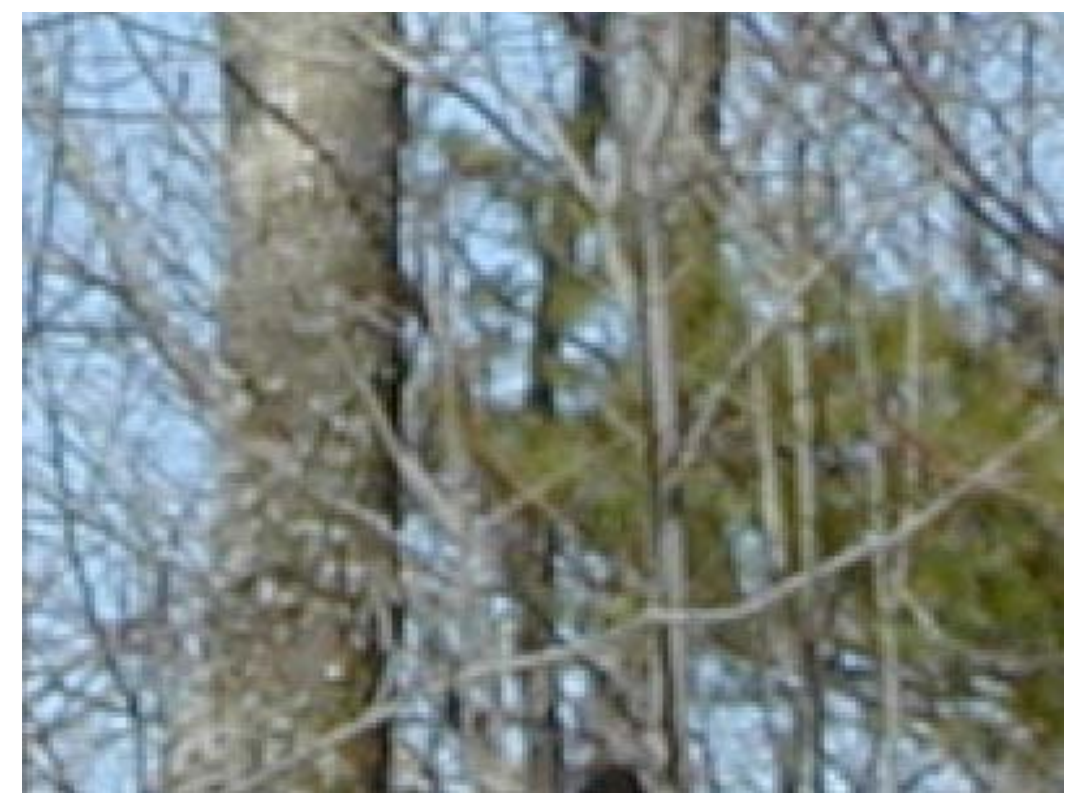

Figure 4.2 - Digital Zoom

(http://www.cs.mtu.edu/ shene/DigiCam/User-Guide/990/ON-CAMERA-LENS/digital-zoom.html)

Using digital zoom will lower image quality. More precisely, digital zoom means taking the center part of an image and blow it up to the desired resolution. This "blow-up" 
process adds extra pixels, but it does not add details because the image details are limited by the area of the original image.

\subsection{Camera Comparisons}

Pictures had been taken with a Sony DSC-F505 Digital Camera and with a Kodak DC4800 Digital Camera. Since different cameras have different Auto Focus, White Balance...etc., different cameras can produce images of the same area very differently. Pictures below were taken on the same day, at the same time using two different digital cameras.

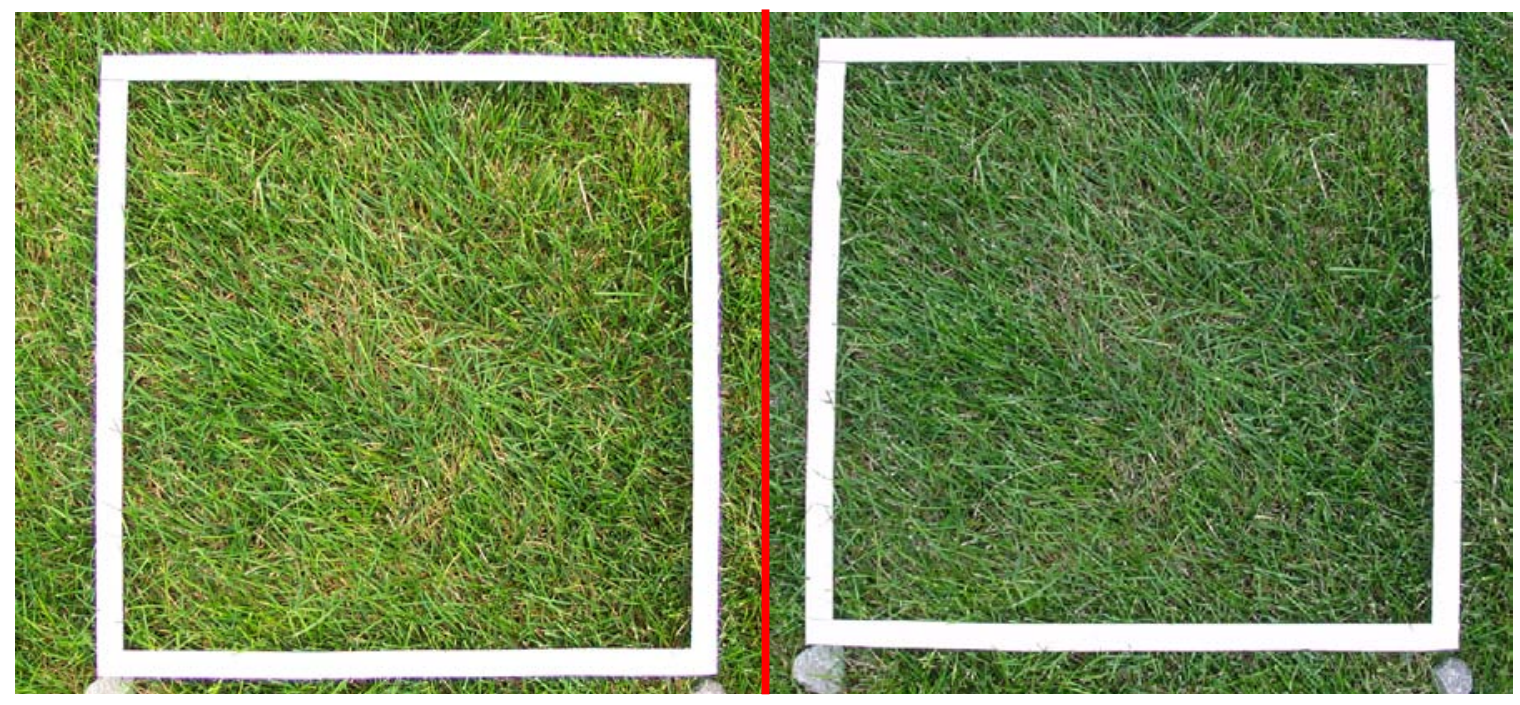

An image taken using Kodak DC4800 Same image taken using Sony DSC-F505

Figure 4.3 - Camera comparisons

Notice the difference between the color shades and the quality of pictures in figure 3.3. The image taken by Kodak is sharper and clearer. However, it also lightens the grass colors creating more yellow and white pixels. Results from the digital vegetation analyzer show a lot less green pixels. Meanwhile, images from Sony are not as sharp as Kodak's. But, they are clear enough to be analyzed.

The image on the left shows $83.13 \%$ of green pixels and the image on the right shows $90.72 \%$ of green pixels. In terms of gray shades, the image on the left shows $6.62 \%$ of gray shades and the image on the right shows $7.01 \%$ of gray shades. These numbers conclude that the Kodak excludes too many green pixels. Some of the green pixels have been turned into yellow that are read as non-green by the digital vegetation analyzer. In terms of producing an image that is near to the representation of the field, Sony DSC-F505 is a better choice although it shows an insignificantly more amount of gray shades than the Kodak’s does. 
However, not all inspectors are equipped with Sony DSC-F505. Therefore, the problem of having a significant difference in percentage of green from camera to camera must be solved.

\section{$\underline{\text { Solution }}$}

Since some cameras such as Kodak DC 4800, turn green into yellow or lighten the actual colors of the real image under high intensity of sunlight. Since most of the sunny days have light intensity about 7,000 foot-candle to 10,000 foot-candle, a shield should be used. The shield should be placed above the object to block excessive sunlight. It can be anything from a cloth to an umbrella as long as it can effectively lower the light intensity to 500 foot-candle and 3,000 foot-candle. By dropping the light intensity, the turning green into yellow effect will be minimized. Consequently, the green on the field will be represented as green in the digital image.

\subsection{Camera Accuracy}

Different cameras produce different results in the analysis program. It is necessary to develop a calibration test to determine the accuracy of color captured by a camera. Therefore, a laboratory color template had been created using Adobe PhotoShop. These colors are set to a specific combination of RGB pixels. Exact percentage of green in the template is $50 \%$. The percentage of black is $13 \%$.

The printed out color template should be laid out in the field under controlled light intensity of about 1,000 to 3,000 foot-candle. Then, pictures of the template will be taken using the camera. The pictures will be analyzed for the percentage of green as described in the procedure section.

If the percentage of green analyzed is within the accepted range, say $\pm 5 \%$ of the exact percent of green, which is $50 \%$, the camera will be qualified. The following page is the sample test template. 


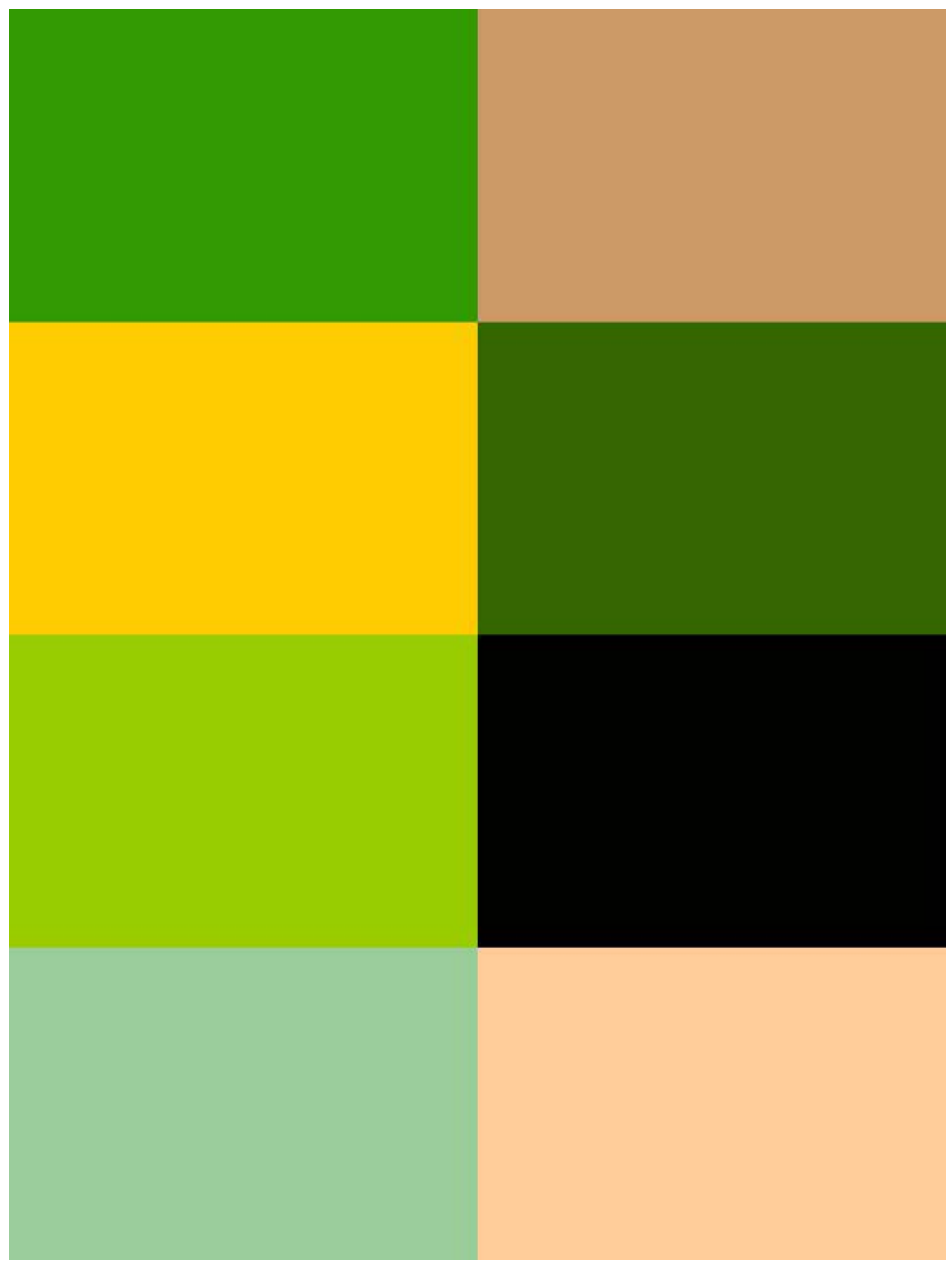

Figure 4.4 - Calibration Template 


\section{Chapter 5 - Field and Analysis Procedures}

\subsection{Taking Pictures and Importing Images}

In order to access the "grass" cover of a particular area, samples of the area need to be taken. On way to accomplish this is using a white template.

1. The template (square white frame shown below), is laid on the desired area as shown. Several images are taken for one desired area in order to minimizing inaccuracies in the result by averaging the results.

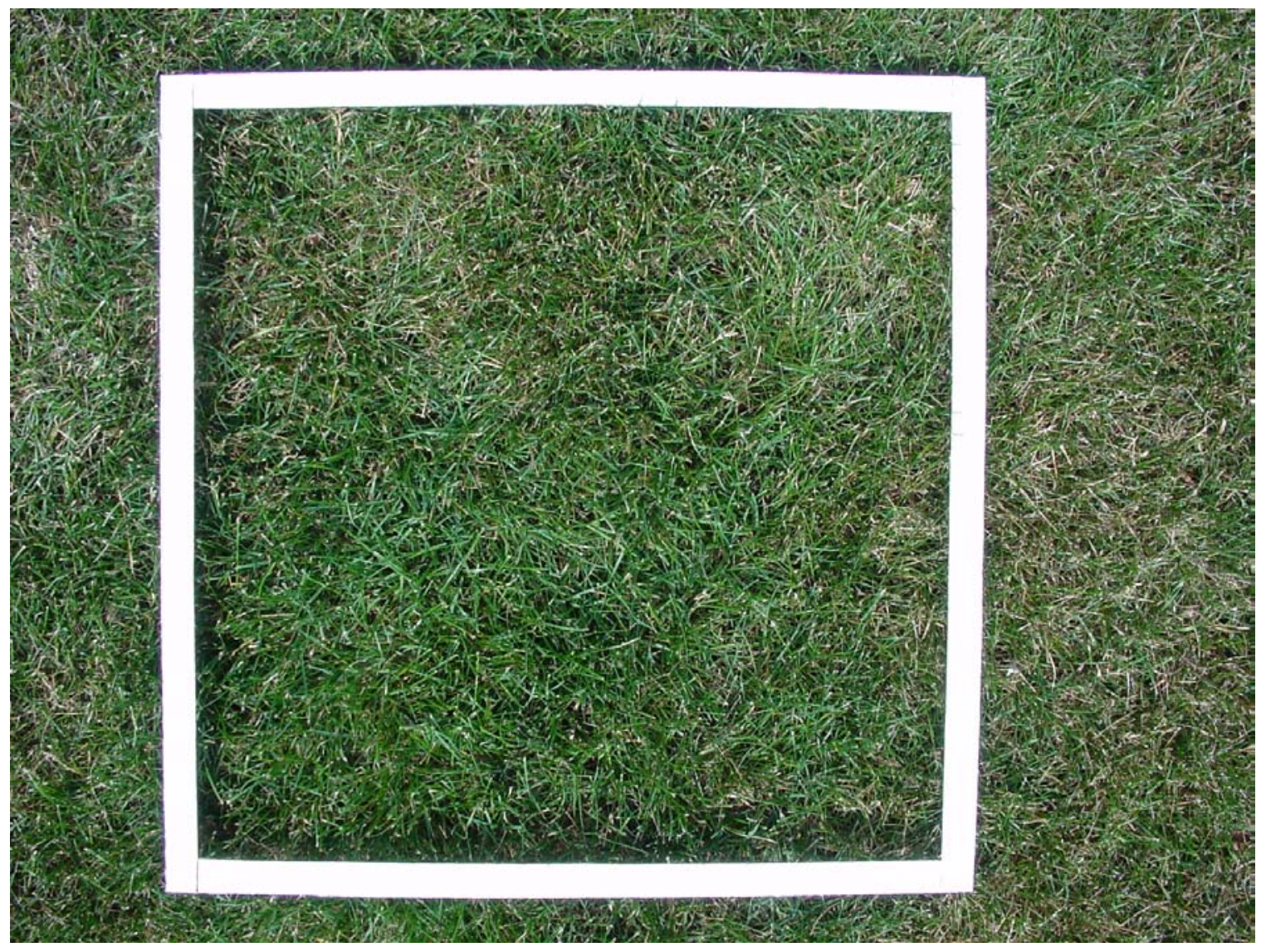

Figure 5.1 - Field capture

2. Import the digital image into the computer as a JPG file as instructed by the Digital Camera Manual 


\subsection{Making Changes to Imported Images}

1. The desired area is enclosed within the frame. The main objective is to determine the percentage of green pixels within the enclosed area. Therefore, it is important to remove all unwanted features outside the desired area.

2. One way to remove unwanted features is the cropping out unwanted features and save it as a new image. The problem with this method is that the boundary between the analysis area and unwanted area is not an exact rectangle or square. As one can see the blue line surrounding the boundary cannot remove all unwanted area (since the frame would not be square or rectangular under the camera lens).

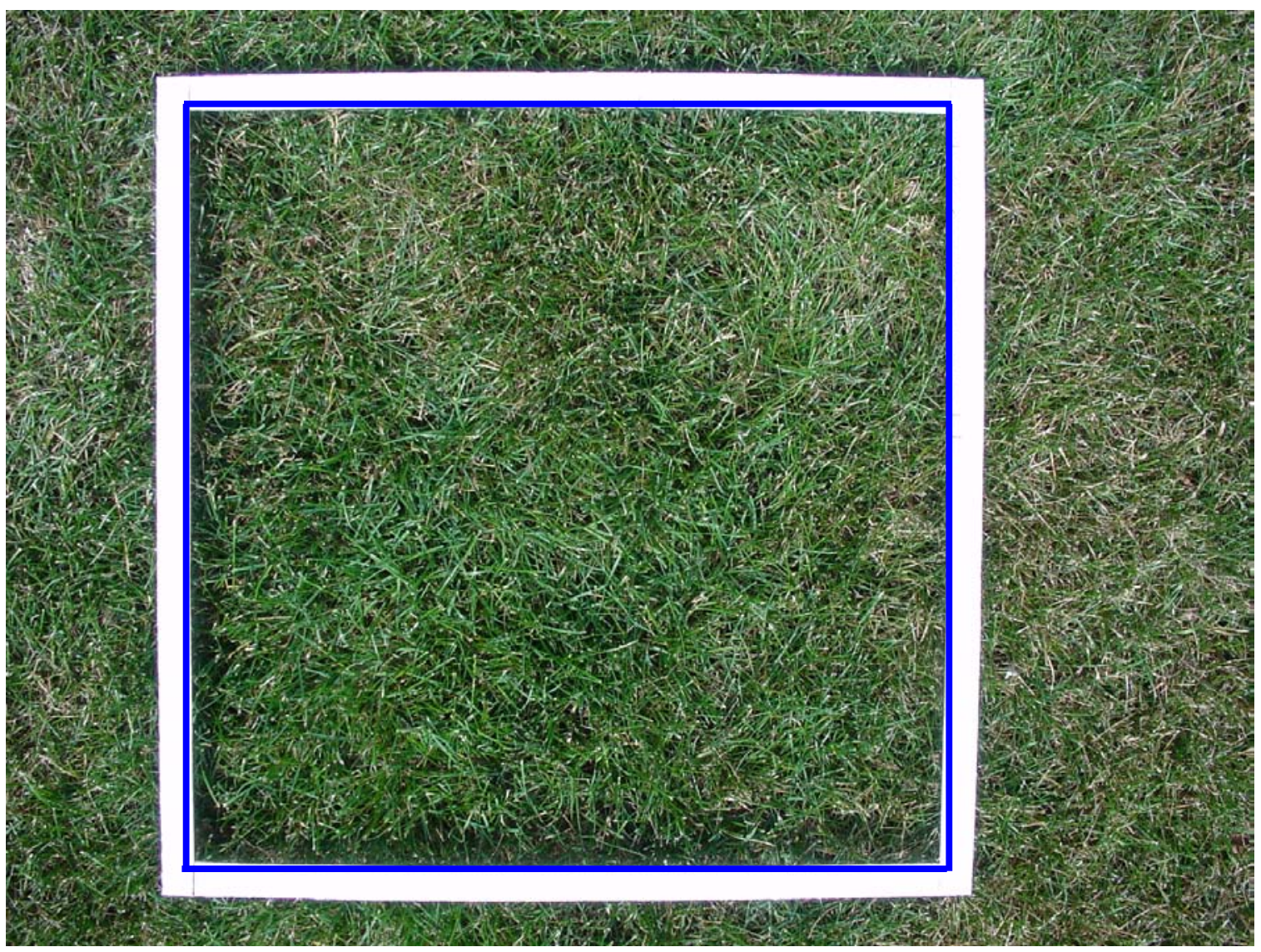

Figure 5.2 - Imported image

3. As a result, this method fails in almost all cases.

4. The only way to remove the unwanted area is by using an indirect method. 
5. First, open the image in the photo editor software like Adobe PhotoShop.

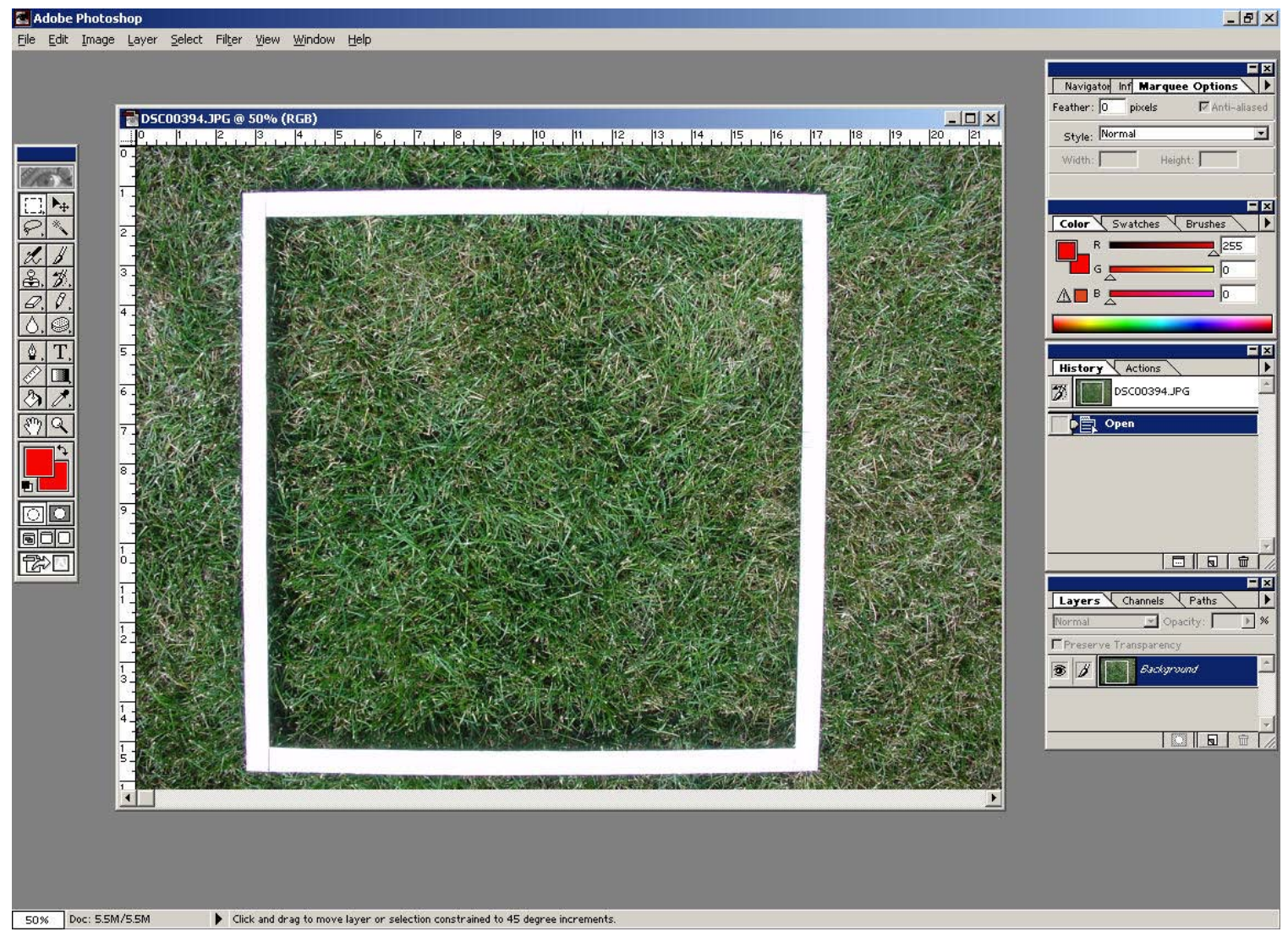

Figure 5.3 - Imported into Adobe Phototshop

6. In the enclosed area, there are green, brown, yellow, and probably white pixels. If the outside area is colored by some other color, which is totally different from the colors inside the boundary, the Pixel Count Program can detect the percentages of the unwanted colors. Then, the percentage of the inside area out of the outside area can be determined. For example, if the outside area is painted with red and analyzed by the Pixel Count Program, percentage of red; that is, the percentage of the outside area will be determined. From there, the percentage of the inside area is determined.

7. From the percentage of the inside area, percentage of green covered can be detected as well, out of the percentage of the area enclosed.

8. So, red color is chosen to paint the outside area. This is to avoid the detection of green by the Pixel Count Program in the outside area. 
9. High contrast red is preferred. So, in the color tab in PhotoShop, set red to 255, green to 0 and blue to 0 .

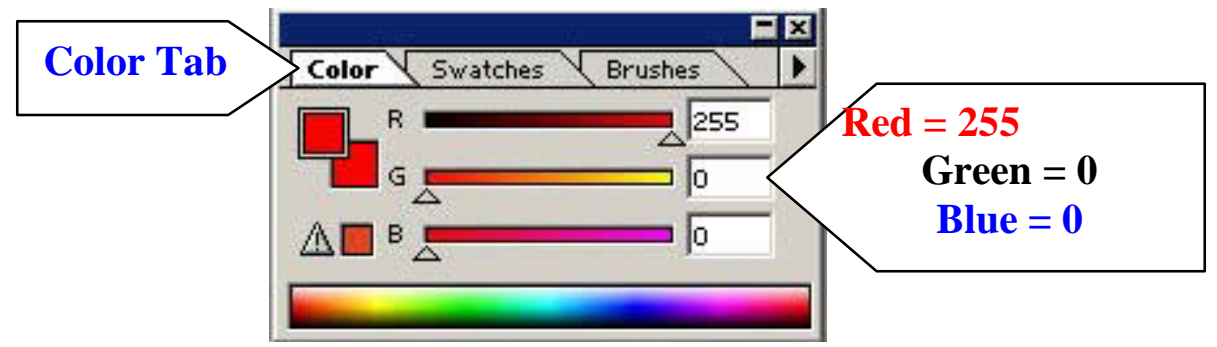

10. There are many ways to color the unwanted area. One of the fastest ways to do it is to color the frame first by making the use of the Magic Wand Tool. The magic wand tool lets you select a consistently colored area (for example, a red flower) without having to trace its outline. Just click the magic wand tool as shown.

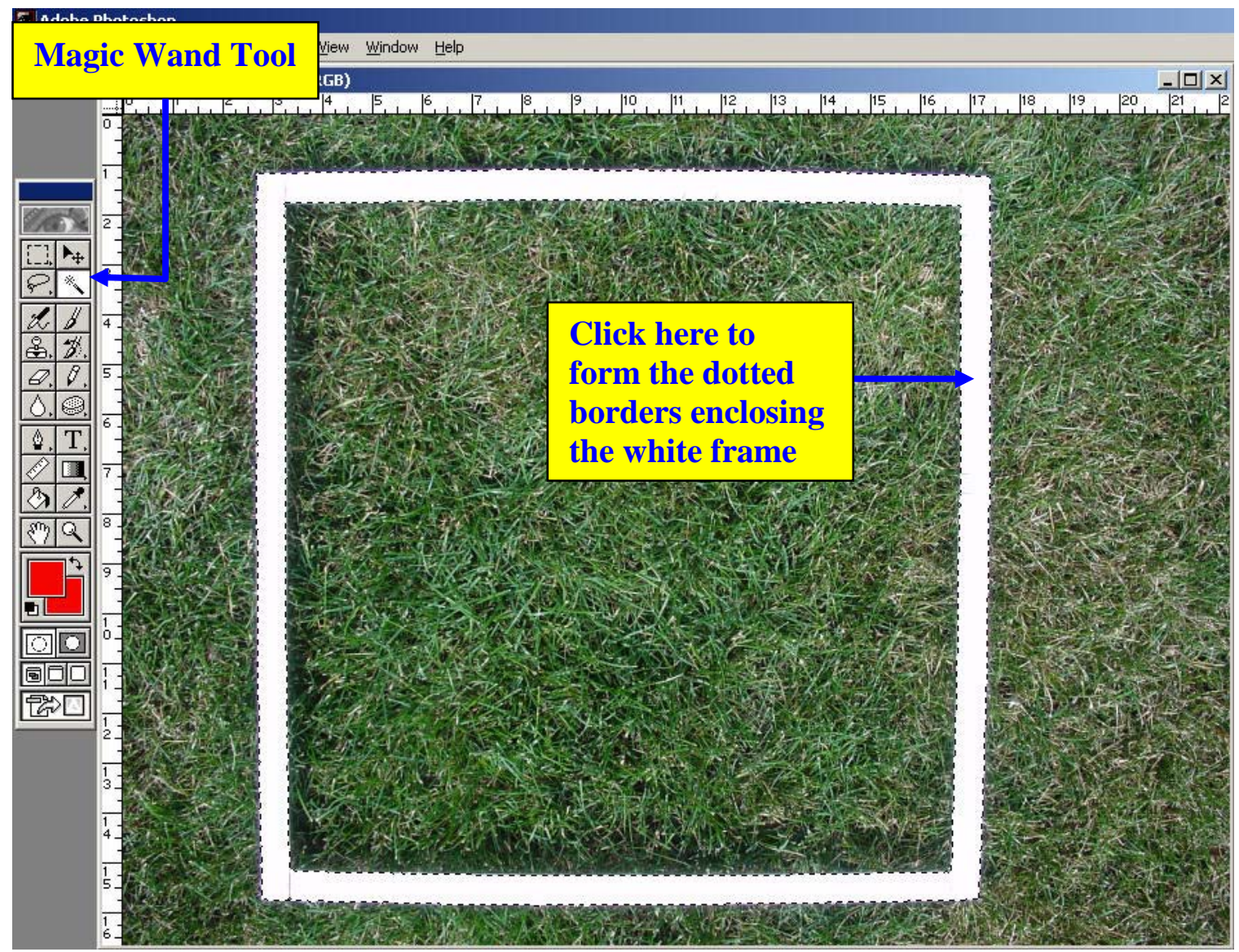

Figure 5.4 - Photoshop Procedure 1 
11. Next, select the pencil tool by clicking on it. Then, select the "Brushes Tab" and choose the largest brush with the largest diameter as shown.

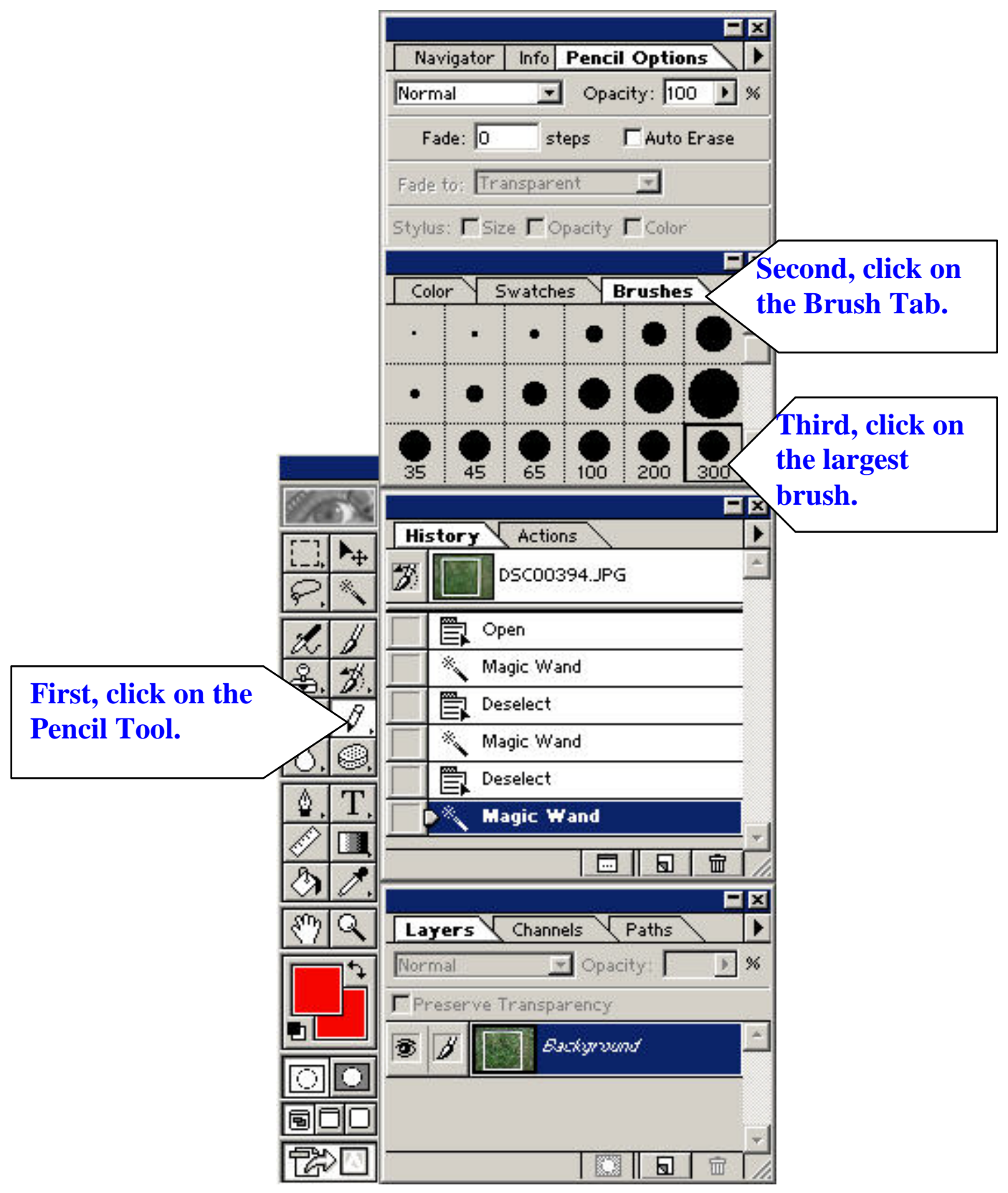

Figure 5.5 - Photoshop features

12. Then, use the selected pencil and click on the selected area and paint it until it is fully red. Notice that the red paint will not get into the desired area. It will only get into the area enclosed by the dotted borders. Therefore, the coloring process will be faster and more accurate compared to painting it slowly and making sure 
that the paint does not go beyond the border. However, this quick way may not be applicable to some images especially when the grasses are long and when they covered a portion of the frame.

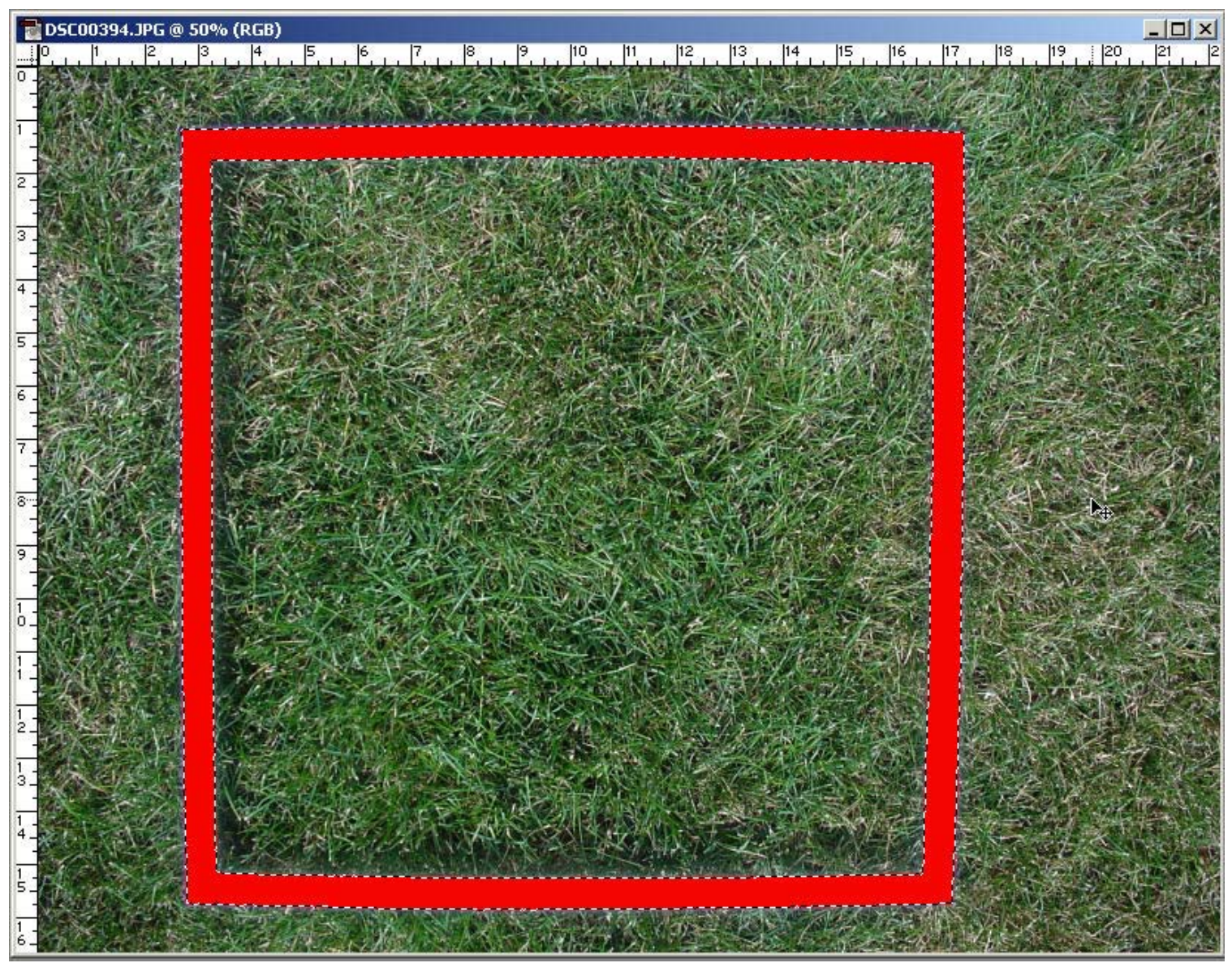

Figure 5.6 - Photoshop Procedure 2

13. Next, unselect the dotted borders by clicking the Rectangular Marquee Tool and click on to anywhere in the image as shown. 


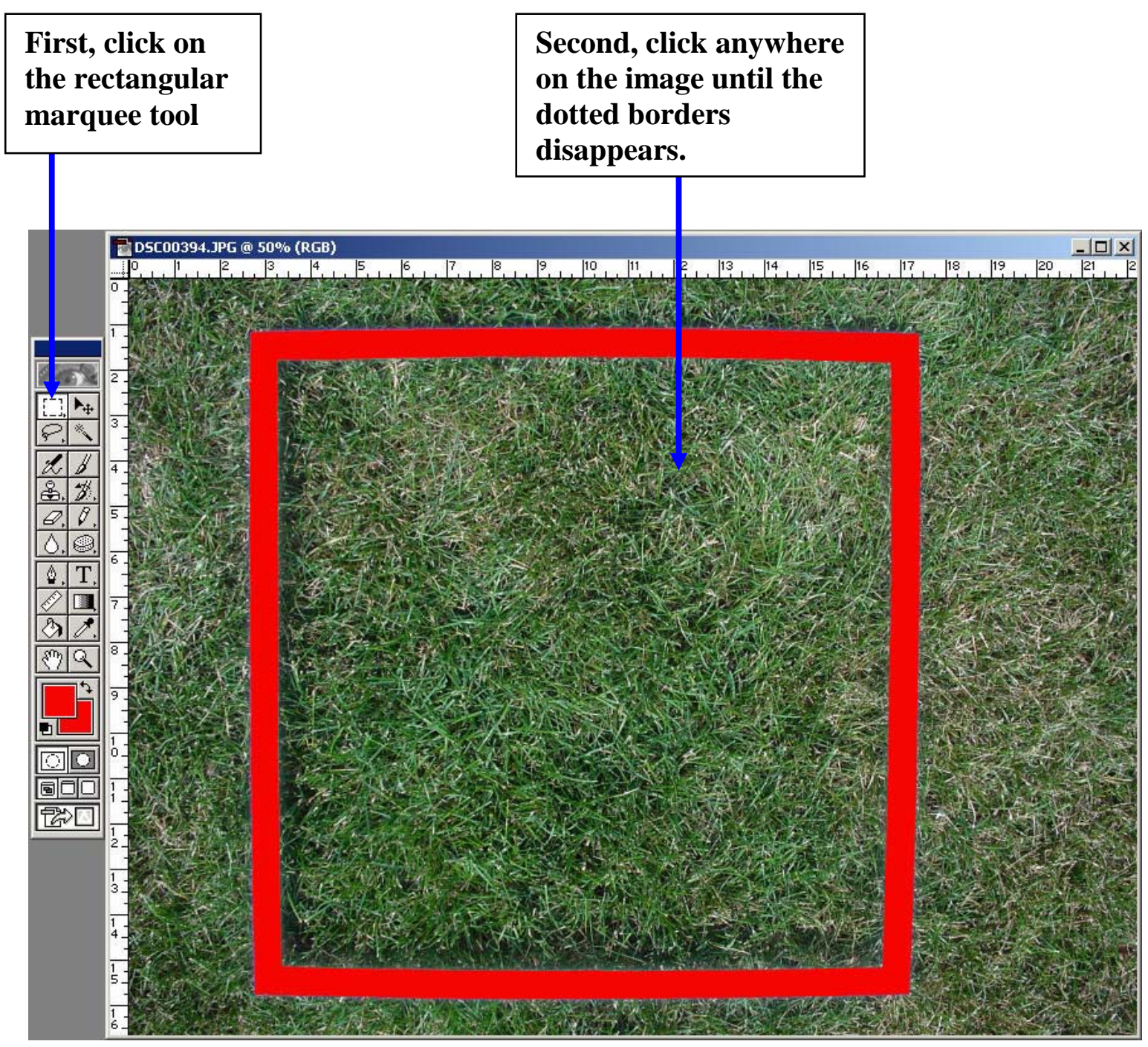

Figure 5.7 - Photoshop Procedure 3

14. Then, color the entire unwanted area with red using pencil tool. The red border will serve as a very good guideline/ safe zone. 


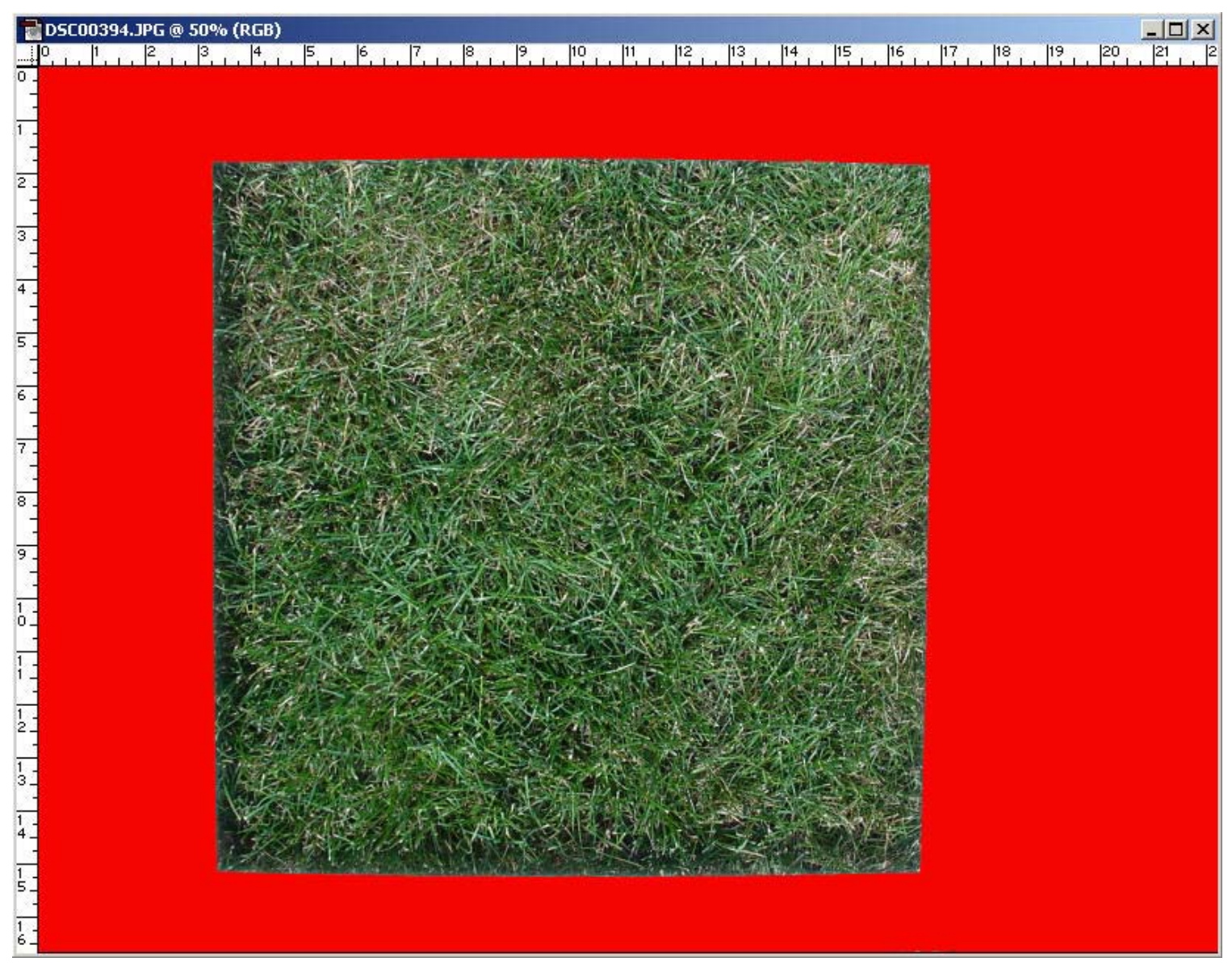

\section{Figure 5.8 - Photoshop Procedure 4}

15. Save it either as the same image file or as a different image file and close the file.

\subsection{Vegetation Analysis Procedure}

1. Open the program Image Savant (either from the Program Menu, or from C: Isavant Isavant.exe) 


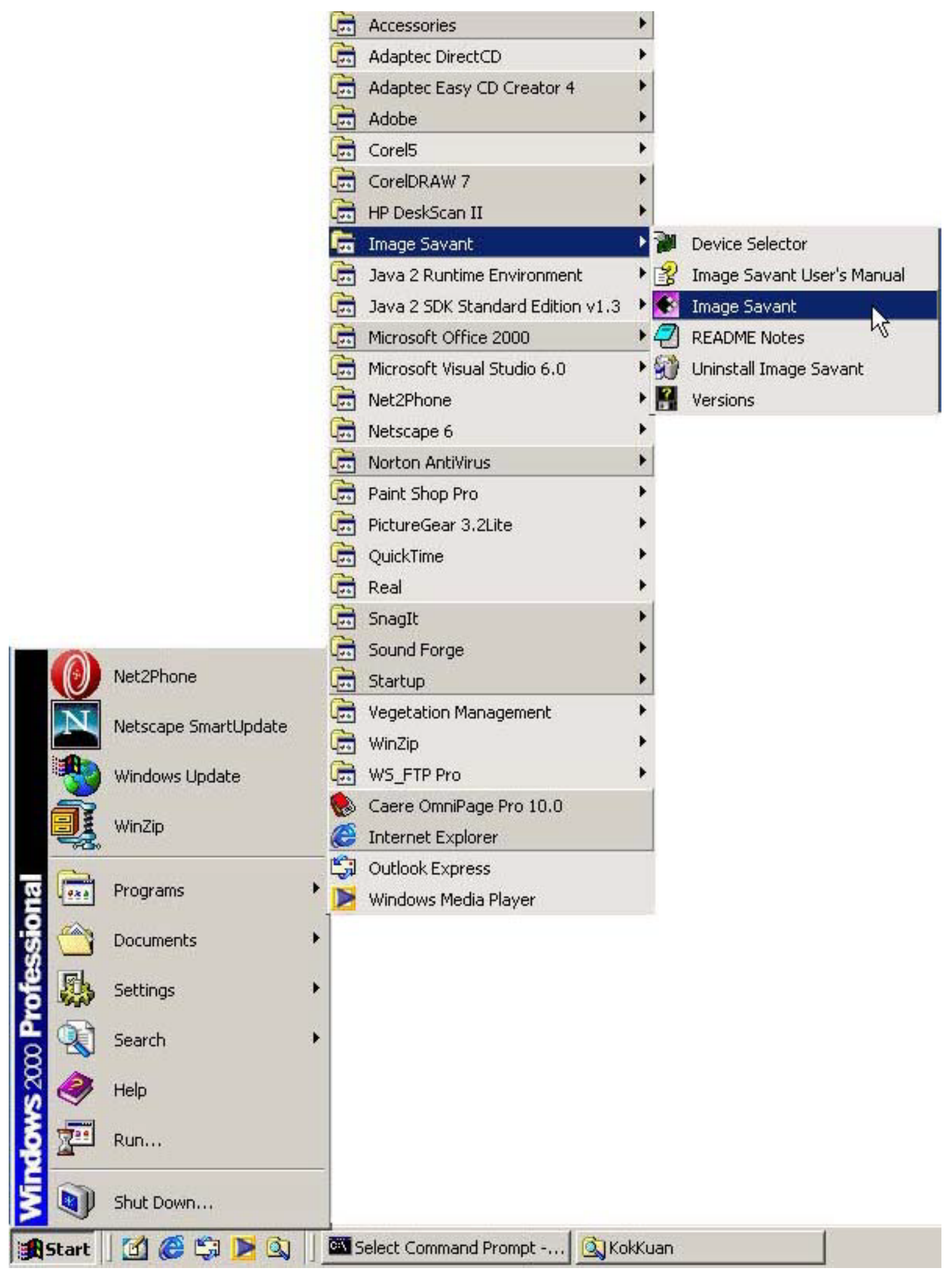




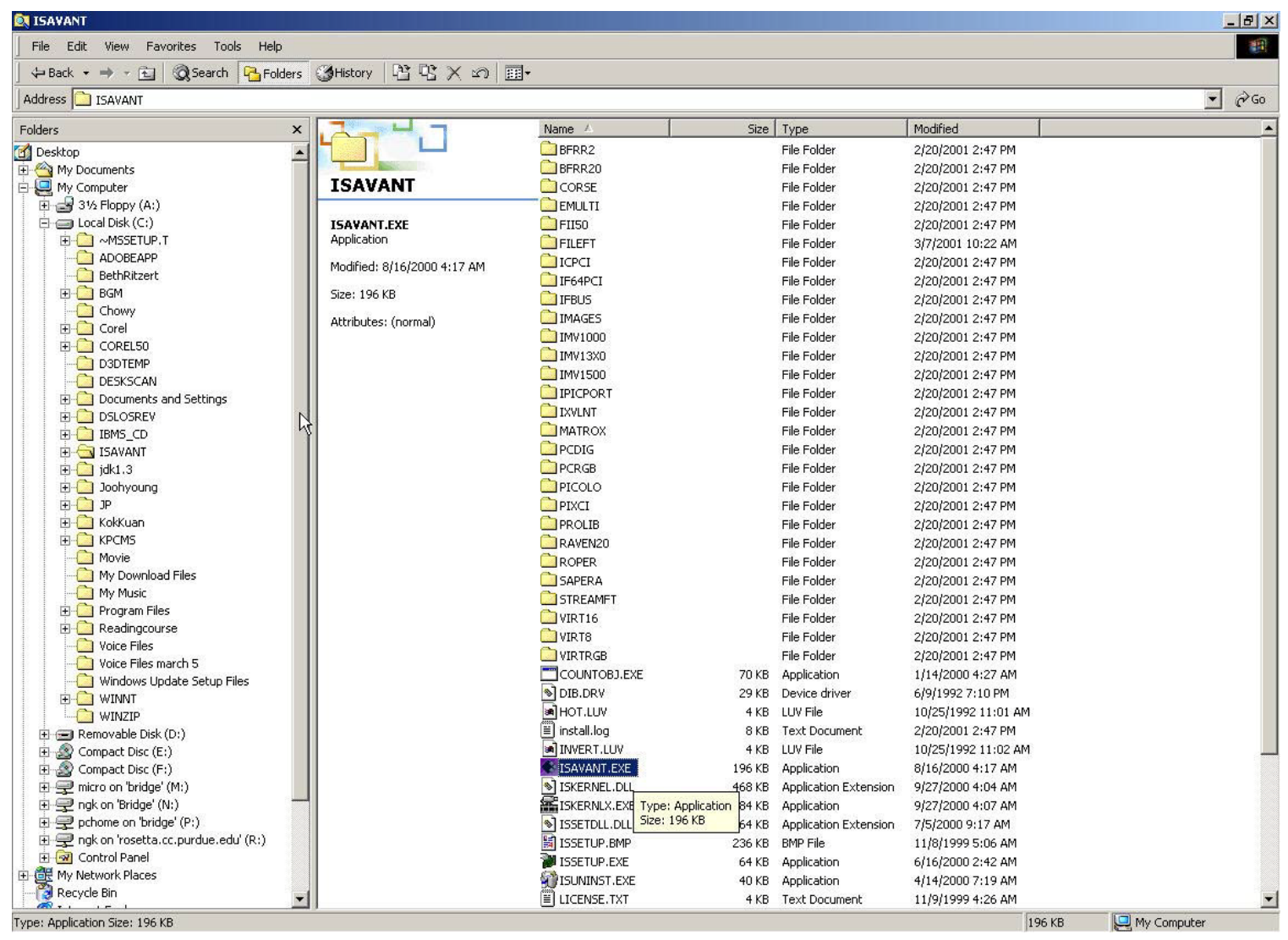

Figure 5.9 - Image Savant Software

(a) Before opening or importing any image in Image Savant the image size must first be checked. It can be done in the following manner:

(b) On the blank screen, right click the mouse button and select "import" and click on import images. 


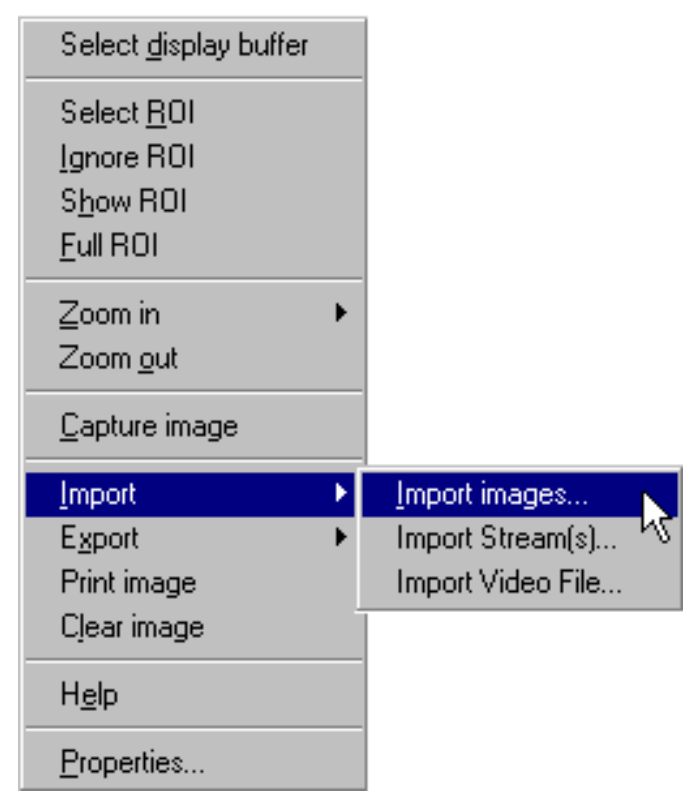

(b) Select the appropriate files of type (jpg, gif, bmp, etc.)

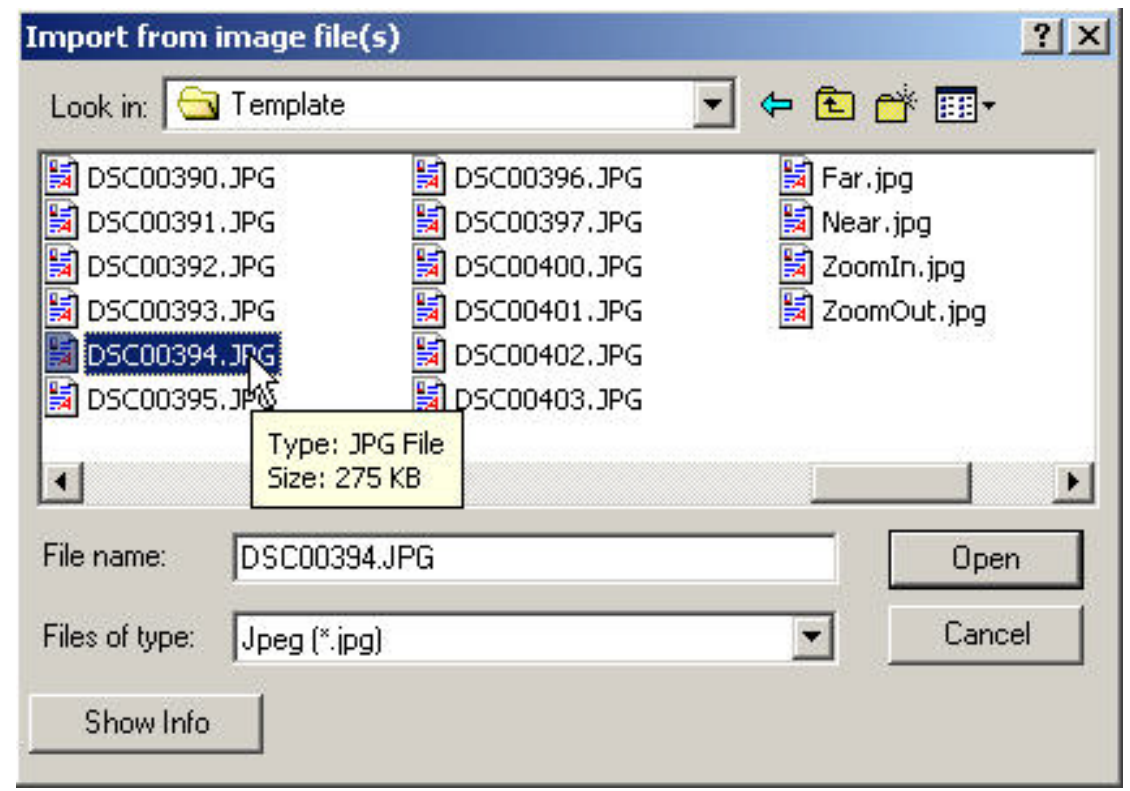

(c) Then, click on the desired image once $\underline{\mathbf{O N L Y}}$ until the file name is shown in the dialog box.

(d) The click the "Show Info" icon. 


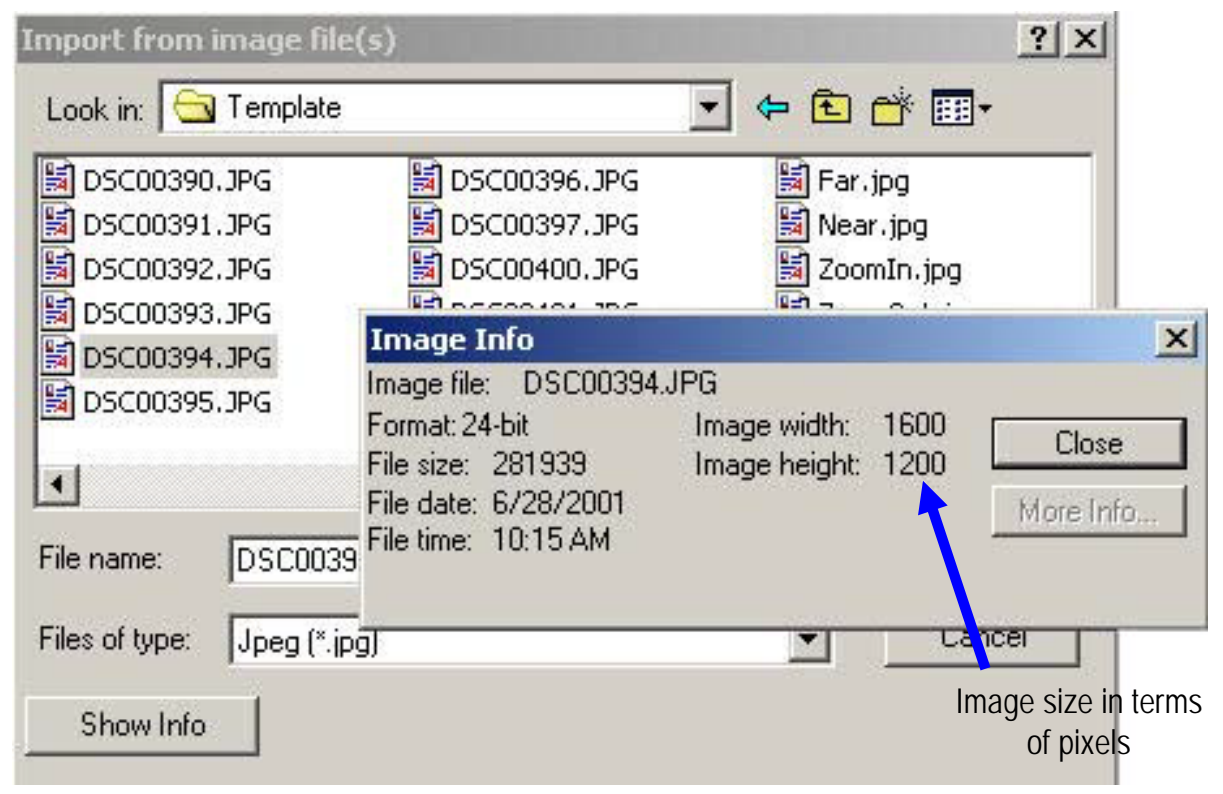

(c) Image size (width and height) in terms of pixels is shown.

(d) Remember the image size and click "close" then click "cancel” in the dialog box until it returns to the black blank screen.

(e) Then, properties of the image window must be set correctly before importing the image.

(f) Right click the mouse and select "properties”.

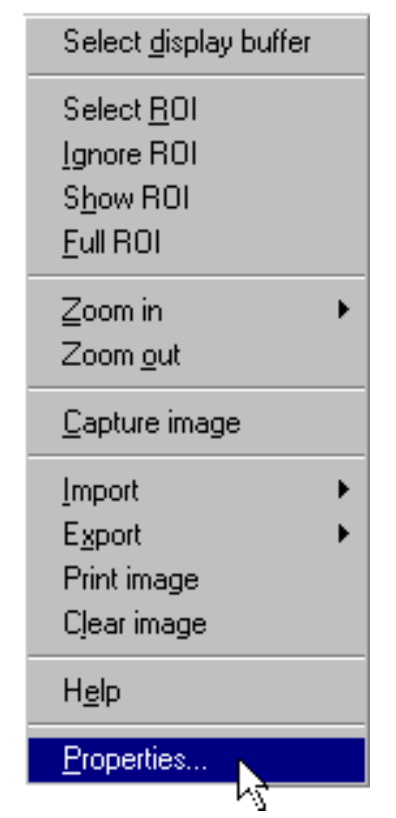

(b) Input the exact size (pixel) and click "OK” 


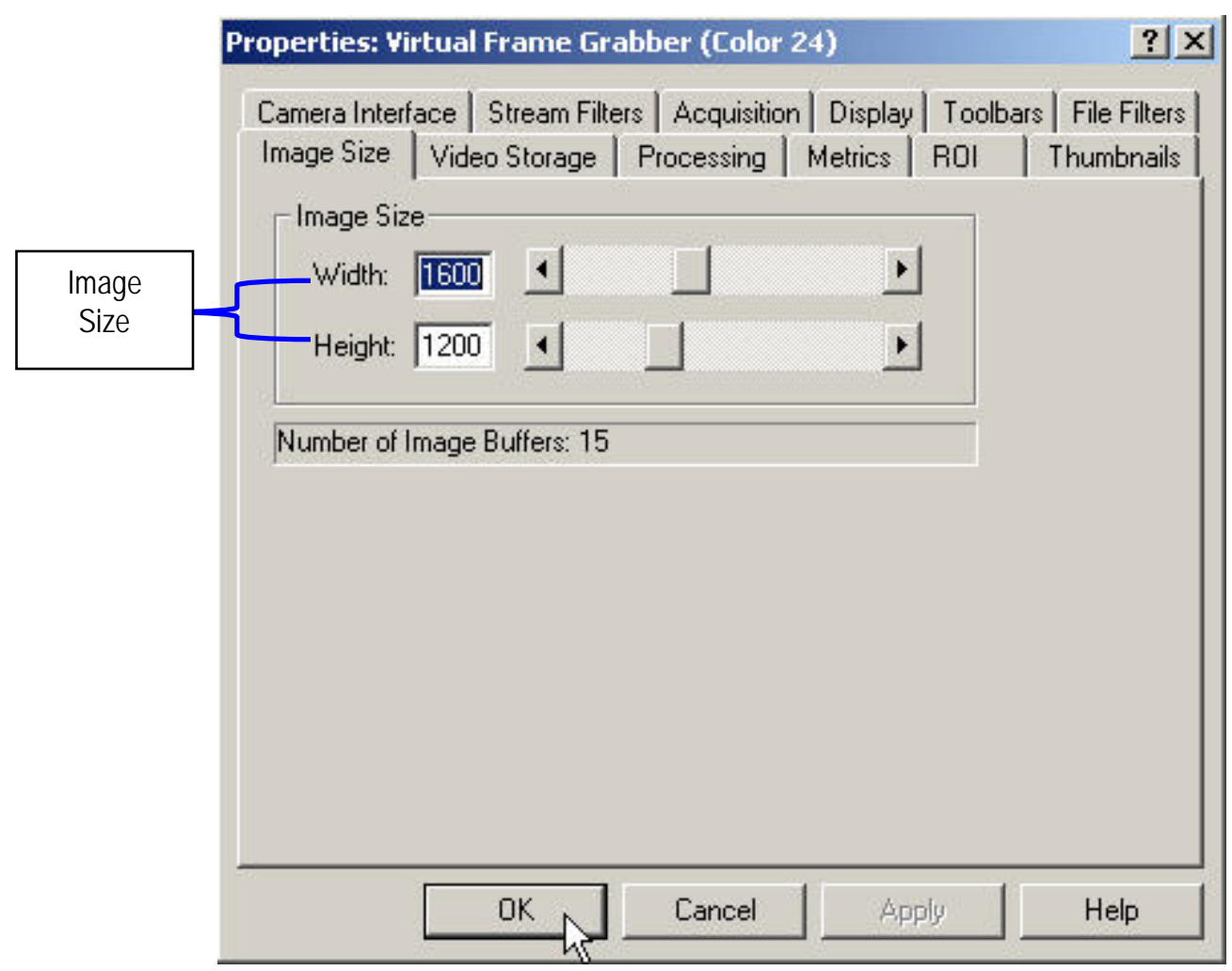

(g) Now the image is ready to be imported. In the blank window, right click the mouse and select "import", then "import images" and open the image file.

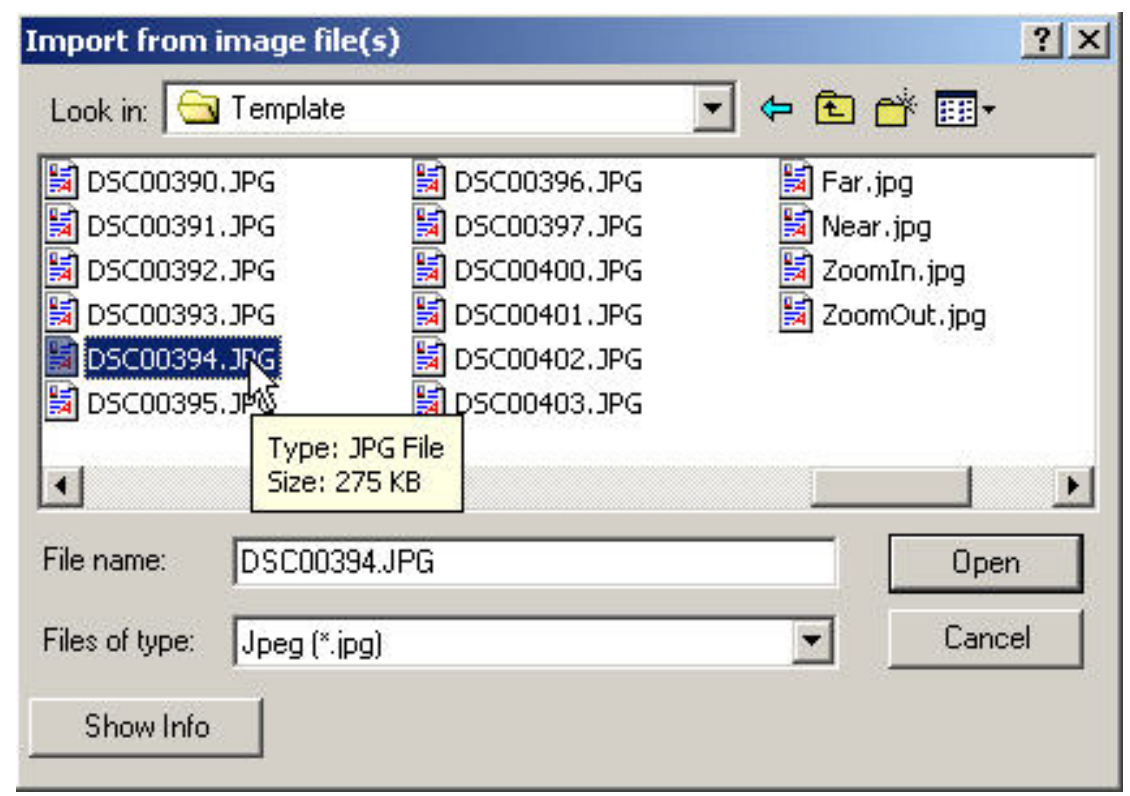

5. Now, the image file is ready to be exported out into "txt" format in order to be analyzed by the pixel count program to determine the number of green pixels. 
(a) Right click the mouse to select "export", then "export images".

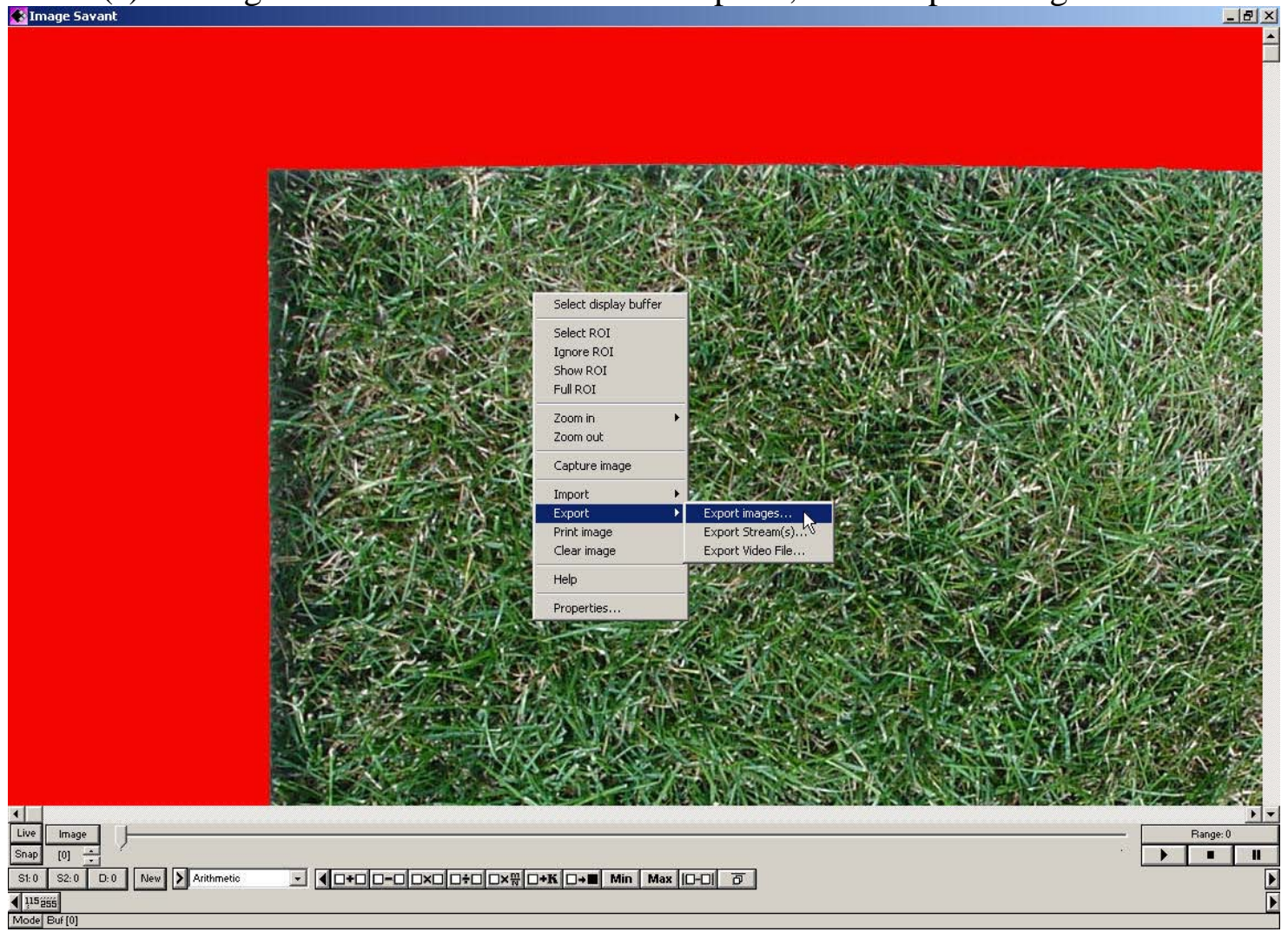

(b) Save the file as a "txt" file.

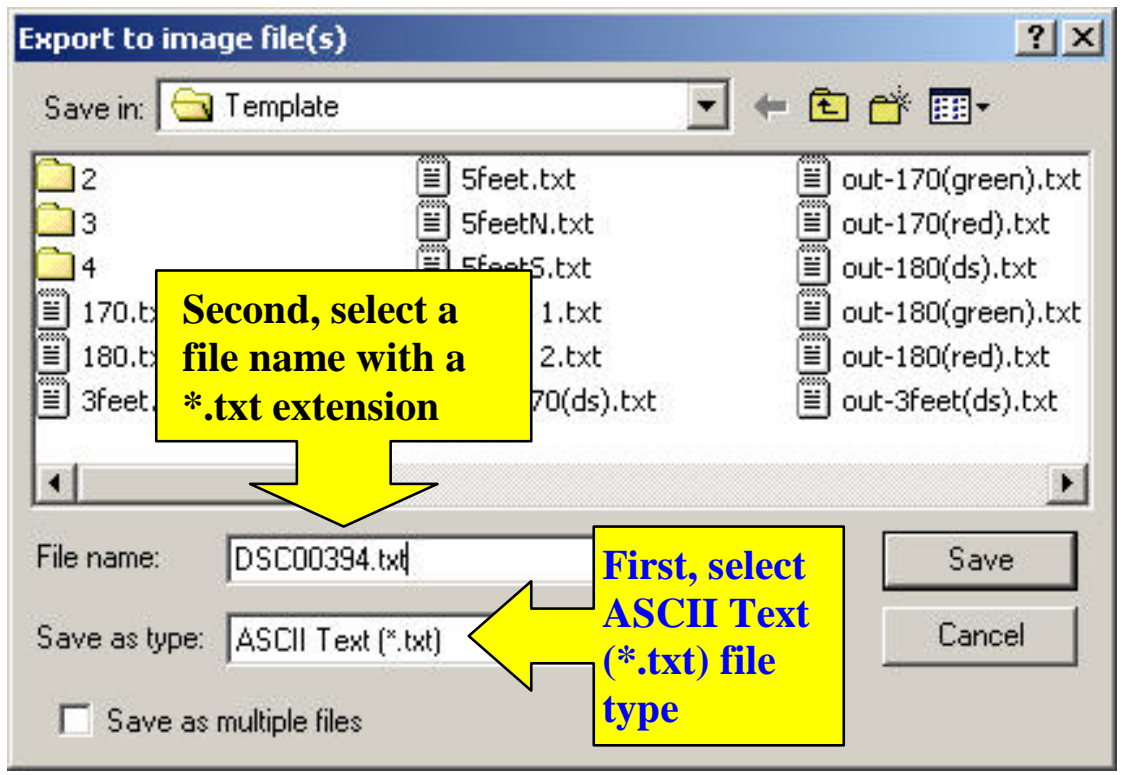

6. Then, the exported file in .txt format should be analyzed with Vegetation Analyzer program that counts the percentage of green pixels within the image. 
(h) Open the Vegetation Coverage Analyzer program and click start as shown.

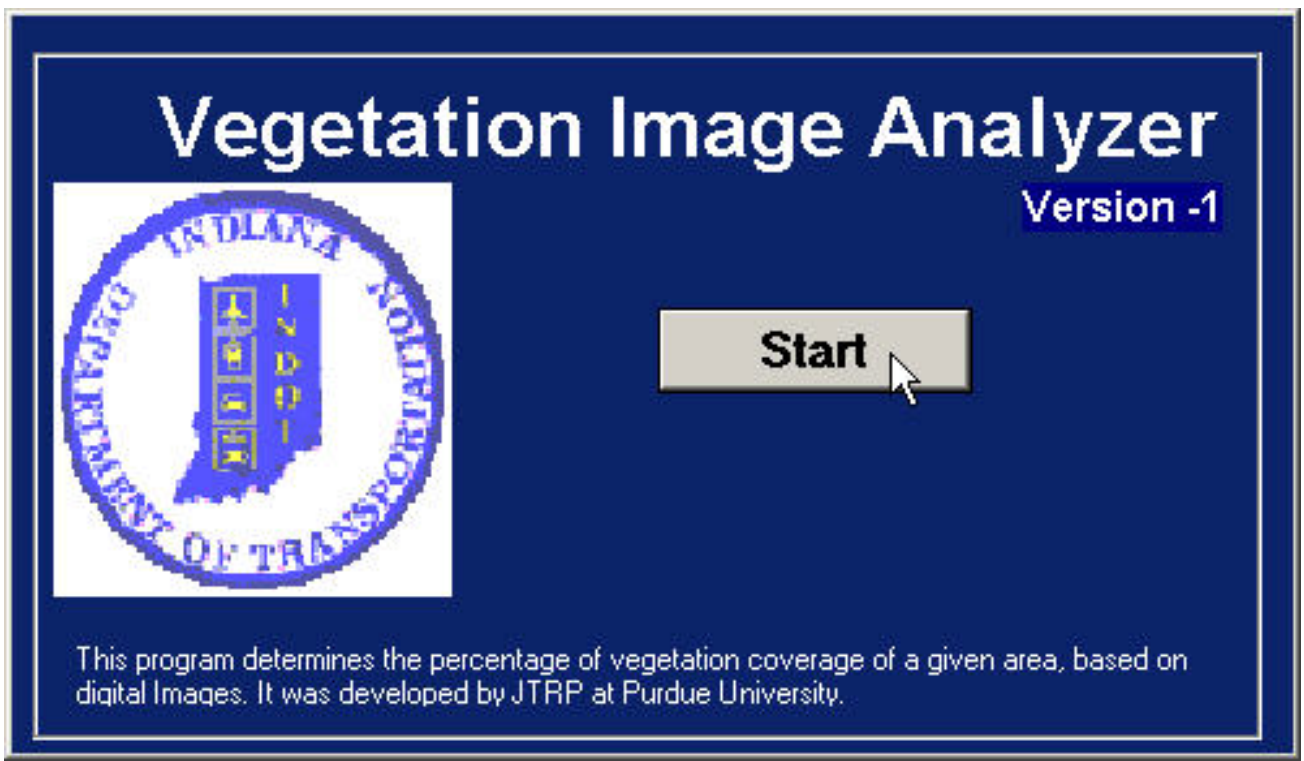

(i) Click Start Analyzing

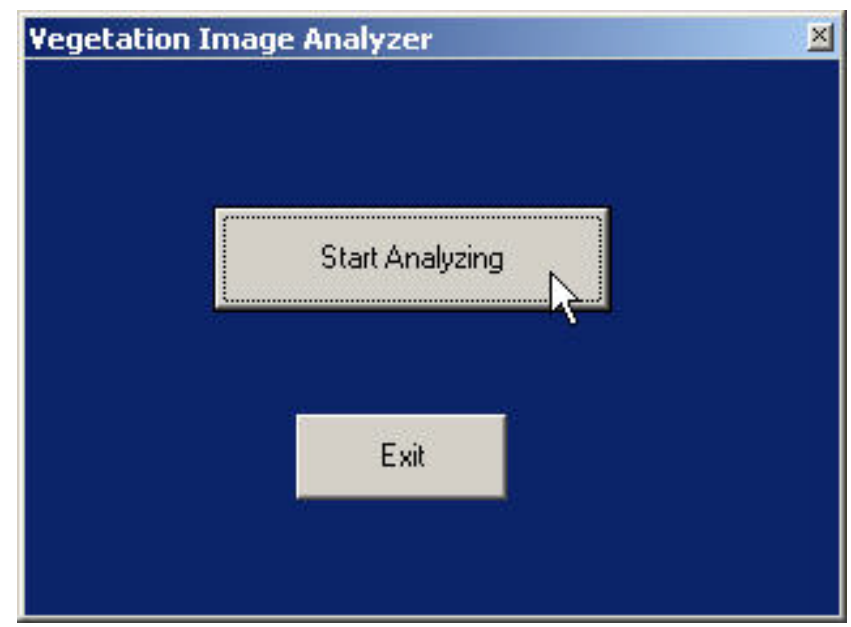

(j) In the program, choose the txt file that was just exported and click open. 


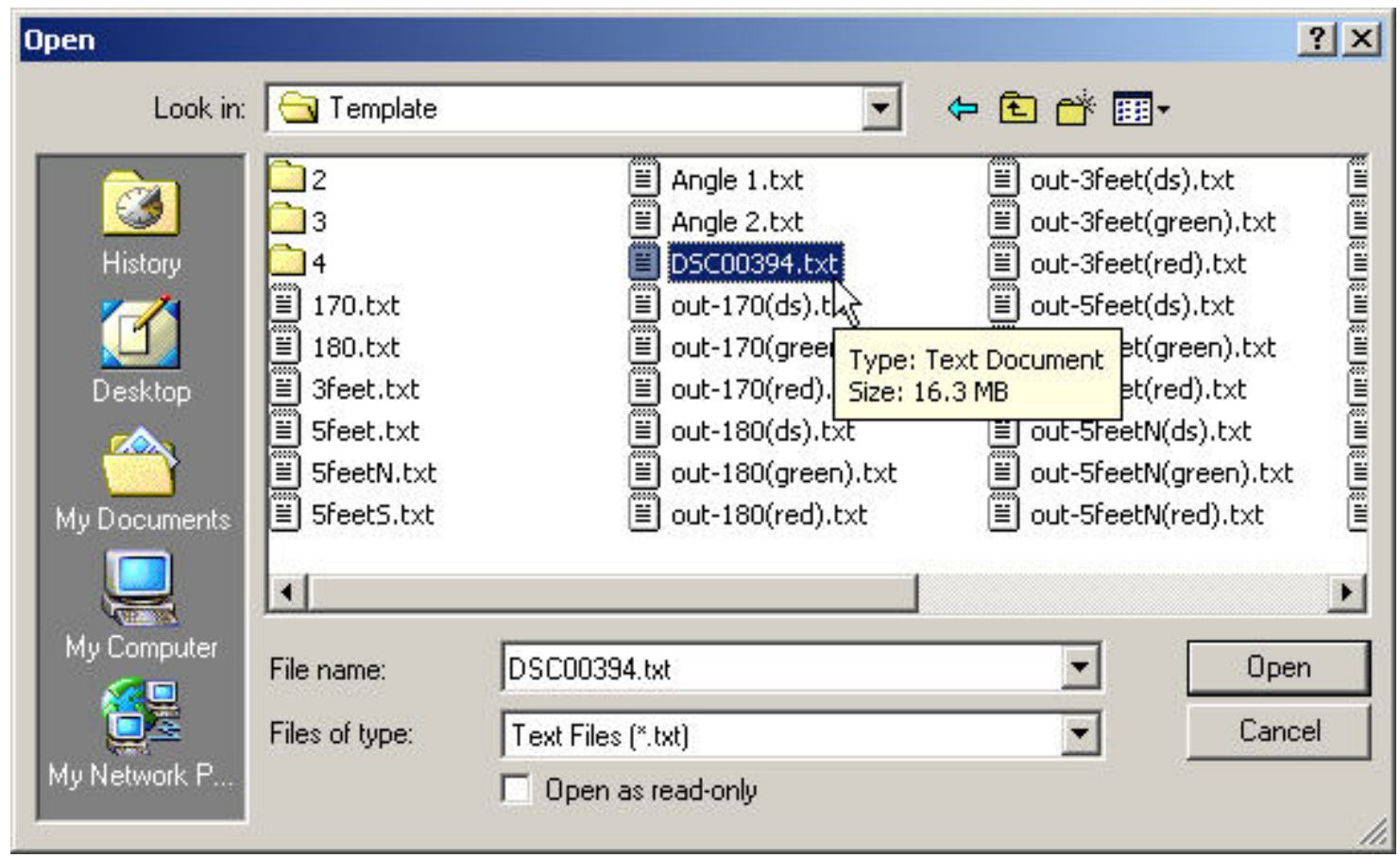

(k) The name of the output file is DSC00394out.txt (filenameout.txt) as provided. It is a text file that stores the result of the analysis. Click OK.

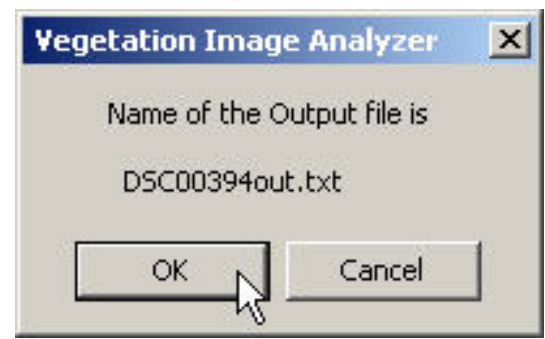

(l) It takes about 7 to 10 minutes for a computer with Intel Pentium III - 500 MHZ processor, $256 \mathrm{MB}$ of RAM running Windows 2000 Operating System to process the whole file. After a couple of minutes, the percentage of green pixels and dark spot pixels will be determined and shown as follow. 


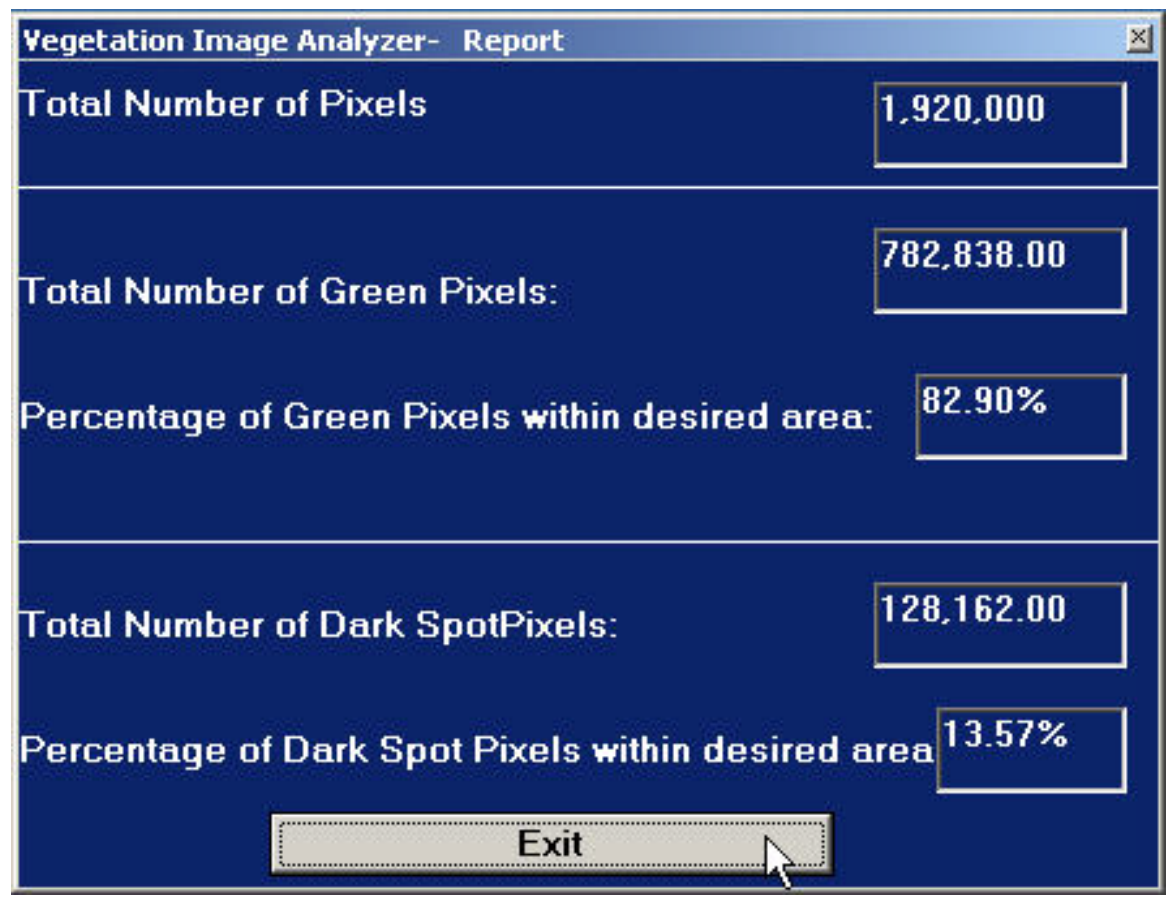

(m) This result is also saved in a text file format as mentioned before. Click Exit to finish the analysis procedure. 


\section{Chapter 6 - Sample Pictures and Analysis}

A series of pictures have been taken and analyzed using the INDOT Vegetation Analyzer. Some sample images and results are shown as follows:

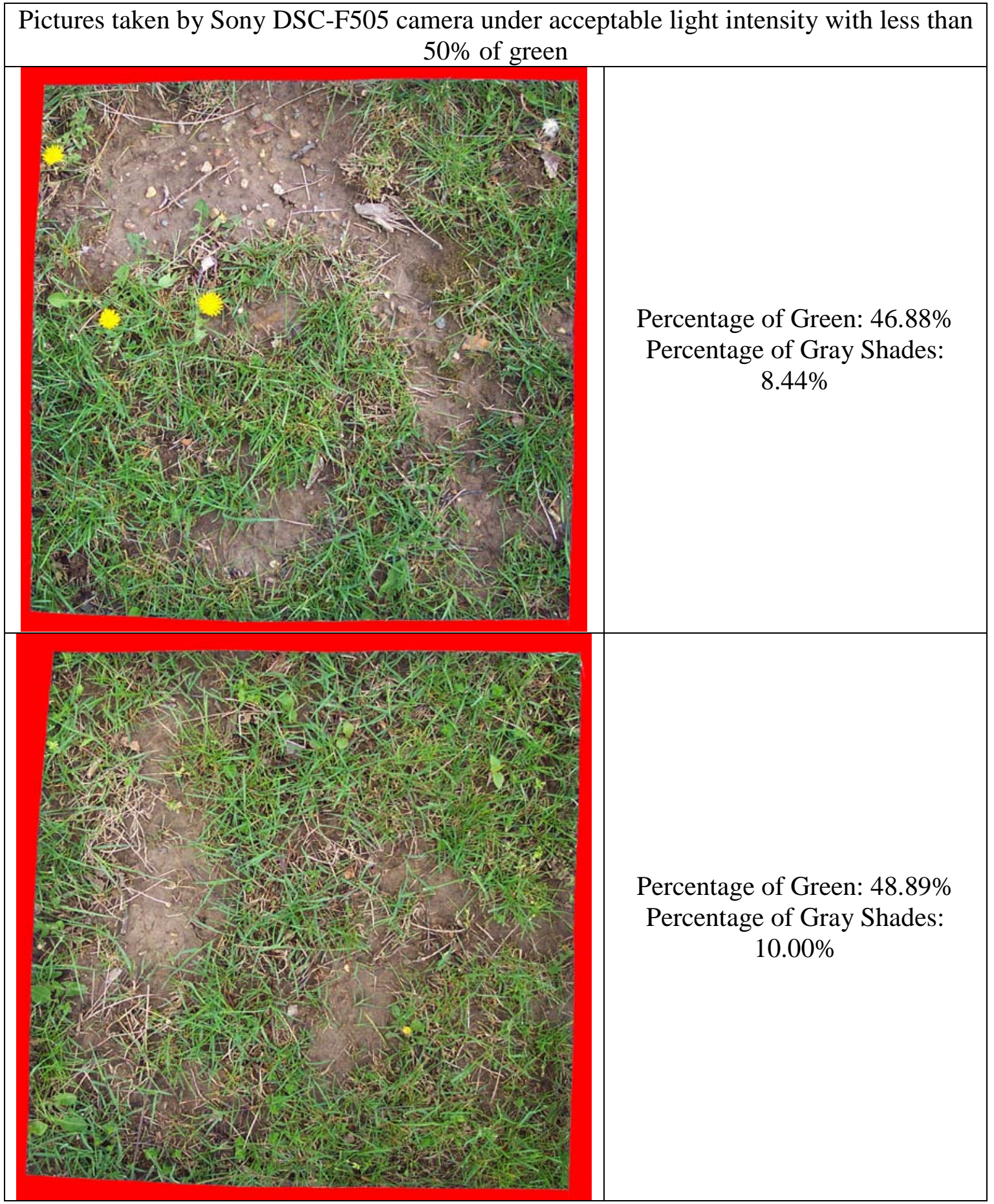




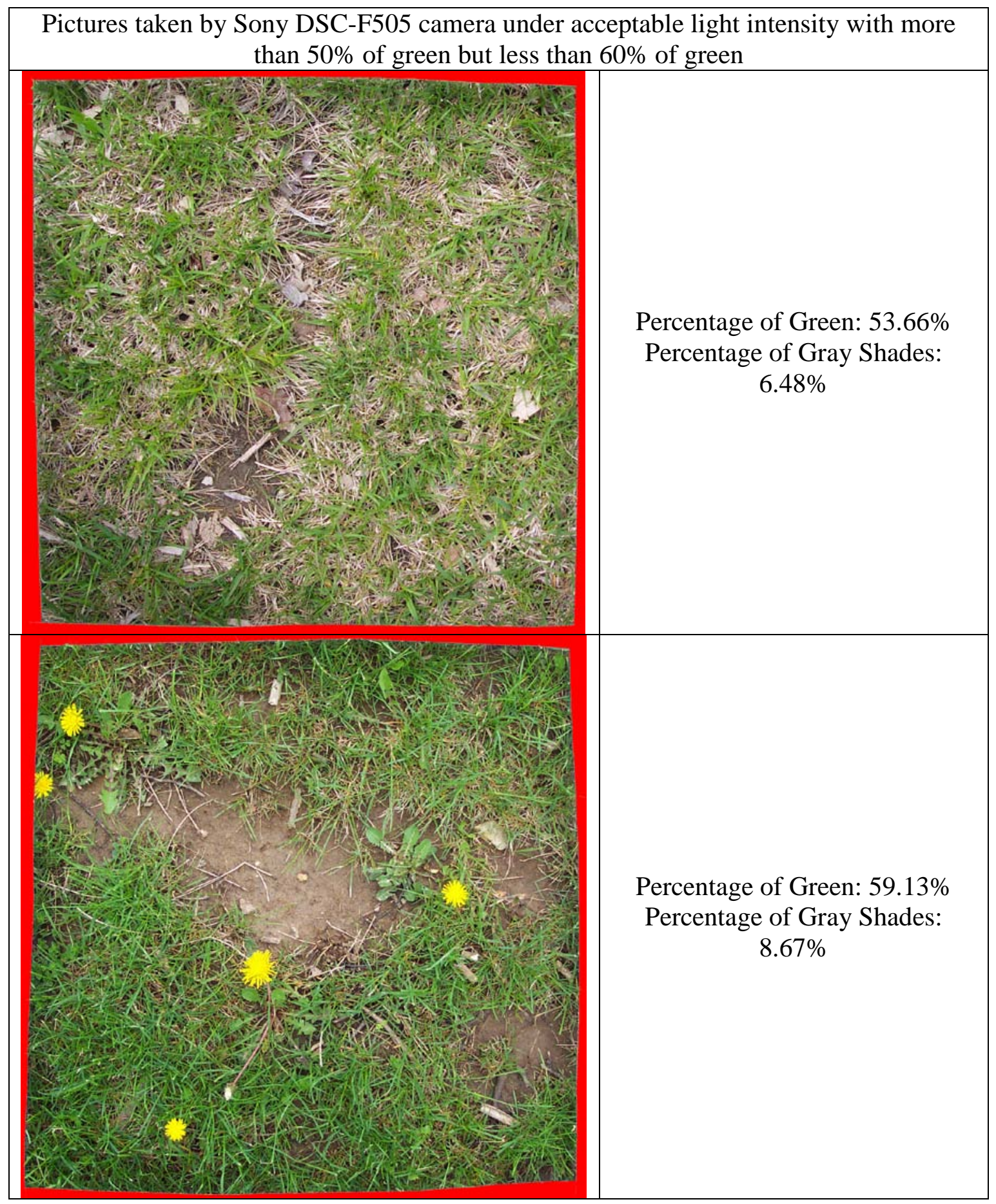




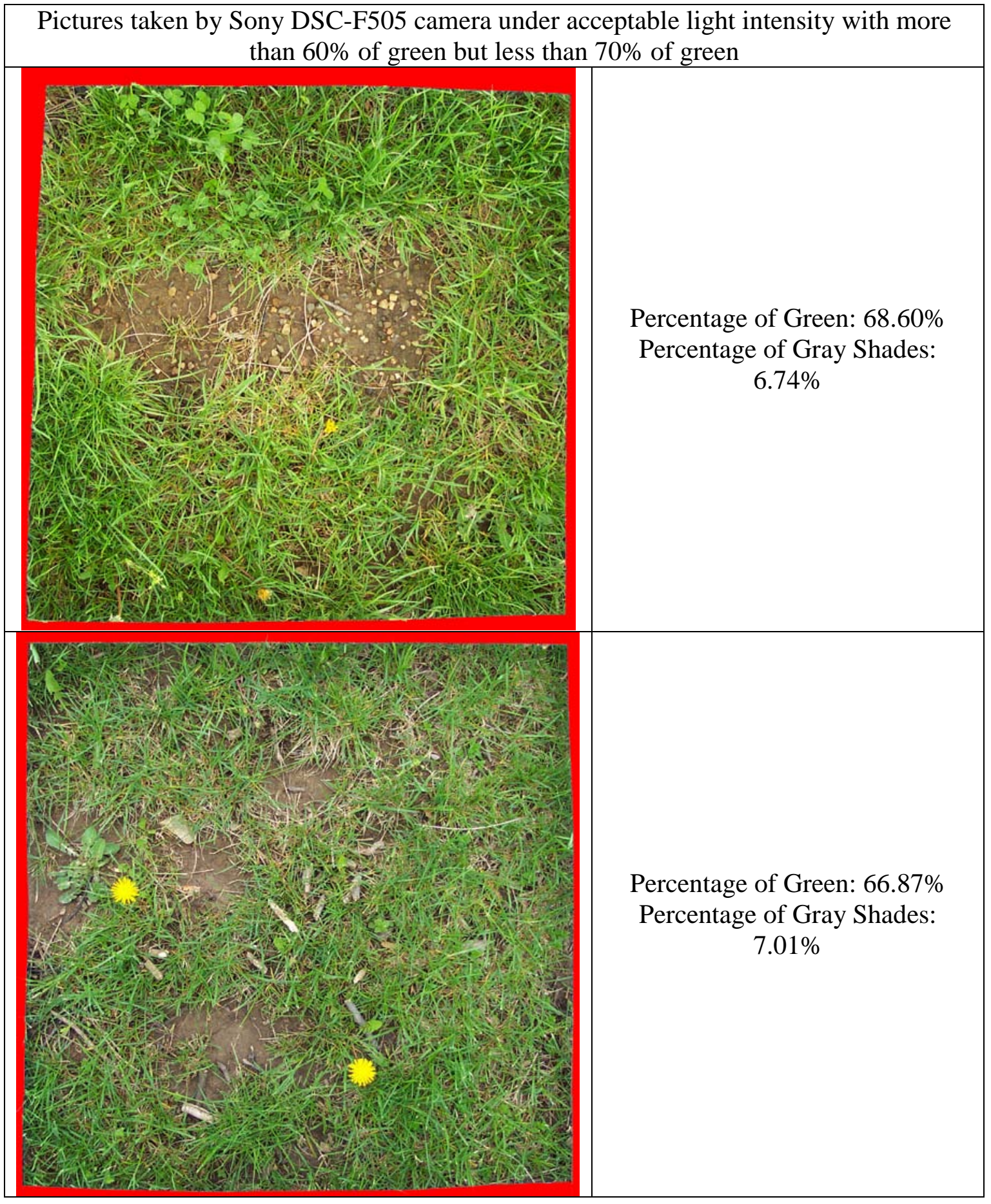




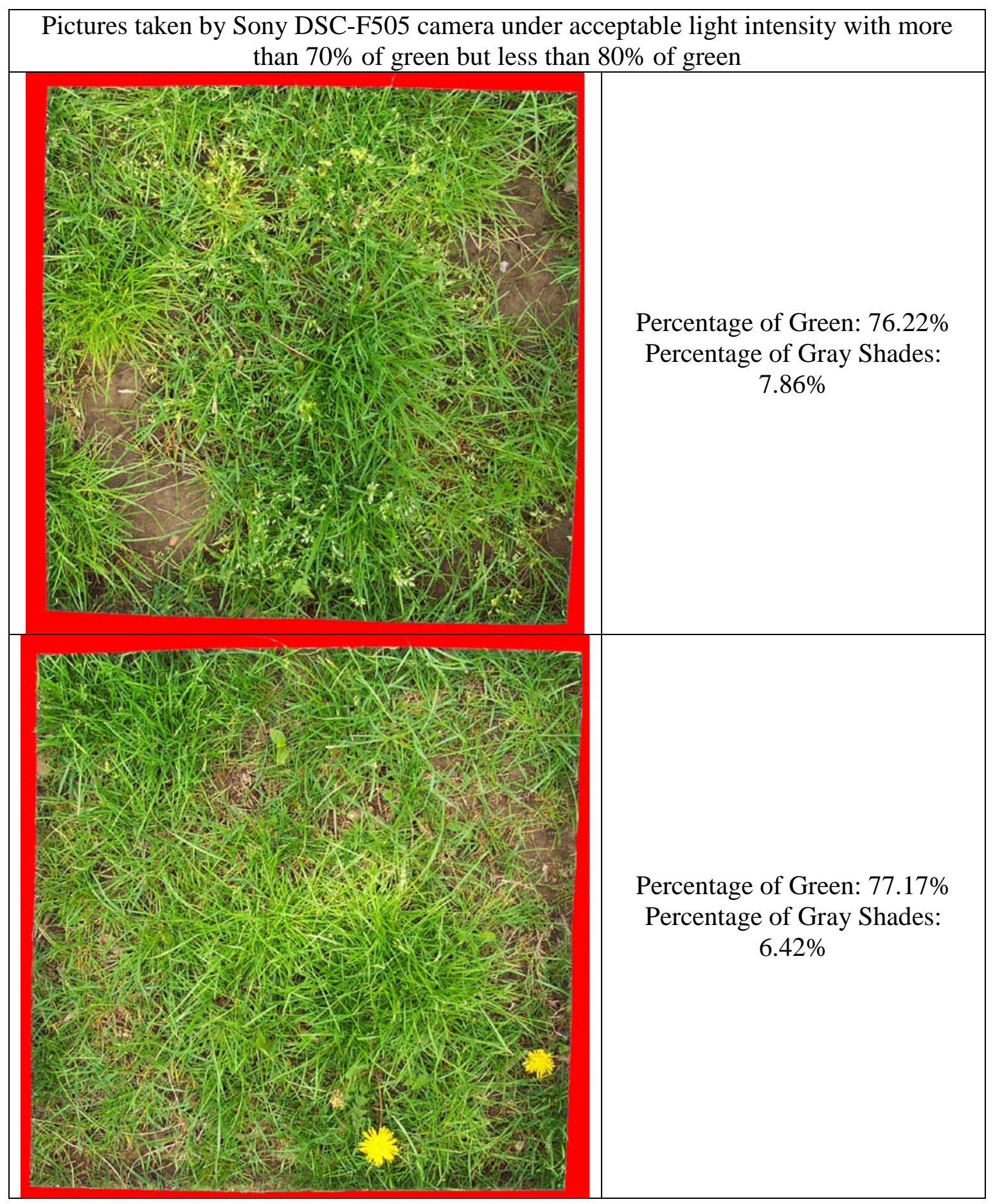




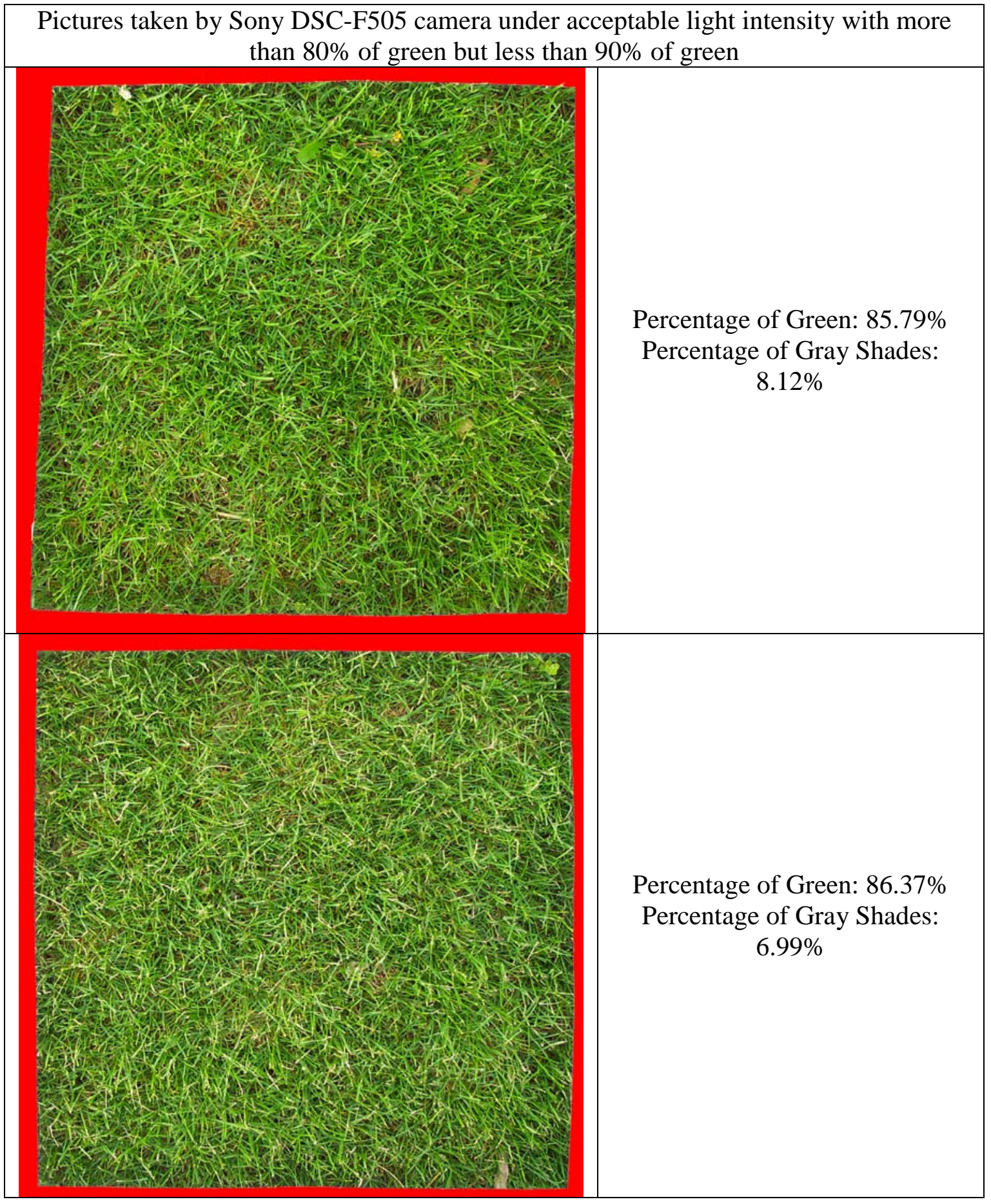




\section{Chapter 7 - Inspection Procedures}

\subsection{Pre-field}

1. Check the camera settings as shown:

Image Size: Image Sizes available for the Sony Digital Camera DSC-F505 (one of the cameras used in the analysis) are $1600 \times 1200,1024 \times 768$, and $640 \times 480$.

Typically, for better accuracy, it is advisable to choose the largest size available; that is, $1600 \times 1200$. A $1600 \times 1200$ image usually takes about 10 to 15 minutes to be analyzed. The percentage of green pixels is more accurately reported.

Quality: $\quad$ There are 2 qualities available: Fine and Standard. For better accuracy, Fine quality is preferred.

Exposure: The exposure levels range from $-1.5 \mathrm{EV}$ to $+1.5 \mathrm{EV}$. Low exposure darkens the background of the image and high exposure adds additional lightings to the background. For neutral and accurate analysis, it is preferably not to add or take out any lighting from the background. Therefore, the exposure level should always be set to $0 \mathrm{EV}$.

Flash Level: $\quad$ Flash level should be left alone as default (normal flash level) since flash will not be used. Flash should never be turned on because it whitens the image. A whiten image may cause some green pixels to be white. Analysis would then be inaccurate.

Digital Zoom: The digital zoom should be turned off. The camera zoom lens can zoom in and out optically by using the optical formula built into the lens. On the other hand, digital zoom can do the same by magnifying the existing image.

2. Take a couple images of the calibration chart shown on the following page with a light intensity between 1,000 to 3,000 foot-candles. Determine the percentage of green and the percentage of black from the images using the Vegetation Image Analyzer. Exact percentage of green in the chart is 50\%. The percentage of black is $13 \%$. If the percentage of green analyzed is within the accepted range, say $\pm 5 \%$ of the exact percent of green, which is $50 \%$, the camera will be qualified to be used in the field. 


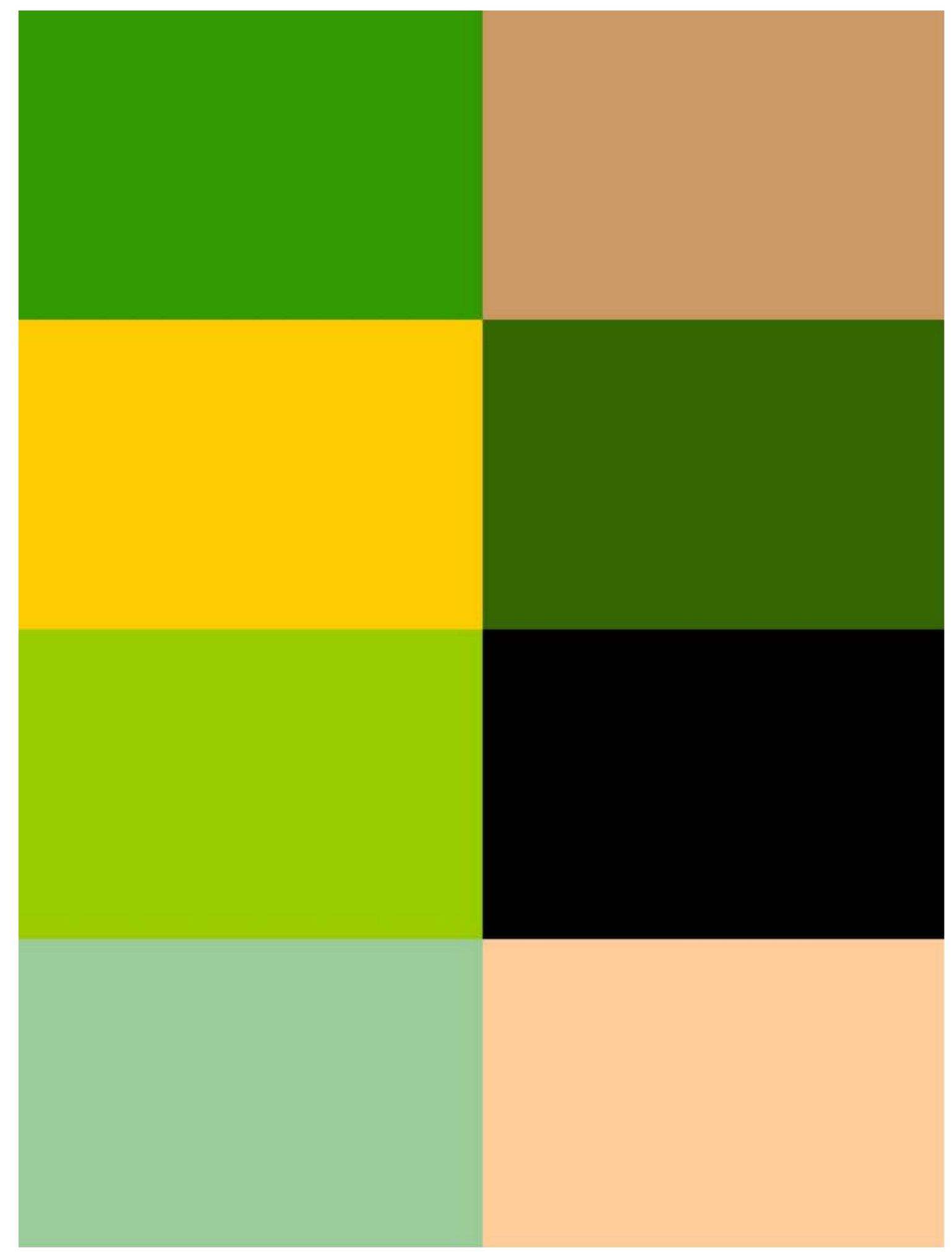

Figure 7.1

Calibration Chart 


\subsection{Field}

3. Determine whether the field environment is ready for taking images. Several conditions need to be checked. First, check the length of the vegetation. There are problems caused by long grasses. When they bend, they will cover some "gray spots". This can be deceptive since the covered areas may be wrongly interpreted as areas with grasses. When grasses bend over, they create dark spots. Therefore, grass length should be less than 8 inches.

4. Determine the intensity of sunlight. The optimum light intensity falls between 1,000 to 3,000 foot-candle. If the intensity exceeds 3,000 foot-candle, a shield should be used to lower the intensity to the optimum range.

5. Determine the direction of the sunlight as the directions of sunlight have a major impact on the percentage of dark spots and dark shades. The direction of the sunlight should be as shown.

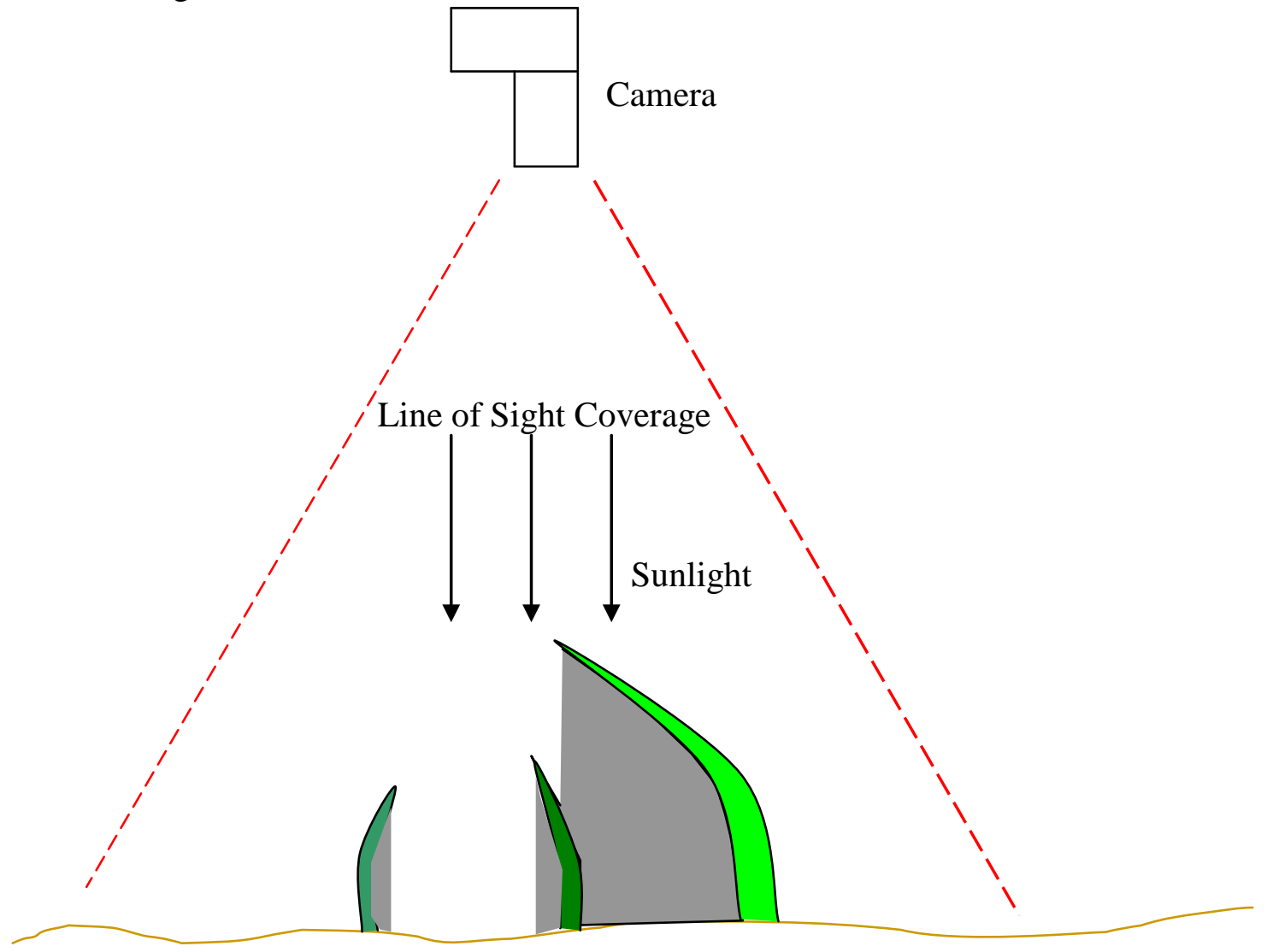

Figure 7.2 - Sunlight direction 
Theoretically, there are gray shades and spots. However, these areas are not seen by cameras. This is the best time to take an image.

6. The camera lens should be faced vertical (in straight line) to the desired area of vegetation shot as shown below:

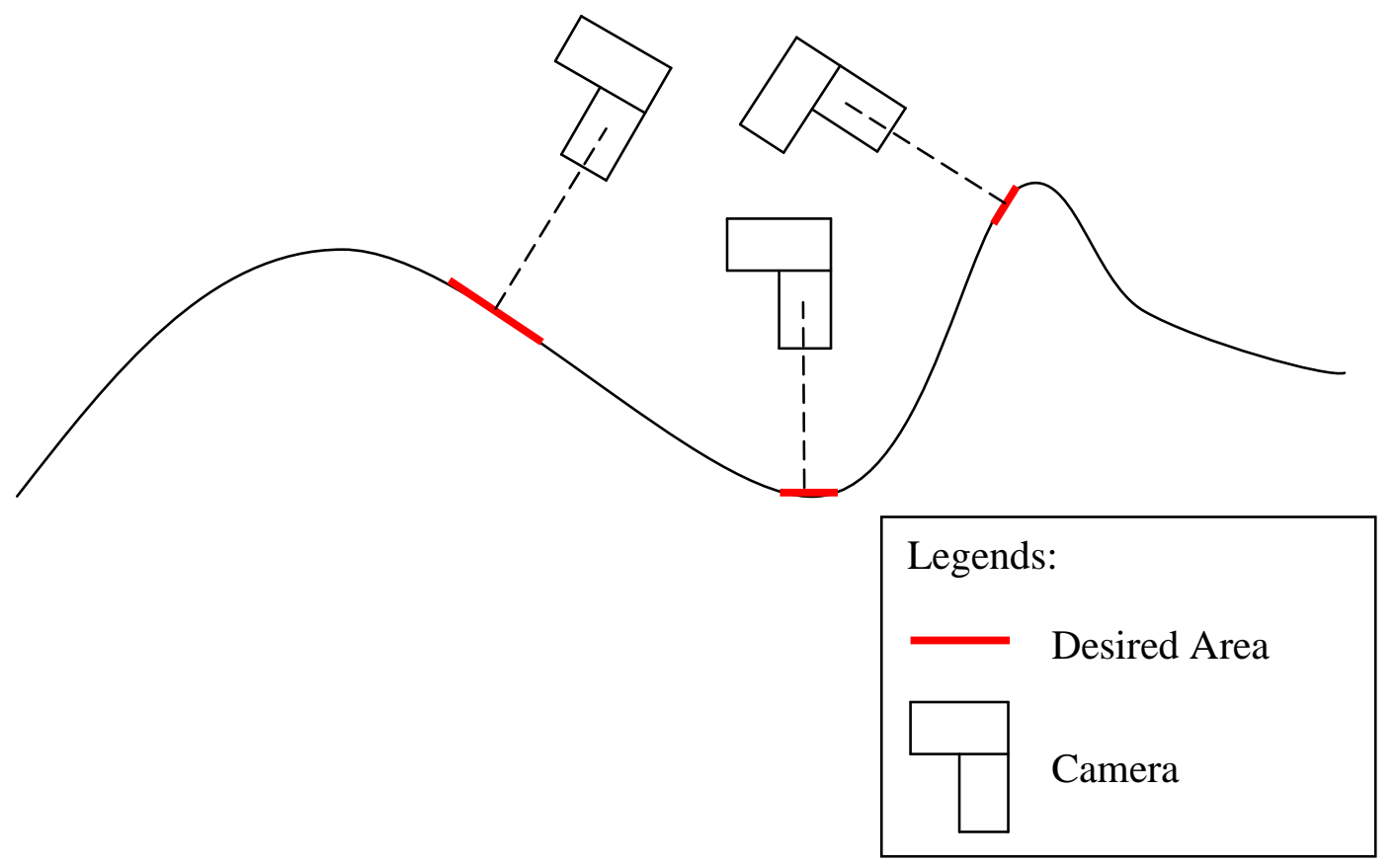

Figure 7.3 - Image areas

There are some gray spots (spots where no vegetation is present) visible when the image is shot vertically. At an angle, some of the grasses may block the gray spots. It may be impossible to have a $90^{\circ}$ shot in the field most of the time. However, the photographer should set the camera as vertical as possible.

7. Lay the square template over the desired vegetation area.

8. Without zooming in or out the camera, take an image of the desired area 3 to 7 feet away from the object.

9. Taking pictures at different directions may have slight differences in the percentages of green pixels due to the fact that it would be very difficult to take an image exactly 90 degree. There are cases where desired areas taken are not flat and even. 


\subsection{June $4^{\text {th }} 2001$ Inspection in State Road 238}

Following are some analyzed vegetation images from SR 238.

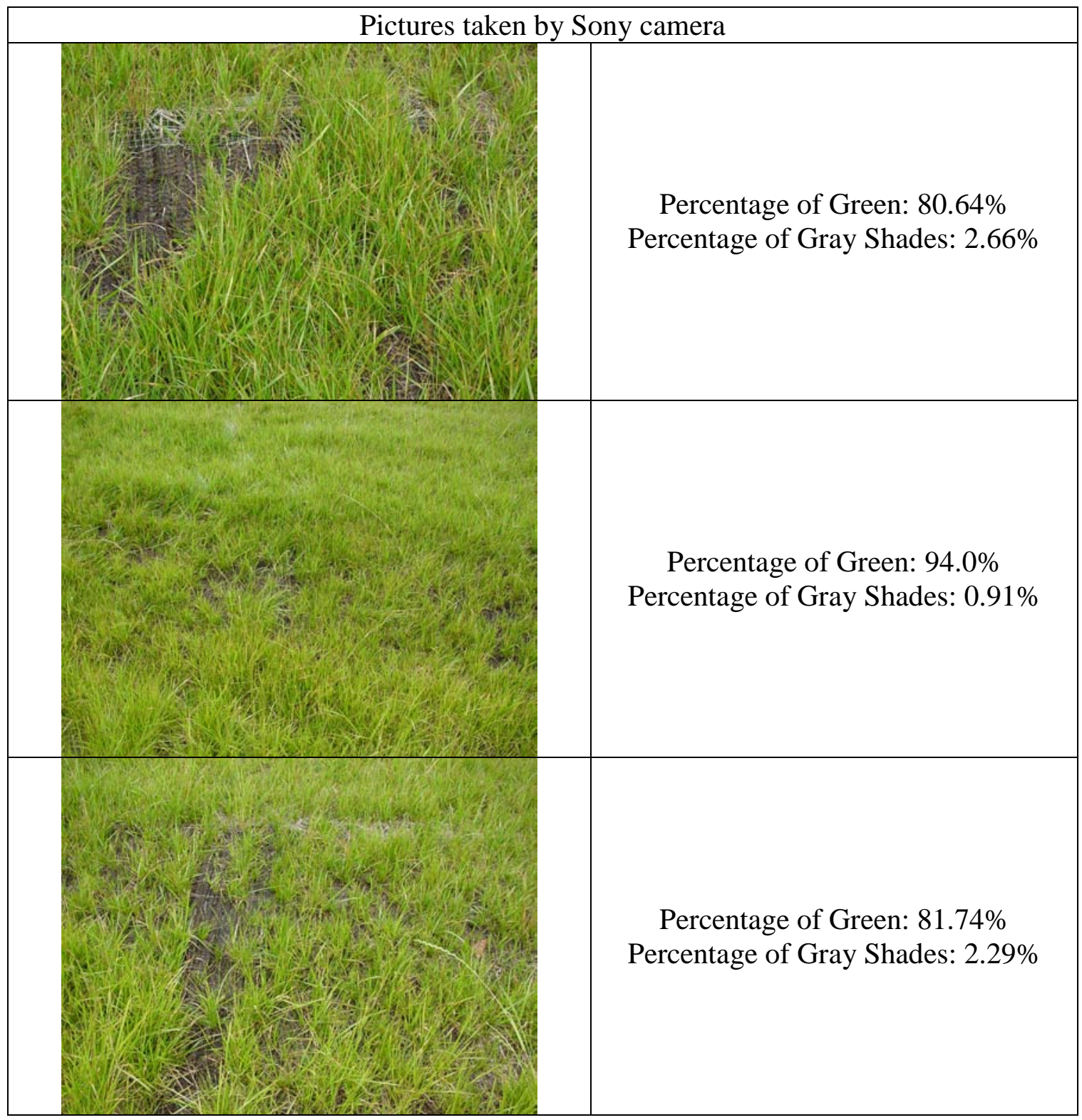




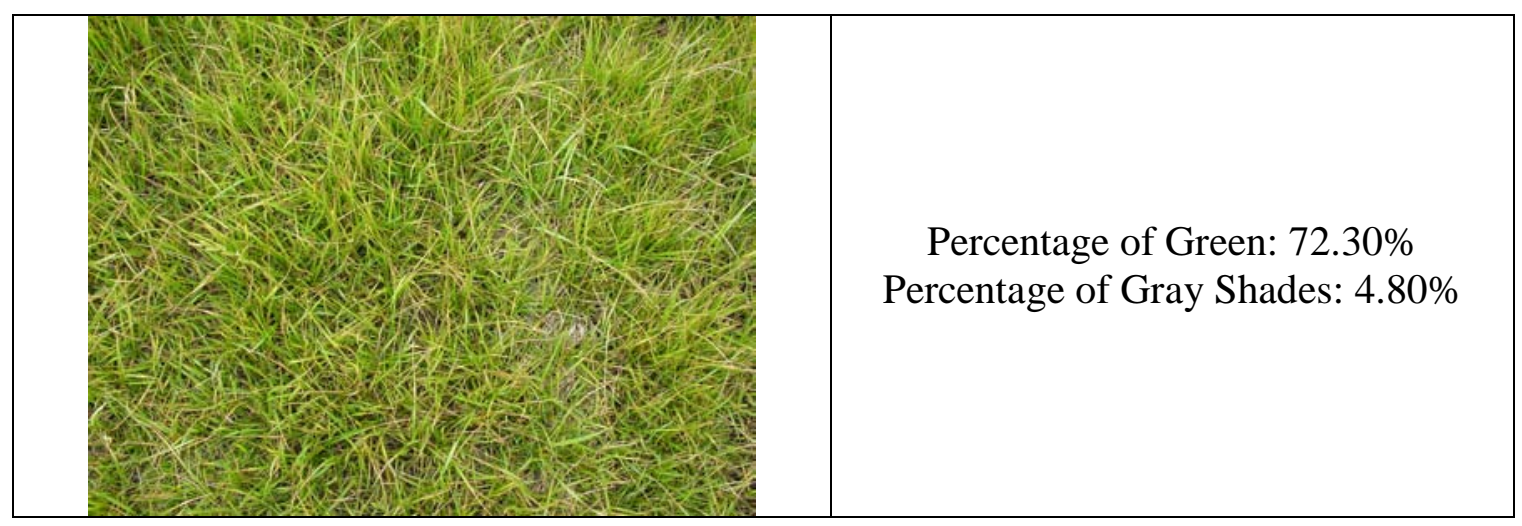

\subsection{Effects of Herbicides}

Herbicides affect the natural growth of vegetation. In fact, they retard the vegetation growth. Here are some example images showing the effect of herbicides from SR 238.

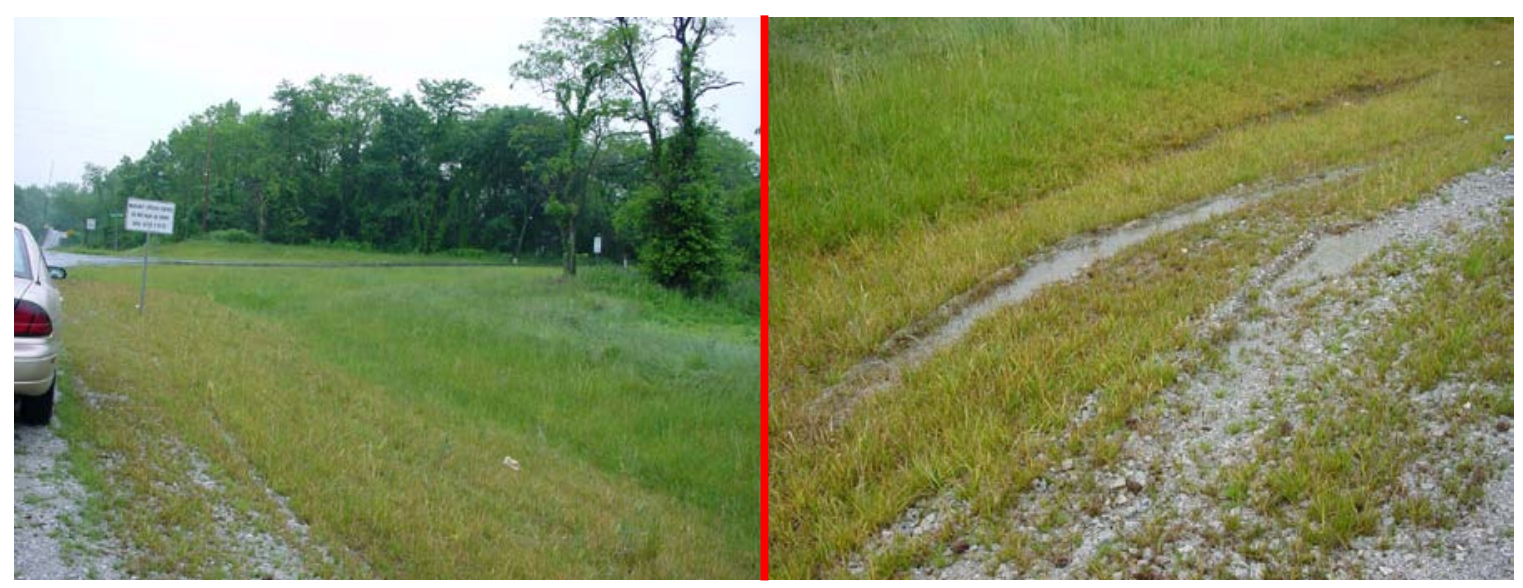

Figure 7.4 - Inspection Results 


\subsection{Inspection Program on Random Locations - For Slopes}

Pictures should be taken at several random locations as shown for an inspection program.

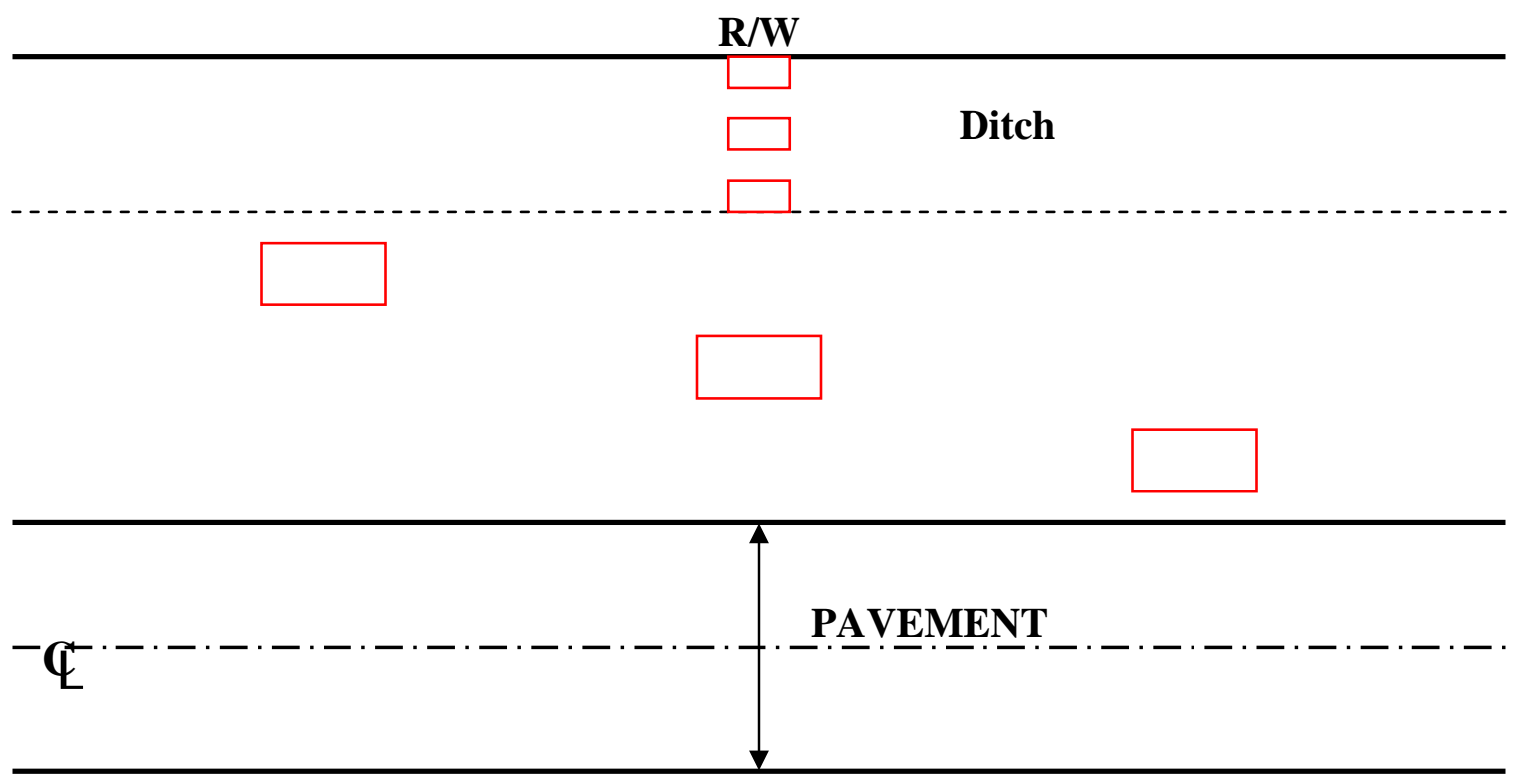

Ditch

R/W

Sectional Plan View

Legends:

$\square$ Desired area of pictures taken

Figure 7.5 - Random Locations 


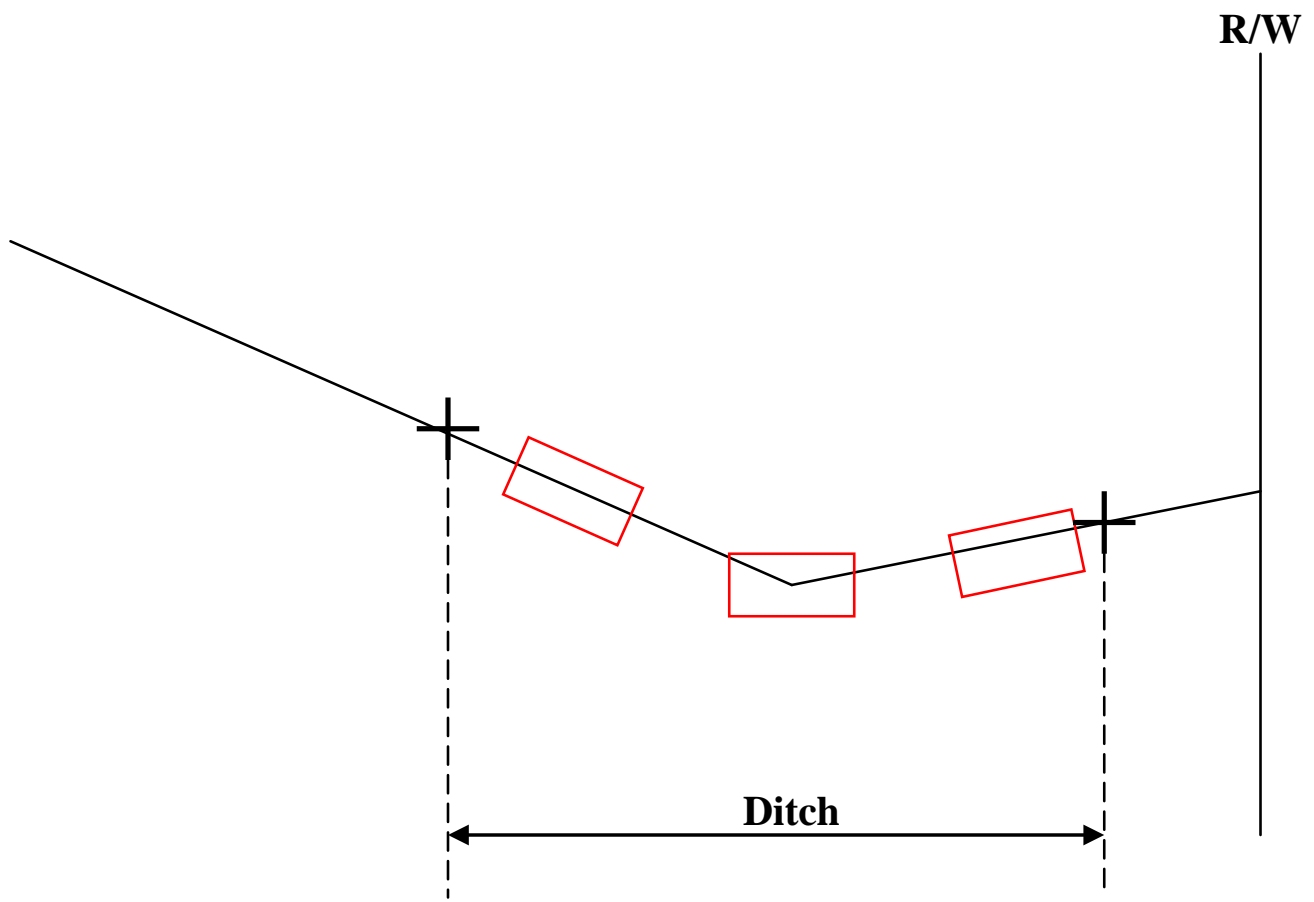

Figure 7.6 - Sectional View 


\section{Chapter 8 - Conclusions}

\subsection{Distance}

Images of the same object were taken at different distances namely 3, 5, and 7 feet away from the camera lens. Results from the percentage of green pixels showed that there was only a slight variation among these images. Generally, the variation of the differences in percentage of green pixels was within 2 percent.

Typically, the distance between the object and the camera lens is determined based on the size of the object. The larger the object size, the greater distance is needed to cover the entire object. Generally, for a good quality image, distance should not be greater than 7 feet. However, the nearer the object, the more curviness the object will show. Therefore, it is recommended that the minimum distance should be 3 feet. As a result, a variation of distances between 3 to 7 feet is acceptable.

\subsection{Zooming}

It was discovered to find that there is a difference in the background brightness for images taken at the same spot using different zoom levels. Generally, zooming in adds brightness to the image. The more zoom, the brighter the image. Perhaps, this is something to do with the "Auto Focus" capability of cameras.

\subsection{Angle of Image Taken}

It was discovered that direction of the image taken with the same object might yield different percentages of green pixels. The difference in the percentages would not vary too much and it is within 5\% range for a 10-degree difference in the direction unless the grasses are long and bent or when there are huge gray spots in between grasses, where no vegetations are present.

\subsection{Template (Rectangular Frame)}

The maximum size of the template (rectangular frame) is determined by the coverage of the camera lens. As the distance between the object and the camera lens increases, the area of coverage increases. Since the minimum distance recommended is 3 feet. From the camera, the maximum coverage is about 30 inches by 21 inches. It is about $2 \frac{1}{2} \times 1 \frac{3}{4}$ '. Therefore, a rectangular frame of inner dimensions of $2 \frac{1}{2}{ }^{\prime} \times 1 \frac{3}{4}$ ' or smaller is preferred. The area of coverage may be different for different cameras.

\subsection{Light Intensity}

Light intensity affects the quality (shade levels, brightness and contrast) of the green pixels within the digital images. For typical grassy vegetation, the recommended light intensity is 1,000 foot-candle to 3,000 foot-candle. When high intensity sunlight is present, a shield should be used to block the object and lower the light intensity to a more suitable level. 
However, the optimum light intensity may be different for other kinds of vegetations. Based on field tests, different vegetation results are minimal and will not affect the final decision.

\subsection{Costs}

Contract bid amounts were obtained from the SR-238 and SR-227 projects. The bid prices for the warranted erosion control items were:

SR-238: $\quad$ slopes - \$5.77/SY $\quad$ side ditches - \$16.02/SY

SR-227 : slopes - \$7.95/SY side ditches - \$15.95/SY

Cost comparisons between warranted items and conventional erosion control items are not possible. Warranted items cost basis is by area (e.g. square yards) while permanent erosion control items are priced using different quantities (e.g. by weight and area).

A project done around the same time period as 238 and 227 was the I-694 project around Fort Wayne. The permanent erosion control consisted of several items that totaled $\$ 1,004,624$. This was a 22 mile long project so the cost per mile is $\$ 45,664$. Bid costs for these items are shown in the below table.

Table 7.1 - I-694 Erosion Control Bid Items

\begin{tabular}{|l|r|r|r|}
\hline EROSION CONTROL BLANKET, STRAW MAT & 59042 & 1.4 & 82658.8 \\
\hline GEOTEXTILES & 30925 & 1.5 & 46387.5 \\
\hline RIPRAP, DUMPED & 10013 & 20 & 200260 \\
\hline RIPRAP, REVETMENT & 426 & 25 & 10650 \\
\hline RIPRAP, UNIFORM & 5173 & 20 & 103460 \\
\hline MOBILIZATION AND DEMOBILIZATION FOR SEED & 2 & 550 & 1100 \\
\hline SEED MIXTURE, PRAIRIE GRASS & 49.5 & 25 & 1237.5 \\
\hline SEED MIXTURE & 300.2 & 30 & 9006 \\
\hline FERTILIZER & 36.2 & 400 & 14480 \\
\hline SEED MIXTURE, R & 15385 & 4 & 61540 \\
\hline MULCHING MATERIAL & 230 & 240 & 55200 \\
\hline TOP SOIL & 34887 & 12 & 418644 \\
\hline
\end{tabular}

\section{Warranty Bond calculations}

Reviewing the three contracts revealed there was not a set formula for calculating the warranty bond. One formula that INDOT has used is (pay item cost + INDOT overhead cost for letting new contract ( $\sim 20,000)$ ) multiplied by 1.5 to 2.50 . The multiplier is based on the percentage the item is of the contract cost, the higher the percentage the lower the multiplier. SR 227 contract warranty bond cost was $\$ 113,476$, which came from $(\$ 36,738$ (warranty item cost) $+\$ 20,000) * 2$. For the SR 69 project the warranty bond was warranty item cost * 1.5 . 


\subsection{Warranty Specification}

A warranty spec was developed and applied to three INDOT construction projects in 2001. The spec was developed through the INDOT specification engineer and a subset group of the SAC. Other sample warranty specs were referenced and similar provisions are reflected in the spec. A copy of the SR 69 spec is included in the Appendix.

\subsection{Project History}

The project start date was December 1, 1999. In 2001 three projects were evaluated for implementation of a warranty spec: The SR 238 and SR 227 projects were small interchange and bridge projects respectively and the permanent erosion control areas were small. Vegetation growth and health on both projects was excellent and the digital analysis tool was not needed. The SR 69 project was a different story. The following explains what transpired on this project. This is a summary of a report issued in 2004.

SR 69 is a 9.5 mile project that consists of rehabbing portions of the existing alignment and constructing new sections. Some of the new sections required constructing temporary runarounds. Thirteen runarounds were constructed. The project is in its fifth year and will most likely continue for another year. These project dynamics have certainly affected the permanent warranty erosion control special provision.

Due to project staging and sequencing of operations some segments will have permanent erosion control placed at different times, in some cases years apart. The below image shows a segment; on the left side the erosion control was installed three years ago and on the right side work is not completed. According to the warranty erosion provision the slope and ditch on the left are to be accepted and maintained by INDOT while on the right side the permanent erosion control has not been installed and the construction contract is not completed. 


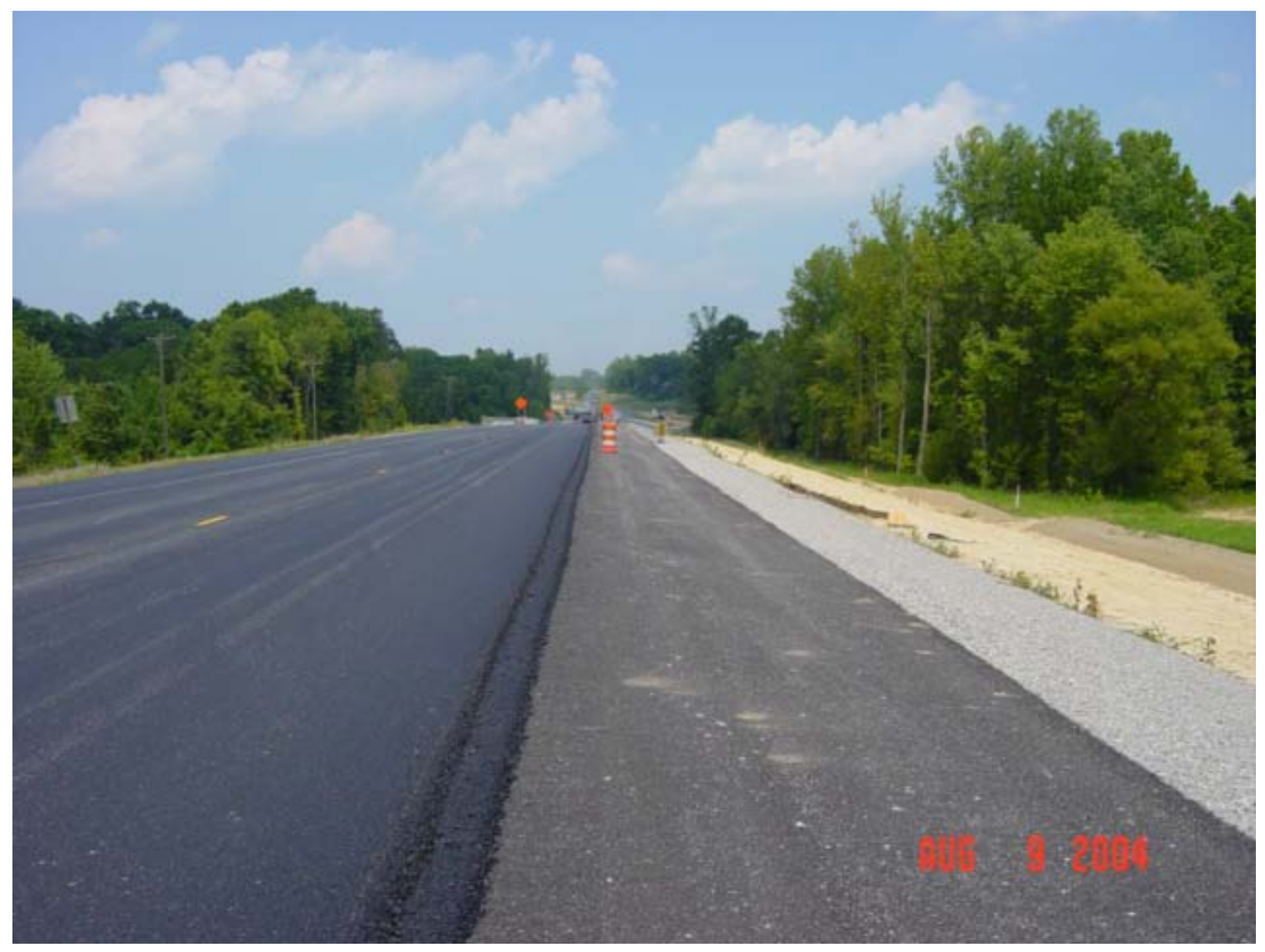

Another issue with applying the warranty provision to this contract is since the contract is broken into numerous phases(e.g. erosion control contractor has mobilized 25 times) tracking and recording completion times and warranty periods is problematic. An extensive effort to do the paperwork and documentation would be required by INDOT. One of the reasons for using this special provision was to reduce the amount of oversight and paperwork by INDOT. This has not happened on this contract.

Another thing to consider is that some segments installed permanent erosion control three years ago and the below image shows a segment where earthwork is occurring. This segment will most likely have permanent erosion control performed in 2006, a four year gap between the first and last one. This does not work well with the warranty provision. 


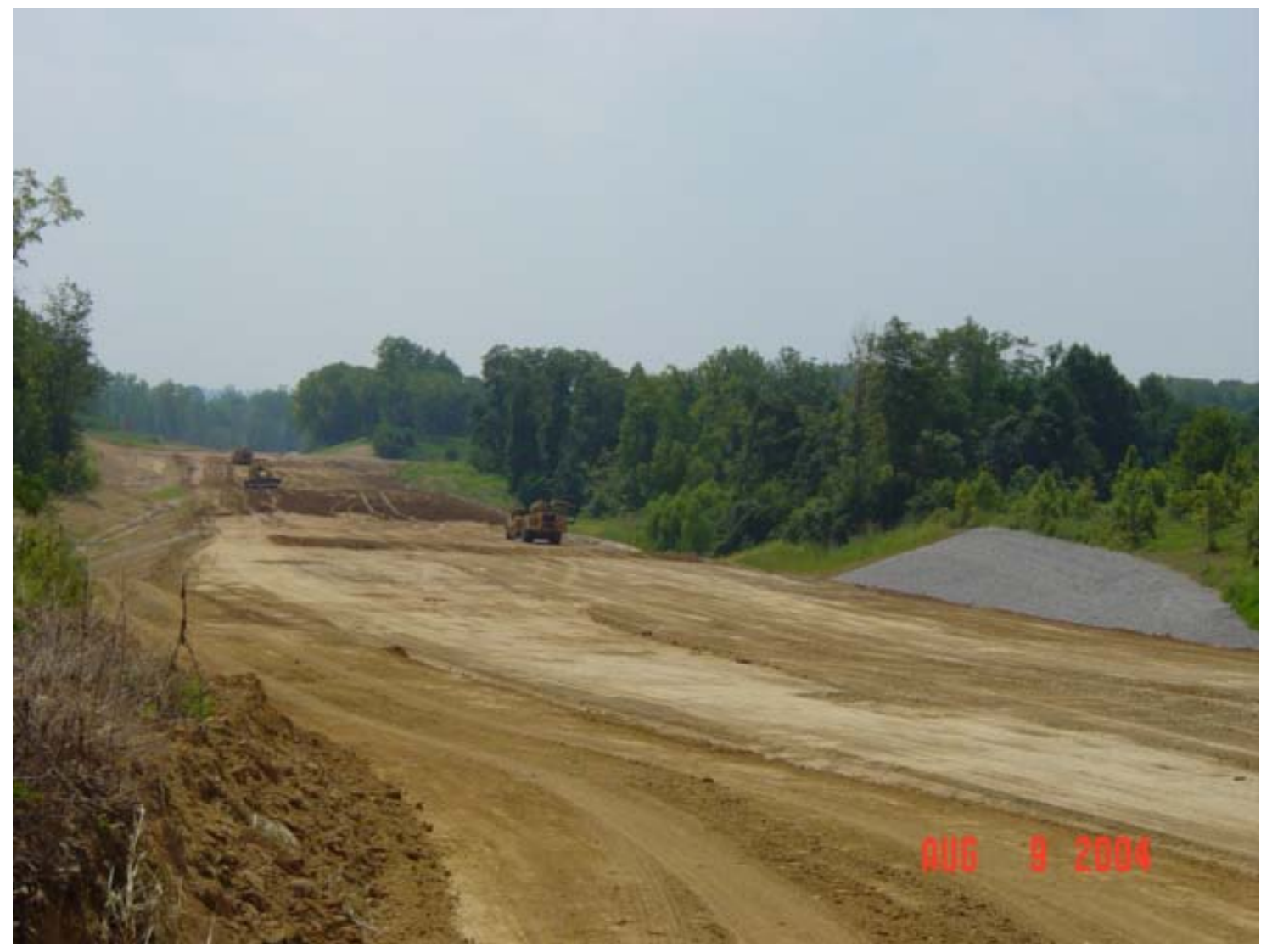

This contract was not a good one for the warranty special provision for the reasons stated above. It did work well with the other two contracts. These were smaller jobs and the work was performed in a sequential manner with the erosion control performed and completed at the same time.

Another issue is the segments that were completed three years ago and where the warranty clause has been satisfied the contractor should be released from the segments.

Due to the Agency reorganization and changing project priorities that occurred shortly after the completion of SR 69; a follow-up implementation project could not be identified. Therefore in early 2006 the SAC decided to put the project into sleep mode until implementation times improve.

In June 2009 a SAC meeting was held to determine how to proceed with the project. The following recommendations were made.

1. The warranty spec should contain a provision on soil modification.

2. The coverage percentage of $85 \%$ is that appropriate or should another value be used. This should be verified through the digital analyzer tool.

3. Complete the final report and close out the project.

4. Initiate an Implementation project that will: 
a. Determine project activities

b. Use digital images to determine \% coverage requirements.

\subsection{Recommendations}

INDOT selected three projects for the erosion control warranty special provision. Due to the timing of the contracts, the process developed by this research could only be applied to the SR 69 project as an objective means to resolve disputes between INDOT and the contractor. Due to the contract characteristics, multiple sections starting at different times, the procedures described herein could be used but were not used. The contract turned out to be very problematic for erosion control. The recommendations that follow are based on the findings of the technical research accomplished by this project and an over view of current vegetation management practices of INDOT.

INDOT uses a methods specification to accomplish seeding and sodding. Disputes arise regarding the adequacy of the results. Additionally, there are literally hundreds of new erosion control products being introduced to the market. Approving these products is problematic (New Products Evaluation Committee, specification development and revision). One approach to resolving these problems is by selecting a warranty that lets the contractor choose the method of erosion control. INDOT then would hold them accountable for the results. Measuring the results in most cases will involve a meeting of the parties to discuss the status of the erosion control measures relative to the stated. On occasion disputes between INDOT and the contractor will arise. To address this problem it is desirable to have a fair objective measure of the adequacy of the erosion control process selected by the contractor.

The research performed by this Study is a potential objective methodology that can be utilized to fairly mitigate contested areas. It is designed essentially for areas where vegetation (grass) is selected as the erosion control measure. The research was a technical approach to examine the feasibility of using digital photographic analysis. It does not address all issues related to field conditions and as such would require review by interested parties to be complete. For example, how often should sample pictures be taken. Should a random selection process be developed similar to ones currently used to sample asphalt materials? What criteria should be used to elect when the technical process becomes binding to both parties etc. and what wording in the warranty provision should be used? Additional items include who makes the inspection and how do they become trained in the process and become equipped with the necessary camera and light meter. Other issues include:

- Use the research findings on an implementation project to address the previously stated concerns and better define the process and develop it into a well defined practical special provision. This would include wording to bind both parties to the process using a legal perspective.

- Test and validate the digital image approach.

- Determine the sampling procedure. Should a statistical approach be used?

- Determine training needs and how training will be accomplished. 
- Determine how training will reside for future access by INDOT (intranet, multimedia CD etc.).

- Determine who will be responsible within INDOT regarding implementation (Landscape Supervisors?).

The Implementation project recommendation will be included in the Implementation Plan. 


\title{
Appendix
}

\author{
SR 69 Warranty Erosion Control Spec
}

\section{WARRANTED PERMANAENT EROSION CONTROL}

\section{General:}

This work shall consist of designing and selecting appropriate permanent erosion control measures and constructing them on all side slopes and side ditches within the project limits. The Contractor will not be restricted in the choice of material or installation technique, but shall provide a warranty of performance in accordance with these provisions. This work applies to slopes and ditches. The erosion control measures in areas other than in ditches or on slopes will be considered as a portion of the slopes. Erosion control measures include seeded areas, erosion blankets, turf mats, modular confinement, grout mattresses, etc., but exclude various waste materials, such as broken concrete or unconventional methods/materials etc. unless these items are approved by the Engineer.

The wetland mitigation area will be exempt from Warranted Permanent Erosion Control.

The following areas shall be constructed as shown on the plans and will be included in the pay items for warranted permanent erosion control:

Lawn sodding as shown on the Paved Side Ditch and Sodding Summary Table.

Riprap, and geotextile at structure numbers 28, 39, 86 and 166.

Riprap, geotextile, and Aggregate, 2 stone on the north and south bridge cones of Str. No. 1 (Big Creek), Str. No. 2(Big Creek Overflow), and Str. No. 3 (Rush Creek).

These items are estimated to be 12,924 sys sodding, 9051 tons of revetment riprap, 11,492 sys of geotextile, and 92 tons aggregate 2 stone.

Two weeks prior to the installation of any warranted erosion control measures, the Contractor shall submit a Quality Control (Qc) Plan for erosion control describing the design(s) selected. This Qc plan shall include all applicable requirements in ITM 803, section 4; the procedures for seeding, mulching, sodding, fertilizing, placement of sod reinforcement, any anticipated maintenance, and all other applicable operations. This Qc plan will be reviewed by the Engineer for completeness.

Within two weeks after completion of the installation(s) of the warranted erosion control measures, the Contractor shall submit videotapes, pictures, or digital images of 
the completed installation(s). This information shall be complete to the extent all facets of the installation(s) are clearly visible. This information will be used to evaluate future inspections. The installation location(s) shall be clearly indicated within these tapes, pictures, or images.

A list of damage criteria is presented herein. This list defines tolerable damage. Non-tolerable damage, as found on inspection, shall be repaired to a like-new condition.

\section{$\underline{\text { Warranty }}$}

The warranty period shall begin upon the Department's acceptance of the contract and shall continue through two successive spring/summer seasons. The minimum time period covered shall be 24 months. The initial inspection will be made in June after the first spring season. The second inspection will be made the following June. If after the second inspection non-tolerable conditions exist, the Contractor shall repair such areas and the warranty period will be extended to June of the following year. Within 30 days after each inspection, the Contractor will be advised of all areas that are non-tolerable. The Contractor shall then repair the erosion damage and the erosion control installation(s) by October of the same year following the inspection. The Contractor may inspect and repair damages at any time during the warranty period in lieu of waiting for the Department's inspection reports. The Contractor shall provide 24 hours advance notice to the Department of these actions and shall comply with applicable traffic safety procedures.

The warranty requirement for side ditch applications will be voided if the flow of water exceeds the 10-year storm for the site location as determined by IDF curves in chapter 29 of the INDOT Design Manual. The warranty requirement for side slopes will not be voided under any circumstances. It will be the Contractor's responsibility to provide verifiable documentation from the Purdue Applied Meteorology Group (Agronomy Dept.) Indiana Climate Page (Data Archives, Hourly NWS \& FAA Automatic Station) http://shadow.agry.purdue.edu/sc.index.html that the 10 -year storm was exceeded.

Warranty will be voided if the Contractor can verify that the erosion control measure was damaged during the warranty period by an outside agent(mowing, vehicle traffic, etc.). Such voiding of the warranty will only affect those damaged areas.

WARRANTY BOND Upon the Department's acceptance of the contract, the warranty bond shall be in effect for a total of two years. The warranty bond must be properly executed by a surety company satisfactory to the Department and be payable to the State of Indiana and submitted with the bid.

The warranty bond is $\$ 1,000,000.00$ for the warranted erosion control for the slopes and side ditches. The bond is intended to insure completion of required warranty work, including payments for all labor, equipment, materials and maintenance of traffic used for remediation. 
Upon the final acceptance of the contract, the contractual obligations of the Contractor are satisfied as long as the erosion control for the slopes and side ditches continues to meet or exceed the warranted values as defined herein.

At the end of the warranty period, the Contractor will be released from further warranty work or responsibility, provided all previous warranty work has been satisfactorily completed and accepted.

\section{Damage Criteria}

The following conditions represent tolerable damage criteria that will be used as a guide to determine acceptable performance. Where these limits are exceeded (by visual inspection), warranty repairs shall be made.

1. Vegetation Density - Sodding or seeding must attain the following:

a. Initial Inspection - 85\% ground cover shall be a healthy green color by June 1st following the project completion. An INDOT Landscape representative will determine ground coverage by visual or photographic means. If the project fails the initial inspection the Contractor may elect to have soil samples taken in the failed areas for mineral deficiency analysis (percentage of nitrogen, phosphorus, potash, $\mathrm{pH}$ value and organic matter). If testing is performed a copy of the soil analysis shall be sent to the Engineer.

b. Second and subsequent Inspections - 85\% ground cover shall be a healthy green color by June 1 following the previous inspection.

c. BASIS FOR APPEAL. If the Department determination of ground cover does not comply with the minimum Specification requirements and the Contractor does not agree with the Department's assessment of the ground cover percentage, the Contractor may appeal the Department's assessment in writing with accompanying supportive photographic documentation. The Contractor's documentation shall state the ground cover percentage.

d. APPEAL PROCEDURE. If the percentage vegetation density between the Department and the Contractor can not be resolved by the aforementioned procedures, the following procedure will be used for final resolution. A grid pattern shall be established completely covering the area in-question. Three (3) random locations will be selected in accordance with ITM 802. Digital photographs will be taken at each of the three locations, documenting a one square meter area. The specific requirements for these digital photographs will be in accordance with ITM 809. These photographs will be analyzed in accordance with ITM 809 - Procedure for Determining the Vegetation Density by 
Photographic Means. The average of these three determinations will be considered the actual vegetation density.

2. Erosion - Eroded areas or barren ground resulting in loss of seed or vegetation shall not exceed $1 \mathrm{~m} 2$ (10 sq. ft.):

3. Appearance - The following shall not be exceeded:

a. Rills - 50 mm (2 in.) wide or deep

b. Ruts - no ruts

c. Dead vegetation areas no larger than $1 \mathrm{~m} 2$ (10 sq. ft.).

d. Fabric distress - no tears, washouts, bunching, or movement of the permanent material.

\section{$\underline{\text { Remediation }}$}

The Contractor shall repair all damaged areas exceeding the tolerability criteria, including the erosion control, and a report indicating the corrective action taken shall be submitted to the Engineer within 30 days after the corrected action.

\section{CONFLICT RESOLUTION TEAM (Team).}

The Team will consist of two Contractor representatives, two Department (District \& Central Office) representatives, and a fifth person mutually agreed upon by both the Department and the Contractor. All costs for the fifth person will be equally shared between the Department and the Contractor.

The Team members shall be identified in writing at the pre-construction meeting and will be knowledgeable in the terms and conditions of this warranty and the methods used in the measurement and calculation of erosion control. Should an impasse develop, the Team will render a final recommendation to the Chief Engineer by a majority vote. Each member has an equal vote.

The scope of the Team includes all issues concerning the warranted erosion control for slopes and side ditches relative to a quality control plan, material selection, distress rate, and remediation.

\section{Method of Measurement and Basis of Payment}

The area of warranted erosion control will be measured by the square meter (square yard). Warranted erosion control for side ditches will be measured as the ditch 
width plus $1 \mathrm{ft}$. vertical distance above ditch profile grade on side slopes. Warranted erosion control will be paid for by the contract unit price per square meter (square yard) for warranted erosion control complete and in place.

Payment will be made under:

Pay Item

Pay Unit

Warranted Permanent Erosion Control Slopes SYS

Warranted Permanent Erosion Control Side Ditches SYS

The cost of all repairs of non-tolerable erosion or sedimentation within the warranted erosion areas, including repairs to the erosion control material, will not be paid for. The cost of the warranty bond shall be included in the pay items of this section. 